Simulação numérica de escoamentos bidimensionais com superfícies livres e linhas de contato dinâmicas

Alysson Alexander Naves Silva 
SERVIÇO DE PÓS-GRADUAÇÃO DO ICMC-USP

Data de Depósito:

Assinatura:

\title{
Simulação numérica de escoamentos bidimensionais com superfícies livres e linhas de contato dinâmicas
}

\author{
Alysson Alexander Naves Silva \\ Orientador: Prof. Dr. Fabrício Simeoni de Sousa
}

Dissertação apresentada ao Instituto de Ciências Matemáticas e de Computação - ICMC-USP, como parte dos requisitos para obtenção do título de Mestre em Ciências - Ciências de Computação e Matemática Computacional.

USP - São Carlos

Abril/2010 
Às pessoas da minha vida: minha amada Stefânia, meus pais, Edna e João, minhas irmãs, Andressa e Alessandra, e claro, minha avó Nair. 



\section{Agradecimentos}

Agradeço especialmente a minha avó Nair, por ter me dado a honra de ser seu neto, a senhora sempre torceu muito por mim (Deus está feliz com a senhora ao lado Dele).

Agradeço a Stefânia, sempre ao meu lado, certamente ela fez este trabalho de mestrado comigo.

A meus pais, Edna e João, e minhas irmãs, Andressa e Alessandra, minha família é meu porto seguro.

Ao pessoal do LCAD, em especial: Mario Liziér, Miguel A. Caro Candezano e Alexandre De Lacassa que contribuíram com dicas significativas para a realização deste trabalho.

Agradeço também, Eliandro R. Cirilo, Ricardo Luis dos Reis e Aline Aparecida de Souza Leão, pelas conversas no ICMC.

Ao professor Fabrício Simeoni de Sousa, pela oportunidade de realizar este trabalho. E também ao professor Gustavo Carlos Buscaglia, por suas valiosas ideias.

A FAPESP pelo suporte dado proc. 2008/01878-1.

Agradeço imensamente a Deus por ter me proporcionado tudo isso. 



\section{Resumo}

Um método lagrangeano-euleriano arbitrário para a resolução de escoamentos dominados por tensão superficial é apresentado neste trabalho. Tais escoamentos são importantes em muitas aplicações, especialmente em canais capilares que frequentemente aparecem em escoamentos em microescala. A resolução deste tipo de escoamento apresenta vários desafios que são abordados neste trabalho. O escoamento é resolvido somente para a fase líquida, com condições de contorno apropriadas para a superfície livre que delimita o líquido e o gás, que é representada por arestas e vértices da malha computacional. Esta se move e se deforma, sendo que sua qualidade é mantida sob controle para não degradar a solução numérica. As equações de Navier-Stokes são discretizadas pelo método de elementos finitos em um referencial arbitrário. O método de incorporação dos efeitos de tensão superficial e linha de contato é explicado em detalhes. Validações comprovam a precisão do método proposto, com comparações através de soluções pseudo-analíticas para casos simples. Finalmente alguns resultados sobre escoamentos em capilares são apresentados. 



\section{Abstract}

An arbitrary lagrangian-eulerian finite element method to solve surface tension dominated flows is presented. Such flows are important in many applications, particularly in capillary channels, that appear in microscale flows. The resolution of such flows presents several challenges that are addressed in this work. The flow is solved only in the liquid phase, and proper boundary conditions are applied on the free-surface, bounding the liquid and gas, which is explicitly represented by vertices and edges of the computational mesh. The mesh is moved and deformed, but its quality is kept under control in order to control errors in the numerical solution. The Navier-Stokes equations are discretized by standard Galerkin finite element method in an arbitrary reference. Details of the computation of surface tension and contact line effects are presented. The methodology is validated for a number of simple test cases against known pseudo-analytical solutions, and numerical results are presented, showing the robustness and accuracy of the methodology. Finally, some results about surface-tension-driven flows in capillaries are presented. 



\section{Sumário}

1 Introdução 1

1.1 O problema modelo: Molhabilidade . . . . . . . . . . . . . . . . 2

1.1 .1 Tensão superficial . . . . . . . . . . . . . . . . . . 2

1.1.2 Ângulo de contato ..................... 4

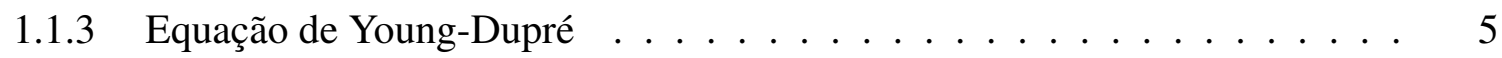

1.1.4 Histerese de ângulo de contato . . . . . . . . . . . . . . . . 6

1.2 Métodos de representação de interface . . . . . . . . . . . . . . . 7

1.3 Proposta deste trabalho . . . . . . . . . . . . . . . . . . 10

1.4 Organização da dissertação . . . . . . . . . . . . . . . . . . . 11

2 Formulação matemática $\quad 13$

2.1 Formulação Lagrangeana-Euleriana Arbitrária (ALE) . . . . . . . . . . . . . . 13

2.1 .1 Movimentação de malha . . . . . . . . . . . . . . . . . 15

2.2 Equações de Navier-Stokes . . . . . . . . . . . . . . . . . . . 16

2.3 Condições auxiliares . . . . . . . . . . . . . . . . 17

2.3.1 Condições para contornos rígidos . . . . . . . . . . . . . 17

2.3.2 Condições na superfície livre . . . . . . . . . . . . . . . . 18

2.4 Adimensionalização das equações de Navier-Stokes . . . . . . . . . . . . . . . 18

3 Discretização das equações de Navier-Stokes $\quad 21$

3.1 Formulação variacional . . . . . . . . . . . . . . . . . . . . 21

3.2 Discretização espacial . . . . . . . . . . . . . . . . . . . 23

3.2.1 Tipos de elementos para escoamentos de fluidos . . . . . . . . . . . . . . 24 
3.2.2 Funções de interpolação para elementos triangulares . . . . . . . . . . . 25

3.3 Discretização temporal . . . . . . . . . . . . . . . . . . . 27

3.4 Método de Galerkin . . . . . . . . . . . . . . . . . . . . . . . . . . 29

3.5 Resolução do sistema . . . . . . . . . . . . . . . . . . . . 33

3.5 .1 Método acoplado . . . . . . . . . . . . . . . 33

4 Cálculo da tensão superficial e ângulo de contato 35

4.1 Cálculo da tensão superficial . . . . . . . . . . . . . . . 35

4.2 Imposição direta do ângulo de contato através da condição de Navier (NBC) . . . . 36

4.2.1 Formulação contínua do problema . . . . . . . . . . . . . . . 37

4.2 .2 Formulação variacional . . . . . . . . . . . . . . . . 38

4.3 Imposição do ângulo de contato através da condição de Navier Generalizada (GNBC) 39

4.3.1 Formulação contínua do problema . . . . . . . . . . . . . . . . . 40

4.3 .2 Formulação variacional . . . . . . . . . . . . . . . . . 41

5 Adaptação de malha $\quad 43$

5.1 Triangulação de Delaunay $\ldots \ldots \ldots$. . . . . . . . . . . . . . . . 43

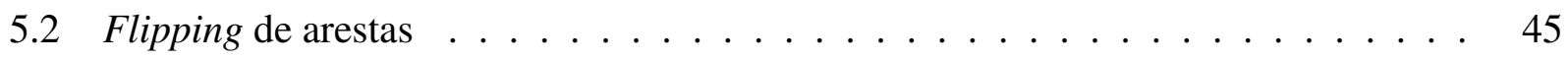

5.3 Inserção e remoção de pontos . . . . . . . . . . . . . . . . . . . 46

5.3.1 Enriquecimento de malha . . . . . . . . . . . . . 47

5.3.2 Simplificação de malha . . . . . . . . . . . . . . . . 48

5.4 Ilustração do esquema de adaptação de malha . . . . . . . . . . . . . . . . . . 48

6 Validação e resultados numéricos $\quad 51$

6.1 Validação para escoamentos com superfícies livres . . . . . . . . . . . 51

6.1 .1 Vibração da superfície livre . . . . . . . . . . . . . . 51

6.2 Validação do cálculo da tensão superficial . . . . . . . . . . . . . . . 53

6.2 .1 Gota estática . . . . . . . . . . . . . . . . . 54

6.2 .2 Gota oscilante . . . . . . . . . . . . . . . 55

6.3 Validação da imposição direta do ângulo de contato com condição de Navier (NBC) 58

6.4 Validação da imposição do ângulo de contato com condição de Navier generalizada

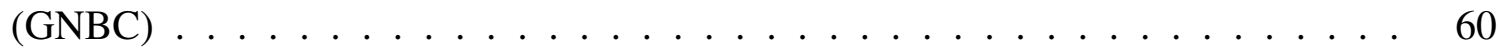

6.5 Comportamento dinâmico da imposição do ângulo de contato . . . . . . . . . . . . 62

6.6 Simulações com linhas de contato dinâmicas . . . . . . . . . . . . . . . . . . 63 
6.6 .1 Gota escorrendo . . . . . . . . . . . . . . . . 63

6.6 .2 Escoamento em um tubo capilar . . . . . . . . . . . . . . 67

6.6.3 Escoamento em um tubo capilar ligado a uma gota . . . . . . . . . . . 69

6.6 .4 Capilaridade ......................... 73

$\begin{array}{lll}7 & \text { Considerações finais } & 77\end{array}$

$\begin{array}{ll}\text { Referências Bibliográficas } & \mathbf{8 0}\end{array}$ 


\section{Lista de Figuras}

1.1 Gota líquida. . . . . . . . . . . . . . . . . . . 3

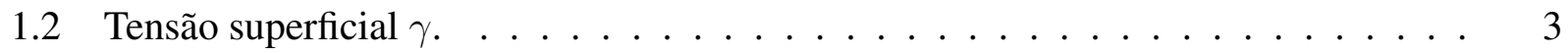

1.3 Definição de ângulo de contato. . . . . . . . . . . . . . . . . . . 4

1.4 Possíveis ângulos de contato. . . . . . . . . . . . . . . . . . . 5

1.5 Regimes de molhabilidade. . . . . . . . . . . . . . . . . 6

1.6 Determinação do ângulo de contato. . . . . . . . . . . . . . . . . . . . . 6

1.7 Histerese de ângulo de contato. . . . . . . . . . . . . . . . . . . 7

2.1 Domínios na formulação lagrangeana-euleriana arbitrária. . . . . . . . . . . . . . . 14

2.2 Exemplo unidimensional do movimento da partícula material e da malha. . . . . . 15

3.1 Exemplo de uma triangulação $T$ de um domínio $\Omega . \ldots \ldots \ldots$. . . . . . . . . . . 24

3.2 Tipo de elemento. . . . . . . . . . . . . . . . . . . . . . 25

3.3 Coordenadas baricêntricas de um elemento triangular. . . . . . . . . . . . . . . 26

4.1 Cálculo da tensão superficial. . . . . . . . . . . . . . . . . . . 36

4.2 Cálculo da curvatura em um ponto de contato. . . . . . . . . . . . . . . 37

4.3 Domínio $\Omega$ de uma gota apoiada. . . . . . . . . . . . . . . 37

4.4 Interpretação do comprimento de escorregamento. . . . . . . . . . . . . . . 38

4.5 Domínio computacional $\Omega$ e interface $\Gamma \ldots \ldots \ldots \ldots$. . . . . . . . 40

4.6 Domínio $\Omega$ de uma gota apoiada. . . . . . . . . . . . . . . . . 40

5.1 Ilustração de um resultado com e sem o controle de malha. . . . . . . . . . . . . 44

5.2 Troca de arestas. . . . . . . . . . . . . . . . . . . 45 
5.3 Definição de aresta localmente Delaunay. . . . . . . . . . . . . . . . . . . 46

5.4 Refinamento de malha. . . . . . . . . . . . . . . . . . . . . 47

5.5 Simplificação de malha. . . . . . . . . . . . . . . . . . . . . . 48

5.6 Controle de malha no caso de uma gota apoiada. . . . . . . . . . . . . . . . . . 49

6.1 Ilustração do problema de vibração da superfície livre . . . . . . . . . . . . . . . 52

6.2 Comparação entre solução analítica e numérica calculada para a vibração da superfície livre. . . . . . . . . . . . . . . . . . . 53

6.3 Verificação da lei de Young-Laplace. . . . . . . . . . . . . . . . . . . 55

6.4 Malha de elementos finitos de uma gota. . . . . . . . . . . . . . . . 57

6.5 Evolução da amplitude no tempo, ilustrando o amortecimento devido a viscosidade. 57

6.6 Inversão no sentido da velocidade $u$, caracterizando oscilação. . . . . . . . . . . . 57

6.7 Validação da imposição direta do ângulo de contato, na ausência da aceleração da gravidade. . . . . . . . . . . . . . . . . . . . . 59

6.8 Validação do ângulo de contato com aceleração da gravidade. . . . . . . . . . . . 60

6.9 Evolução de uma gota apoiada sobre uma superfície sólida. . . . . . . . . . . . . . 61

6.10 Validação da imposição do ângulo de contato com a utilização da condição GNBC. 61

6.11 Variação temporal do diâmetro da região apoiada sobre a superfície sólida. . . . . . . 62

6.12 Evolução temporal da posição $x$ do ponto de contato. . . . . . . . . . . . . . . 62

6.13 Gota sobre um plano horizontal na ausência de gravidade. . . . . . . . . . . . . . . 64

6.14 Gota escorrendo sobre uma superfície horizontal sem os efeitos gravitacionais. . . 65

6.15 Gota sobre um plano inclinado a um ângulo de $45^{\circ} \ldots \ldots$. . . . . . . . . . . 66

6.16 Gota escorrendo. . . . . . . . . . . . . . . . . . . . 66

6.17 Identificação dos pontos de contato em um tubo capilar. . . . . . . . . . . . . . . . 67

6.18 Escoamento em um tubo capilar. . . . . . . . . . . . . . . . . . . 68

6.19 Identificação dos pontos de contato. . . . . . . . . . . . . . . . . . . 69

6.20 Escoamento em um tubo capilar com uma gota. . . . . . . . . . . . . . . . 70

6.21 Escoamento em um tubo capilar com uma gota. . . . . . . . . . . . . . . 71

6.22 Escoamento em um tubo capilar com uma gota. . . . . . . . . . . . . 72

6.23 Ascensão de um fluido dentro de um tubo capilar. . . . . . . . . . . . . . . . . 73

6.24 Caso 1 - Ascensão de um fluido dentro de um tubo capilar. . . . . . . . . . . . . . 74

6.25 Caso 2 - Ascensão de um fluido dentro de um tubo capilar. . . . . . . . . . . . . 74

6.26 Caso 3 - Ascensão de um fluido dentro de um tubo capilar. . . . . . . . . . . . . 75 


\section{Lista de Tabelas}

6.1 Comparação entre a amplitude da curva analítica e numérica no problema de vibração da superfície livre. . . . . . . . . . . . . . . . . . . . . 53

6.2 Tabela de comparação entre a pressão interna em diferentes malhas de elementos finitos para uma gota estática. . . . . . . . . . . . . . . . . . . . 54

6.3 Tabela comparativa entre período analítico e numérico de uma gota oscilante. . . . 56

6.4 Teste de convergência para o ângulo de contato estático. . . . . . . . . . . . . . 58 


\section{Introdução}

A importância do estudo de problemas que envolvem fenômenos de superfície, quando diferentes fluidos podem interagir com superfícies sólidas, é confirmada por diversos processos tecnológicos que aplicam fluidos diretamente sobre diferentes tipos de superfícies. Pode-se citar o uso de tintas, pesticidas, lubrificantes, detergentes, recuperação de petróleo e revestimentos por filmes finos. Também aparecem em fenômenos do cotidiano, como gotas escorrendo em folhas ou janelas, em processos biológicos e sempre quando um fluido deslocar outro em cima de uma superfície sólida.

Uma das principais dificuldades na representação de tal fenômeno no computador vem do fato que as equações de Navier-Stokes, sujeitas às condições de contorno de não-escorregamento, dão origem a uma singularidade das tensões na linha de contato entre o fluido e o sólido, obtendo-se como resultado uma força infinita para mover a linha de contato (Spelt, 2005). Claramente, como pode ser comprovado experimentalmente, as linhas de contato se movem ao longo da parede sólida, e portanto as equações de Navier-Stokes sujeitas às condições de contorno de não-escorregamento não representam inteiramente a física envolvida neste fenômeno.

A molhabilidade é um fenômeno de superfície que se origina da interação de dois ou mais fluidos com uma superfície sólida, e representa o efeito macroscópico de interações microscópicas entre as moléculas do fluido e do sólido (Schlangen et al., 1994). 


\section{1 problema modelo: Molhabilidade}

A interação entre dois ou mais fluidos com uma superfície sólida originam a molhabilidade e a capilaridade, que são fenômenos de superfície amplamente estudados, e representam o efeito macroscópico de interações microscópicas entre as moléculas do fluido e do sólido (Schlangen et al., 1994). Pode-se ver a capilaridade como um caso particular da molhabilidade quando um substrato sólido deixa de ser uma superfície simples e passa a ser um meio poroso. A principal ideia para entender a molhabilidade é tratá-la como uma propriedade resultante da competição entre as forças adesivas entre o líquido e o sólido e as forças coesivas no interior de um líquido (de Gennes, 1985).

Quando ocorre o espalhamento espontâneo de uma gota sobre uma superfície, ou quando um líquido penetra em um meio poroso, ou na dinâmica de fluidos imiscíveis, pode ser observado o efeito da molhabilidade, que é resultado das interações intermoleculares existentes entre os fluidos envolvidos (Schlangen et al., 1994).

A molhabilidade pode ser vista quando uma gota está em equilíbrio com seu vapor e com um substrato sólido, onde é observada a existência de uma linha (ou região) comum para as fases (líquida / gasosa / sólida) denominada ponto de contato em $2 D$ ou de maneira geral, linha de contato, que pode ser utilizado tanto para o caso $2 D$ quanto para o caso $3 D$ (Ding and Spelt, 2007; de Gennes, 1985).

\subsubsection{Tensão superficial}

Em um fluido, suas moléculas sofrem forças de atração e repulsão entre si, além de sofrerem ação da força gravitacional. As forças intermoleculares nos líquidos são responsáveis por fenômenos de capilaridade tais como a subida de líquido em tubos capilares e também por fenômenos de superfície tais como um corpo com densidade muito maior que a da água flutue sobre a sua superfície, ou que insetos caminhem sobre superfícies líquidas. Assim há um efeito, denominado tensão superficial, na camada superficial de um fluido que leva a sua superfície a comportar-se como uma membrana elástica (de Gennes et al., 2004). 


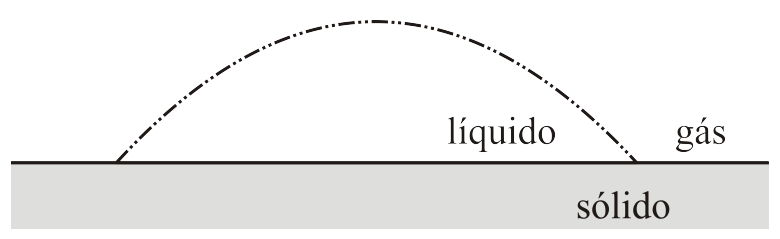

Figura 1.1: Uma gota líquida em contato com a superfície sólida. Verificam-se três diferentes fronteiras de separação, sólido/líquido (SL), sólido/gás (SG) e líquido/gás (LG).

A Fig. 1.1 ilustra uma gota líquida depositada sobre uma superfície sólida em um ambiente como o ar, por exemplo. Na interface ${ }^{1}$ (SL, SG e LG), a força resultante em uma molécula próxima à interface se torna diferente da força resultante sobre uma molécula que se encontra em uma região homogênea, na qual a força resultante é, em média, nula (veja a Fig. 1.2). A tensão superficial, $\gamma$, ocorre devido a forças de atração assimétricas na superfície de um fluido, ou na interface entre dois fluidos imiscíveis, sendo as moléculas superficiais "puxadas" para dentro do volume, portanto a superfície tende a contrair-se espontaneamente para adquirir a menor área possível (Rabockai, 1979).

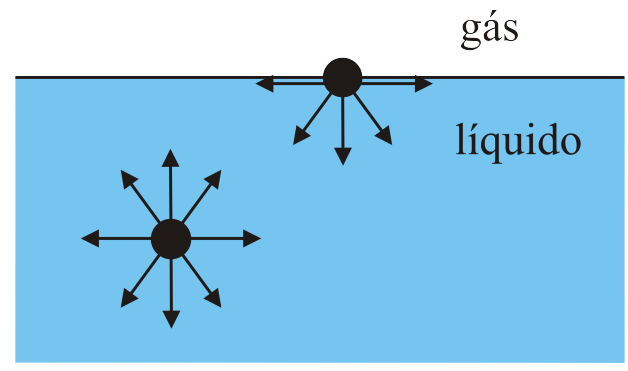

Figura 1.2: Uma molécula no interior de um líquido beneficia-se da interação com todas moléculas vizinhas, em contraste, uma molécula situada na superfície perde parte das interações coesivas.

É definida como tensão superficial (interfacial) a força por unidade de comprimento que deve ser aplicada paralelamente a uma superfície (interface) com a finalidade de contrabalancear a força que é imposta em direção ao interior do líquido. No sistema internacional de medidas sua unidade é $m N / m$ (de Gennes et al., 2004). Pode também ser interpretada como o trabalho necessário para aumentar a área superficial por uma unidade, sendo também expressa em unidades de energia por área.

A tensão superficial entre dois líquidos imiscíveis $A$ e $B$ é caracterizada por uma tensão interfacial $\gamma_{A B}$. Geralmente a tensão interfacial entre estes líquidos é menor que a tensão superficial de um

\footnotetext{
${ }^{1} \mathrm{O}$ termo interface será utilizado para designar a fronteira entre dois fluidos ou entre um fluido e o vácuo (superfície livre), no caso em que um dos fluidos possua massa específica desprezível.
} 
destes líquidos com algum gás, porque a força de adesão que ocorre na interface entre dois líquidos é maior do que a formada entre um líquido e um gás (de Gennes, 1985).

\subsection{2 Ângulo de contato}

O ângulo de contato (também conhecido como ângulo de molhabilidade) entre uma gota de um líquido e uma superfície sólida, como está ilustrado na Fig. 1.3, depende da relação entre as forças de adesão, que fazem a gota se espalhar sobre a superfície e as forças coesivas do líquido que tentam contrair a gota na forma de uma esfera com uma superfície mínima (de Gennes, 1985). Deste modo, o ângulo de contato é uma medida de molhabilidade. Se a gota está em repouso sobre uma superfície, um ângulo $\theta_{S}$ de contato estático é formado entre o líquido e a superfície sólida em qualquer ponto da linha tríplice (interface entre sólido, líquido e a fase gasosa). O ângulo de contato é o ângulo resultante entre a linha tangente à interface que separa o líquido e o gás e a linha paralela à superfície do sólido. $\mathrm{O}$ ângulo de contato não é específico dos sistemas que possuem pelo menos uma interface líquido/gás, é igualmente aplicável para interfaces de dois liquidos (Wolf et al., 2005).

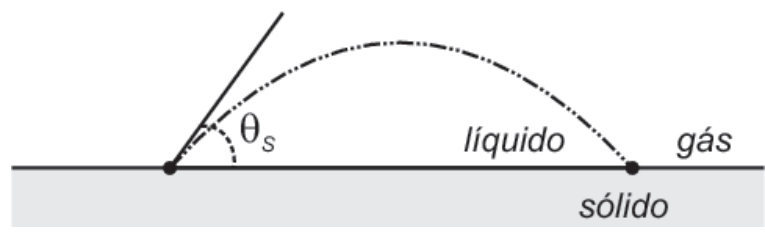

Figura 1.3: Definição de ângulo de contato estático $\left(\theta_{S}\right)$ entre uma gota de um líquido e uma superfície sólida.

Uma gota de água, por exemplo, depositada sobre determinadas superfícies, se apresenta em formatos diferentes, pois o modo como o volume de água de uma gota se acomoda depende das interações entre a água e a superfície em que foi depositada. É possível medir o ângulo com que uma gota fica na superfície e com isto caracterizar a superfície. Quanto menor o ângulo de contato, maior é a molhabilidade. O ângulo de contato de uma gota de água depositada numa folha, no azulejo, no espelho, etc. são todos diferentes, e influencia como a água fica numa superfície, o que determina a molhabilidade da mesma, como pode ser visto na Fig. 1.4.

Podem ser observados três possíveis comportamentos para a gota em contato com a superfície sólida, quando em contato com a superfície $\mathrm{A}$, a gota se espalha até atingir um ângulo $\theta_{S}>90^{\circ}$, ou seja, a gota é dita não-molhante, já quando a gota é depositada na superfície B, ela se espalha até atingir um ângulo $\theta_{S}<90^{\circ}$, neste caso, a gota é dita molhante. O último comportamento possível é quando a gota se espalha completamente, recobrindo toda a superfície $\mathrm{C}$ e uma fina camada do 

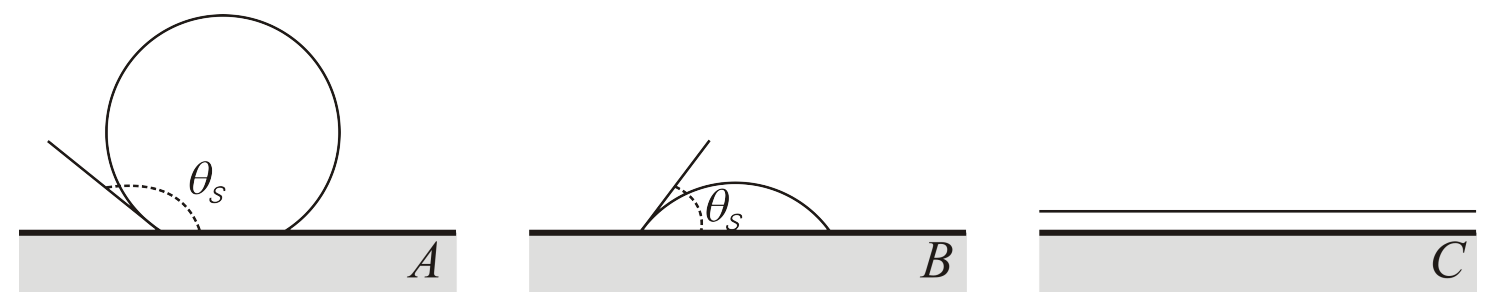

Figura 1.4: Possíveis ângulos de contato entre uma mesma gota de um líquido depositada sobre as superfícies sólidas $A, B$ e $C$, respectivamente.

fluido molhante é formada, o ângulo de contato estático é $\theta_{S}=0^{\circ}$, ou então, $\theta_{S} \rightarrow 0^{\circ}$.

O ângulo de contato estático é uma medida utilizada para quantificar a afinidade entre um líquido e uma superfície sólida. Quando $\theta_{S} \approx 0^{\circ}$, a superfície sólida é dita hidrofílica, e a gota líquida tende a espalhar completamente, caso contrário a superfície é dita hidrofóbica (Wang et al., 2005).

\subsubsection{Equação de Young-Dupré}

Os comportamentos observados na Fig. 1.4 podem ser identificados a partir do parâmetro de espalhamento $S$, que mede a diferença entre a energia superficial do substrato quando seco (sólido/gás) por unidade de área, e a energia superficial do substrato molhado (sólido/líquido e líquido/gás) (de Gennes et al., 2004).

O parâmetro de espalhamento $S$ pode ser obtido através da seguinte relação:

$$
S=\gamma_{S G}-\left(\gamma_{S L}+\gamma_{L G}\right)
$$

em que os três coeficientes $\gamma$ são as tensões superficiais das interfaces sólido/gás, sólido/líquido e líquido/gás, respectivamente. Na Fig. 1.5 pode-se observar o comportamento da gota sobre uma superfície dependendo do parâmetro de espalhamento $S$.

- $S<0$ : a gota se espalha sobre a superfície sólida até atingir um regime de molhabilidade parcial, com ângulo de contato $\left(\theta_{S}>0^{\circ}\right)$, a energia superficial do substrato seco é mais baixa $\left(\gamma_{S G}<\gamma_{S L}+\gamma_{L G}\right)$

- $S>0$ : a gota se espalha totalmente sobre a superfície sólida, pois a energia superficial do substrato seco é mais alta $\left(\gamma_{S G}>\gamma_{S L}+\gamma_{L G}\right)$. 


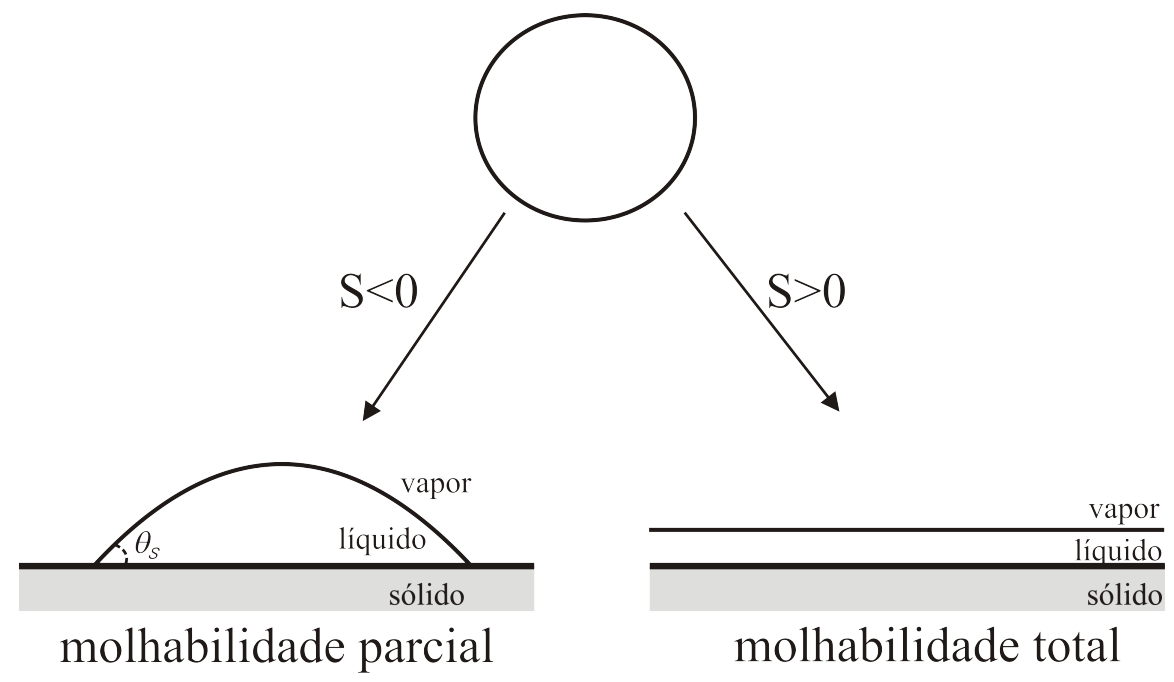

Figura 1.5: Regimes de molhabilidade parcial e total.

O ângulo de contato estático $\theta_{S}$, está relacionado com as tensões superficiais presentes no sistema ilustrado na Fig. 1.6, de forma que as tensões superficiais satisfaçam as condições de equilíbrio dada pela Eq. (1.2), que é conhecida como relação de Young-Dupré (de Gennes et al., 2004).

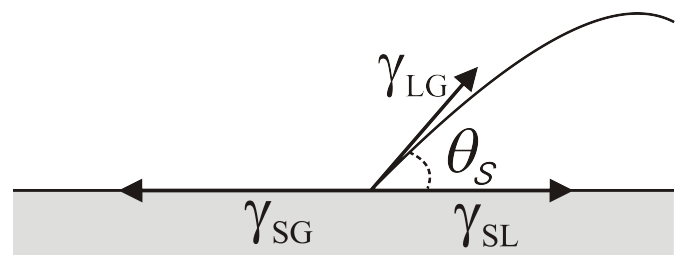

Figura 1.6: Determinação do ângulo de contato.

$$
\gamma_{L G} \cos \left(\theta_{S}\right)=\gamma_{S G}-\gamma_{S L}
$$

substituindo a Eq. (1.1) na (1.2) obtem-se:

$$
S=\gamma_{L G}\left(\cos \left(\theta_{S}\right)-1\right)
$$

\subsubsection{Histerese de ângulo de contato}

Na prática, quando uma gota líquida é depositada sobre uma superfície sólida, a situação de equilíbrio pode ser alcançada não somente com o ângulo de contato $\theta=\theta_{S}$ e sim para $\theta_{R}<\theta<\theta_{A}$, em que $\theta_{R}$ é o ângulo de contato de retrocesso e $\theta_{A}$ é o ângulo de contato de avanço (de Gennes, 1985). Os ângulos de contato $\theta_{A}$ e $\theta_{R}$ são determinados quando a inclinação crítica é atingida e a gota entra em movimento, sendo $\theta_{A}$ o maior ângulo de contato estável, enquanto que $\theta_{R}$ é o menor 
ângulo de contato estável. Histerese de ângulo de contato é definido como a diferença entre os ângulos de contato de avanço e de retrocesso (de Gennes et al., 2004).

Segundo de Gennes (1985), as três principais causas da histerese de ângulo de contato são: rugosidade da superfície - do ponto de vista macroscópico, uma superfície pode parecer plana, porém do ponto de vista microscópico a superfície pode não ser plana, pois irregularidades podem existir e serem maiores que o tamanho das moléculas do líquido, o que pode provocar a histerese (Joanny and de Gennes, 1984); heterogeneidade química da superfície - a presença de componentes químicos no substrato podem modificar as tensões superficiais e modificar as características de molhabilidade da superfície, o que pode facilitar ou dificultar o espalhamento do líquido; e contaminantes a contaminação do fluido por surfactantes, pode facilitar a formação de um filme de soluto sobre a superfície sólida, que pode levar aos efeitos de histerese (de Gennes, 1985).

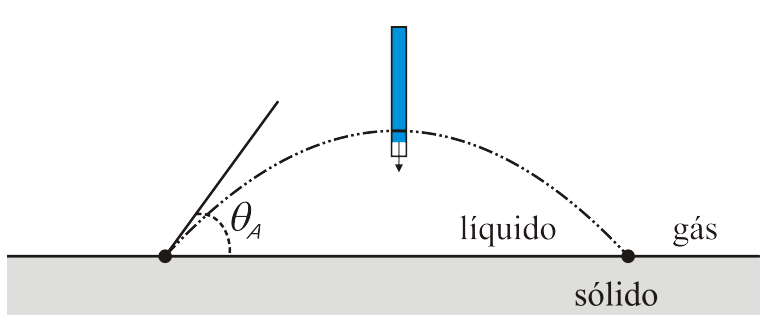

(a)

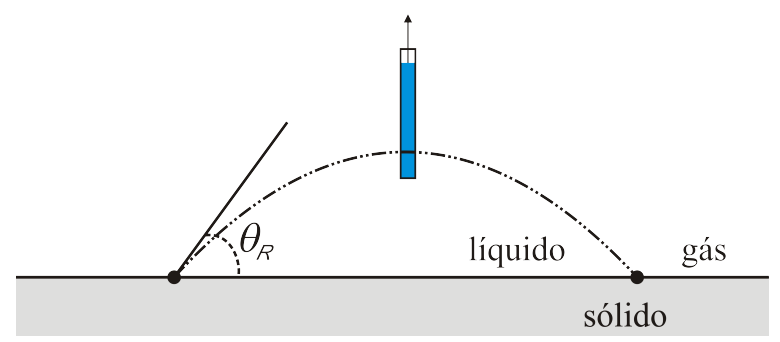

(b)

Figura 1.7: Histerese de ângulo de contato. (a) ângulo de avanço $\theta_{A}$ é obtido quando se infla a gota, o ângulo $\theta$ aumenta até que seja alcançada a inclinação crítica; (b) ângulo de retrocesso $\theta_{R}$ é obtido quando se drena a gota, o ângulo $\theta$ diminui até que seja alcançada a inclinação crítica.

\subsection{Métodos de representação de interface}

Há diversas aplicações que tratam o problema de linhas de contato dinâmicas, e apesar disto, o movimento do ponto de contato ainda não está esclarecido tanto do ponto de vista físico quanto matemático (Shikhmurzaev, 1993, 1996; Gerbeau and Lelièvre, 2009) e a simulação numérica deste problema é considerada uma difícil tarefa que ainda não está padronizada (Manservisi and Scardovelli, 2009). Na simulação do problema de linhas de contato dinâmicas, uma das dificuldades está em representar o deslocamento do ponto de contato. A dificuldade vem do fato que:

- A interface acompanha o movimento do fluido: a velocidade normal de um ponto na interface é a velocidade normal de uma partícula de fluido no mesmo ponto; 
- As partículas de fluido próximas ao contorno do domínio tendem a ter a mesma velocidade que os pontos do contorno.

Assim, se a velocidade dos pontos da fronteira do domínio é igual a zero (condição de contorno de não escorregamento, que será detalhada na subseção 2.3.1), o ponto de contato não se move. A representação de pontos de contato que se movem ao longo de uma superfície sólida pode ser abordada de várias maneiras. Inúmeros modelos e soluções tem sido propostos para este problema, mas sem nenhuma resposta definitiva, dependendo da escala das aplicações que pretende-se estudar. Por exemplo, em uma escala nanométrica, as interações entre as moléculas geram forças microscópicas que devem ser levadas em consideração, em particular, forças de van der Waals para fluidos orgânicos e forças de camada dupla para água (de Gennes, 1985). Tais considerações valem em escalas da ordem de $30 \AA$ até $1 \mu m$, e não são objeto de estudo do presente trabalho.

Considerando-se uma escala maior, da ordem de centenas de $\mu m$ à alguns milímetros, tais forças devem ser computadas através de um modelo ou condição que introduza o comportamento correto do fluido às equações de Navier-Stokes, para que a simulação através de um método numérico seja viável. Dentre os modelos existentes na literatura, se destacam os métodos de camada precursora, interface difusa e condição de escorregamento.

Nos métodos de camada precursora, uma fina camada de fluido envolve a interface, gerando uma película que separa um dos fluidos do sólido, evitando assim efetivamente a linha de contato tríplice. Contudo o método se torna instável a partir de uma certa espessura limite desta camada, o que degrada a precisão do mesmo (Levy and Shearer, 2004). Já nos métodos de interface difusa, uma concentração, chamada de fração de volume, é transportada sobre o domínio computacional, assumindo valores entre 0 a 1 , onde 0 representaria um fluido e 1 representaria o outro fluido, a massa específica $\rho$ e a viscosidade $\mu$ são variáveis no sentido que elas tomarão valores diferentes para cada fase, sendo constantes no interior das mesmas. A interface entre os fluidos seria localizada em algum lugar entre 0 e 1, com uma variação suave entre estes dois valores, o que resulta em uma interface com espessura finita. E com uma transição também suave na interface dos parâmetros físicos tais como massa específica e viscosidade (Ding and Spelt, 2007). Nos métodos que uma condição de escorregamento é especificada, aplica-se a condição de Navier para o ponto de contato, esta condição não apresenta os problemas das formulações difusas, mas introduz um parâmetro, que deve ser adequadamente calibrado, o que geralmente requer a especificação do ângulo de contato no ponto tríplice (Spelt, 2005).

A simulação física do ponto de contato depende claramente da representação da interface entre os fluidos. Existem diversas maneiras de se representar a interface que podem ser classificados 
em dois tipos, que são: métodos de fronteiras imersas e métodos de representação exata. Nos métodos de fronteiras imersas, a interface é aproximada de alguma forma na malha computacional, utilizando-se interpolações para transferir informações da interface à malha e vice-versa (operação conhecida como book-keeping, em inglês). Enquanto que na representação exata, a interface é marcada exatamente, a nível discreto, sendo que os elementos que a compõe (vértices, arestas, faces) delimitam regiões bem definidas na malha computacional, não sendo necessário a transferência de informações entre malha e interface (Ding and Spelt, 2007).

Dentre os métodos de fronteiras imersas, as diferentes formas de aproximações levam à duas classes de métodos, que são os métodos de captura de fronteira e os métodos de acompanhamento de fronteira.

Nos métodos de captura de fronteira, a interface é tratada como uma região com variação acentuada, não havendo necessidade de marcá-la explicitamente, contudo, a interface deve ser reconstruída a cada passo no tempo. A desvantagem é que há uma difusão da interface sobre várias células, ou seja, ela não é bem definida, o que resulta em perda de precisão. Exemplos são: o método conjunto de nível (do inglês, level-set) (Sussman et al., 1994) e volume de fluido, (do inglês, volume of fluid), conhecido como VOF (Hirt and Nichols, 1981). No método de conjunto de nível, a interface é representada por um conjunto de nível de uma função suave $\phi$, que conduz a fórmulas convenientes para o cálculo da normal e curvatura da interface, e não utiliza procedimentos especiais para modelar mudanças topológicas de regiões. Neste método a interface é representada pelo conjunto de nível zero de uma função de pseudo-concentração $\phi$ (Sussman et al., 1994), a qual é transportada pelo domínio computacional juntamente com o fluido (Sousa, 2005). O valor da função $\phi$ será positiva de um lado da interface e negativo do outro lado sendo o valor de $\phi$ atualizado a cada passo no tempo e a localização da interface será o contorno zero de $\phi$. O método de conjunto de nível tem sido utilizado para simular problemas de espalhamento como podem ser vistos nos trabalhos de Ding and Spelt (2007); Spelt (2005); Liu et al. (2005). O método VOF é uma técnica geométrica em que o volume ocupado por cada fase é identificado a todo passo no tempo por funções marcadoras em cada célula ocupada pelos fluidos. Estes volumes são então utilizados para reconstruir uma aproximação da interface. A interface é transportada com a velocidade do fluido e as funções marcadoras são atualizadas. Este método tem sido aplicado em simulações de impacto de uma gota sobre superfícies (Bussmann et al., 2000; Fukai et al., 1995).

Nos métodos de acompanhamento de fronteira, a interface é tratada explicitamente (representada por um conjunto interligado de pontos) como uma forma descontínua que se move sobre a malha, geralmente fixa no espaço, com a mesma velocidade do fluido, formando uma malha lagrangeana 
(Sousa, 2005). Este método é mais preciso, a conservação de massa é superior a dos métodos de captura de fronteira, por outro lado, mudanças topológicas são difíceis de serem representadas. Pode-se citar como exemplo o método de acompanhamento proposto por Tryggvason et al. (2001).

Dentre os métodos de representação exata, existem técnicas para o transporte de interface com malha dinâmica, na qual a representação da interface é feita utilizando-se um método de acompanhamento de fronteira lagrangeano, onde a interface entre diferentes fluidos (ou entre um fluido e o vácuo) é descrita diretamente por pontos, arestas e faces da malha computacional sobre ela (Sousa and Mangiavacchi, 2005). Nesta metodologia, não há qualquer tipo de interpolação entre a interface e a malha computacional o que garante boa precisão, porém, há a necessidade de controlar a malha dinâmica para prevenir o aparecimento de elementos de baixa qualidade, (por exemplo, elementos muito finos), que podem degradar a precisão do método. No presente trabalho, esta será a metodologia adotada, onde o fluido é representado por uma malha dinâmica de elementos finitos triangulares não estruturada, em que a superfície livre, que é a interface entre líquido/gás envolvendo um gás de massa específica e viscosidade desprezível, é explicitamente representada por vértices e arestas da malha. No trabalho de Manservisi and Scardovelli (2009) foi utilizado um método de acompanhamento da interface lagrangeano para simular ângulo de contato dinâmico e espalhamento de gotas. A técnica forneceu uma representação precisa da interface com boas propriedades em termos de conservação de massa para escoamentos incompressíveis.

\subsection{Proposta deste trabalho}

Este trabalho propõe o desenvolvimento e implementação de um método numérico para a simulação de escoamentos bidimensionais com superfícies livres em contato com substratos sólidos em malhas não estruturadas com inclusão de condições de ângulo de contato e linhas de contato dinâmicas. São empregadas técnicas de movimento de malha em uma estratégia Lagrangeana-Euleriana arbitrária (Arbitrary Lagrangian-Eulerian - ALE, em inglês), sobre uma malha de elementos finitos não estruturada e deformável. Para o cálculo da tensão superficial, utilizou-se uma estratégia simples, baseada no ajuste de círculos a pontos da superfície livre, com resultados bem precisos. Para a imposição direta do ângulo de contato, propõe-se uma estratégia baseada em superfície virtual, que permite o cálculo da curvatura nos pontos de contato, que os movimente para uma posição de equilíbrio. Outra maneira é impor o ângulo de contato através da condição de contorno de Navier generalizada, conhecida como condição GNBC, do inglês, Generalized Navier boundary condition proposta por Qian et al. (2003, 2006), e tem se mostrado muito natural com métodos dos elementos 
finitos em uma estratégia ALE (Gerbeau and Lelièvre, 2009).

Nesta abordagem, a malha de elementos finitos é deformada para se adaptar ao transporte da superfície livre. Tal deformação provoca o aparecimento de elementos de qualidade ruim, que são eliminados por um processo de adaptação. Foi utilizada a estrutura de dados Opposite Face (OF) proposta por Liziér (2006), para representação da malha, o que facilita a realização destas operações de adaptação de malha, como por exemplo inserção ou remoção de vértices, flipping de arestas, etc.

\subsection{Organização da dissertação}

Esta dissertação está organizada da seguinte forma:

- O capítulo 2 apresenta as equações de Navier-Stokes para escoamentos de fluidos baseando-se na Formulação Lagrangeana-Euleriana Arbitrária (ALE), além das condições auxiliares para contornos rígidos e interface;

- O capítulo 3 descreve a aproximação espacial das equações através de discretizações pelo método de elementos finitos e temporal através do método semi-lagrangeano;

- O capítulo 4 apresenta o cálculo da tensão superficial e ângulo de contato;

- O capítulo 5 descreve a técnica de refinamento e simplificação de malha empregada neste trabalho;

- O capítulo 6 apresenta as validações e resultados numéricos;

- O capítulo 7 apresenta as considerações finais. 


\section{Formulação matemática}

Escoamentos compressíveis e incompressíveis, turbulentos e laminares são modelados através das equações de Navier-Stokes, que representam matematicamente princípios físicos tais como: conservação de massa e conservação de quantidade de movimento. São estas equações de conservação que constituem um modelo matemático para o escoamento. Será considerado que o fluido é um contínuo, ou seja, a estrutura molecular do material é ignorada, e assume-se que é possível definir variáveis físicas como pressão, velocidade e massa específica num ponto do fluido (Fortuna, 2000).

\subsection{Formulação Lagrangeana-Euleriana Arbitrária (ALE)}

As formulações euleriana e lagrangeana são as duas maneiras de descrever as equações governantes da dinâmica dos fluidos em uma dada região do espaço (Nachbin, 2001). Na formulação euleriana, uma região fixa no espaço é definida, e o comportamento do fluido será estudado nesta região, que não muda sua forma com relação ao tempo. Na formulação lagrangeana, é definida uma região material formada por um conjunto de partículas de fluido, esta região se deforma a medida que as partículas se movimentam no escoamento (Sousa, 2005).

Uma generalização para descrever a dinâmica de um fluido é utilizar a formulação lagrangeanaeuleriana arbitrária (ALE), que consiste basicamente em introduzir um domínio referencial $\left(\Omega_{\zeta}\right)$, que se move com velocidade arbitrária no espaço independente dos pontos materiais e espaciais, 
como pode ser visto na Fig. 2.1.

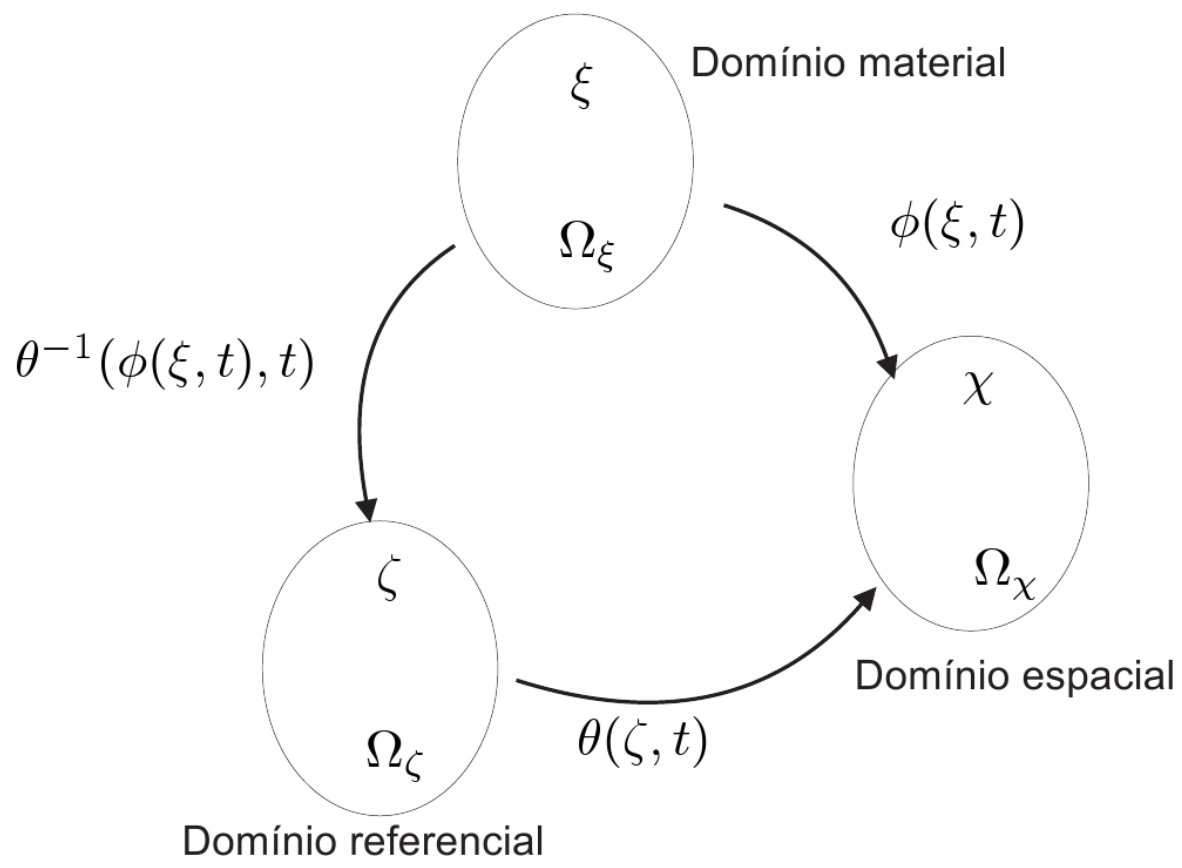

Figura 2.1: Diagrama esquemático do relacionamento entre os domínios utilizados na formulação lagrangeana-euleriana arbitrária (Hughes et al., 1981). Neste diagrama, $\phi(\xi, t)$ é a transformação que leva coordenadas (partículas de fluido) do domínio material $\left(\Omega_{\xi}\right)$ no domínio espacial $\left(\Omega_{\chi}\right)$, ou seja, $\chi=\phi(\xi, t)$ no instante $t$. Ainda, $\theta(\zeta, t)$ é a transformação que leva coordenadas (pontos) do domínio referencial $\left(\Omega_{\zeta}\right)$ no domínio espacial $\left(\Omega_{\chi}\right)$, ou seja, $\chi=\theta(\zeta, t)$ no instante $t$.

A equação fundamental da formulação ALE estabelece a derivada material no tempo de uma propriedade $f$ da seguinte forma:

$$
\frac{D f}{D t}=\left.\frac{\partial f}{\partial t}\right|_{\xi}=\left.\frac{\partial f}{\partial t}\right|_{\zeta}+((\boldsymbol{u}-\hat{\boldsymbol{u}}) \cdot \nabla) f
$$

em que $\boldsymbol{u}=\frac{\partial}{\partial t} \phi(\xi, t)$ define a velocidade de uma partícula de fluido $\xi$ no domínio espacial $\Omega_{\chi}$, e $\hat{\boldsymbol{u}}=\frac{\partial}{\partial t} \theta(\zeta, t)$ define a velocidade de um ponto $\zeta$ no domínio espacial.

Na formulação lagrangeana, o domínio referencial se desloca com velocidade idêntica do domínio material (velocidade do fluido), portanto, $\hat{\boldsymbol{u}}=\boldsymbol{u}$, e a variação temporal de uma propriedade $f$ no domínio material equivale a variação temporal no domínio referencial. Na formulação euleriana o domínio referencial está parado, $\hat{\boldsymbol{u}}=\mathbf{0}$.

Está exemplicado na Fig. 2.2, o movimento do ponto material e do domínio referencial (malha), nas formulações euleriana Fig. 2.2(a), onde a malha permanece parada, na formulação lagrangeana Fig. 2.2(b), em que a malha movimenta segundo a velocidade da partícula material e em Fig. 2.2(c) a malha se movimenta de maneira arbitrária. 


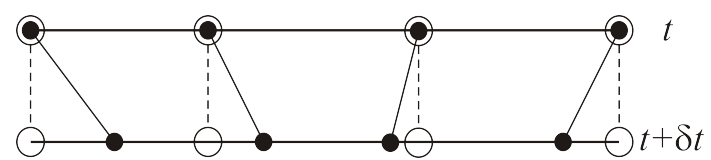

(a) Formulação Euleriana

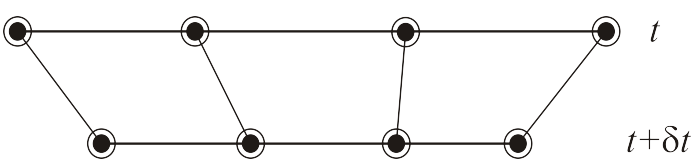

(b) Formulação Lagrangeana

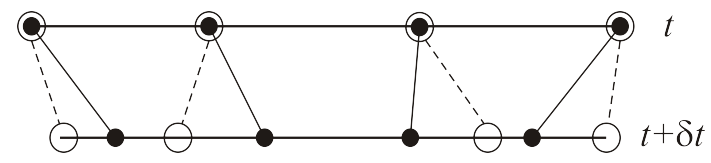

(c) Formulação ALE

- ponto material _ movimento da partícula

vértice da malha ---- movimento da malha

Figura 2.2: Exemplo unidimensional do movimento da partícula material e da malha euleriana, lagrangeana e ALE.

\subsubsection{Movimentação de malha}

A velocidade da malha, $\hat{\boldsymbol{u}}$, determina a movimentação dos pontos da malha de elementos finitos em uma formulação lagrangeana-euleriana arbitrária, e será definida da seguinte maneira:

$$
\hat{\boldsymbol{u}}=\beta_{1} \boldsymbol{u}+\beta_{2} \boldsymbol{u}_{e}
$$

em que $\boldsymbol{u}$ determina a velocidade do escoamento e, $\boldsymbol{u}_{e}$ uma velocidade dita elástica, que será calculada através de uma estratégia de suavização laplaciana (Sousa, 2005).

As constantes $\beta_{1}$ e $\beta_{2}$ pertencentes ao intervalo [0,1], controlam as contribuições de cada velocidade na velocidade final da malha. A estratégia puramente lagrangeana poderá ser recuperada se $\beta_{1}=1$ e $\beta_{2}=0$, caso $\beta_{1}=\beta_{2}=0$, a velocidade da malha é nula e recupera-se a estratégia euleriana.

Define-se a velocidade elástica a cada passo no tempo $\Delta t$ como:

$$
\boldsymbol{u}_{e}\left(\boldsymbol{x}_{i}, t+\Delta t\right)=\frac{\hat{\boldsymbol{x}}_{i}-\boldsymbol{x}_{i}}{\Delta t}
$$

onde $\boldsymbol{x}_{i}$ é a posição do vértice $i$ e a sua nova posição $\hat{\boldsymbol{x}}_{i}$ é calculada através do método de suavização laplaciana, no qual as novas coordenadas dos vértices são médias das coordenadas dos vértices adjacentes, ou seja,

$$
\hat{\boldsymbol{x}}_{i}=\frac{1}{n} \sum_{j \in A\left(\boldsymbol{x}_{i}\right)} \boldsymbol{x}_{j},
$$

onde $A\left(\boldsymbol{x}_{i}\right)$ é o conjunto dos pontos adjacentes ao vértice $i$ e $n$ corresponde ao número de vértices em $A\left(\boldsymbol{x}_{i}\right)$. 
A velocidade $\hat{\boldsymbol{u}}$ dada na Eq. (2.2) é utilizada para a movimentação da malha de elementos finitos que discretiza o domínio. Porém os vértices pertencentes à interface, devem ser movimentados de acordo com o campo de velocidade do escoamento, $\boldsymbol{u}$, portanto, a velocidade que movimenta os pontos de superfície não pode ser calculada diretamente da Eq. (2.2).

O movimento da interface utilizando a velocidade do fluido pode levar a uma distribuição não uniforme dos pontos que discretizam a interface (Sousa, 2005). Portanto, a estratégia de movimentação dos pontos na interface, consiste na utilização somente da componente normal, $\boldsymbol{n}$, da velocidade do escoamento, ou seja,

$$
\hat{\boldsymbol{u}}=(\boldsymbol{u} \cdot \boldsymbol{n}) \boldsymbol{n},
$$

logo a velocidade $\hat{\boldsymbol{u}}$ calculada pode ser generalizada como

$$
\hat{\boldsymbol{u}}(\boldsymbol{x})= \begin{cases}\beta_{1} \boldsymbol{u}+\beta_{2} \boldsymbol{u}_{e} & \text { se } \boldsymbol{x} \text { não pertence à interface, } \\ \left(1-\beta_{3}\right) \boldsymbol{u}+\beta_{3}(\boldsymbol{u} \cdot \boldsymbol{n}) \boldsymbol{n} & \text { se } \boldsymbol{x} \text { pertence à interface, }\end{cases}
$$

onde $\beta_{3}$ é um fator de controle da aplicação da estratégia de movimentação na componente normal da velocidade da interface, sendo que $\beta_{3} \in\{0,1\}$, se $\beta_{3}=1$ então os pontos da interface são movimentados com a utilização apenas da componente normal da velocidade do escoamento, caso $\beta_{3}=0$, recupera-se a estratégia lagrangeana e os pontos da interface são movimentados com a velocidade do fluido.

\subsection{Equações de Navier-Stokes}

As equações que modelam escoamentos incompressíveis de fluidos Newtonianos são as equações de Navier-Stokes, dadas pela equação da conservação da quantidade de movimento

$$
\rho \frac{D \boldsymbol{u}}{D t}-\nabla \cdot\left[-p \boldsymbol{I}+\mu\left(\nabla \boldsymbol{u}+\nabla \boldsymbol{u}^{T}\right)\right]-\rho \boldsymbol{g}=0,
$$

e a equação da continuidade

$$
\nabla \cdot \boldsymbol{u}=0
$$

onde $p=p(\boldsymbol{x}, t)$ é o campo de pressões, $\boldsymbol{u}=\boldsymbol{u}(\boldsymbol{x}, t)$ é a velocidade do fluido, $\rho$ é a massa específica, $\mu$ é a viscosidade dinâmica, ambos considerados constantes. Na formulação lagrangeanaeuleriana arbitrária, a derivada material $D \boldsymbol{u} / D t$ que aparece na Eq. (2.6) é dada por,

$$
\frac{D \boldsymbol{u}}{D t}=\frac{\partial \boldsymbol{u}}{\partial t}+((\boldsymbol{u}-\hat{\boldsymbol{u}}) \cdot \nabla) \boldsymbol{u}
$$


onde $\hat{\boldsymbol{u}}=\hat{\boldsymbol{u}}(\boldsymbol{x}, t)$ define a velocidade da malha.

Em adição aos efeitos da gravidade, viscosidade e movimento, a tensão superficial também deverá ser incorporada na formulação. Como será adotada a formulação de 1-fluido, os efeitos de tensão superficial serão incorporados através da imposição de condições de contorno na Eq. (2.6), tal como em Saksono and Perić (2006a); Sousa et al. (2007). Em problemas multifásicos, tal imposição poderia ser feita através da adição de um termo fonte correspondente a uma força volumétrica agindo sobre a interface, no lado direito da mesma equação (Brackbill et al., 1992; Tryggvason et al., 2001).

\subsection{Condições auxiliares}

As condições iniciais e de contorno, devem ser apropriadamente especificadas em problemas que são modelados por equações diferenciais parciais, pois a solução do problema depende continuamente de tais condições (Fortuna, 2000).

\subsubsection{Condições para contornos rígidos}

As condições de fronteira para os contornos rígidos podem ser:

- Condição de contorno de não escorregamento (no-slip, em inglês): as componentes do vetor velocidade são impostas, esta condição considera que o fluido imediatamente adjacente à superfície sólida deve estar em repouso em relação a mesma, ou seja, as componentes normal, $u_{n}$, e tangencial, $u_{t}$, da velocidade na parede são definidas como nulas, $(\boldsymbol{u}=0)$.

- Condição de contorno de escorregamento (free-slip, em inglês): esta condição permite que o fluido deslize livremente sobre a superfície sólida, é também aplicada em problemas onde há um plano de simetria. Define-se, neste caso,

$$
u_{n}=0 \quad \text { e } \frac{\partial u_{t}}{\partial n}=0
$$

Em ambos os casos, $n$ representa a direção normal e $t$ a direção tangencial ao contorno rígido. 


\subsubsection{Condições na superfície livre}

$\mathrm{Na}$ interface gás/líquido envolvendo um gás de massa específica e viscosidade desprezível, a tensão na superfície livre, satisfaz

$$
\begin{aligned}
& (\boldsymbol{\sigma n}) \cdot \boldsymbol{n}=\quad \gamma \kappa \\
& (\boldsymbol{\sigma} \boldsymbol{n}) \cdot \boldsymbol{m}=0
\end{aligned}
$$

onde $\gamma$ é o coeficiente de tensão superficial, que neste trabalho será considerado constante, e $\kappa$ é a curvatura (parâmetro geométrico) da superfície, $\boldsymbol{n}$ e $\boldsymbol{m}$ correspondem respectivamente ao vetor normal e tangencial à interface líquido/gás, e ainda $\sigma$ é o tensor de Cauchy, que é dado por

$$
\boldsymbol{\sigma}=-p \boldsymbol{I}+\mu\left(\nabla \boldsymbol{u}+\nabla \boldsymbol{u}^{T}\right)
$$

\subsection{Adimensionalização das equações de Navier-Stokes}

Os problemas em mecânica dos fluidos envolvem grandezas que os caracterizam, como velocidade, pressão, massa específica, etc. Tais grandezas na forma dimensional são diferenciadas por suas magnitudes, dadas através de um sistema métrico escolhido previamente. O processo de adimensionalização consiste em normalizar as dimensões das grandezas envolvidas no escoamento e identificar os parâmetros que o governam. Como resultado deste processo, aparecem os parâmetros adimensionais, que são relações únicas sobre as forças que atuam no escoamento. Deste modo, problemas em escalas de dimensões diferentes, mas que tenham os mesmos parâmetros adimensionais, terão resultados equivalentes, e são denominados similares (Sousa, 2005).

Para cada grandeza relevante no problema, o seu valor dimensional pode ser expresso como o produto de uma grandeza adimensional por um valor dimensional de referência. A adimensionalização das equações de conservação para escoamentos incompressíveis e isotérmicos pode ser feita a partir das grandezas adimensionais:

$$
\begin{array}{ll}
p=\rho_{0} U^{2} p^{*}, & \boldsymbol{u}=U \boldsymbol{u}^{*}, \quad \boldsymbol{x}=L \boldsymbol{x}^{*}, \quad t=\frac{L}{U} t^{*}, \\
\boldsymbol{g}=g \boldsymbol{g}^{*}, \quad \kappa=\frac{1}{L} \kappa^{*}, \quad \gamma=\gamma_{0} \gamma^{*} . &
\end{array}
$$

E para os operadores diferenciais,

$$
\frac{\partial}{\partial t}=\frac{U}{L} \frac{\partial}{\partial t^{*}} \text { e } \nabla=\frac{1}{L} \nabla^{*},
$$


em que $L, U, \rho_{0}, g, t$ e $\gamma_{0}$ são, respectivamente, valores de referência de comprimento, velocidade, massa específica, gravidade, tempo e coeficiente de tensão superficial $\left(\gamma_{0}=\gamma\right)$. Em escoamentos incompressíveis e monofásicos, pode-se tomar $\rho_{0}=\rho$.

As equações de Navier-Stokes, (2.6) e (2.7), adimensionalizadas tornam-se

$$
\begin{aligned}
\frac{D \boldsymbol{u}}{D t}-\nabla \cdot\left[-p \boldsymbol{I}+\frac{1}{R e}\left(\nabla \boldsymbol{u}+\nabla \boldsymbol{u}^{T}\right)\right]-\frac{1}{F r^{2}} \boldsymbol{g} & =0 \\
\nabla \cdot \boldsymbol{u} & =0
\end{aligned}
$$

onde $R e=\rho L U / \mu$ é o número de Reynolds que caracteriza o escoamento, e $F r=U /(g L)^{1 / 2}$ é o número de Froude que caracteriza escoamentos em que a gravidade tem papel importante, como é o caso de escoamentos com superfícies livres.

No caso das simulações envolvendo gotas, onde não há informação sobre a velocidade de referência $U$, os comprimentos são normalmente adimensionalizados pelo diâmetro de referência $D$ (normalmente adotado como o diâmetro equivalente de bolhas circulares), ou seja, o comprimento de referência é tomado como o diâmetro de referência $L=D$, e as velocidades são adimensionalizadas por $(g D)^{1 / 2}$ (Sousa, 2005). Assim, as equações de conservação, (2.17) e (2.18), são obtidas de maneira análoga à utilizada acima.

$$
\begin{aligned}
\frac{D \boldsymbol{u}}{D t}-\nabla \cdot\left[-p \boldsymbol{I}+\frac{1}{G a^{1 / 2}}\left(\nabla \boldsymbol{u}+\nabla \boldsymbol{u}^{T}\right)\right]-\boldsymbol{g} & =0 \\
\nabla \cdot \boldsymbol{u} & =0
\end{aligned}
$$

onde $G a=\rho^{2} D^{3} g / \mu^{2}$ é o número de Galileo, que é a razão entre as forças de empuxo e as forças viscosas.

A condição de contorno para superfície livre, dada pelas Eqs. (2.10) e (2.11) também deve ser adimensionalizada. De forma que

$$
\begin{aligned}
& (\boldsymbol{\sigma n}) \cdot \boldsymbol{n}=\frac{\gamma \kappa}{E O} \\
& (\boldsymbol{\sigma n}) \cdot \boldsymbol{m}=0
\end{aligned}
$$

onde o tensor de Cauchy é dado por $\boldsymbol{\sigma}=-p \boldsymbol{I}+G a^{-1 / 2}\left(\nabla \boldsymbol{u}+\nabla \boldsymbol{u}^{T}\right)$, e o número Eo que aparece na Eq. (2.19) é o número de Eötvös, que relaciona forças de empuxo e forças de tensão superficial, e caracteriza a forma de uma gota. Este número é definido por $E_{o}=\rho g D^{2} / \gamma$. Quando $E_{o} \gg 1$, as forças de tensão superficial não são importantes no escoamento. 


\section{Discretização das equações de Navier-Stokes}

Neste trabalho as equações de Navier-Stokes serão discretizadas pelo método de elementos finitos, sendo as interfaces e contornos diretamente representados como arestas de elementos triangulares. Além disso, sempre que uma aresta de um elemento faz parte da fronteira do domínio computacional, as condições de contorno podem ser aplicadas de uma maneira direta e elegante, utilizando uma formulação variacional adequada para as equações de Navier-Stokes (Peterson, 1999).

\subsection{Formulação variacional}

Nesta seção, as equações de Navier-Stokes serão escritas na formulação variacional. Considere as equações de conservação para escoamentos incompressíveis na formulação ALE, as equações de Navier-Stokes, dadas na forma adimensional, vistas na seção 2.4, por

$$
\begin{aligned}
\frac{D \boldsymbol{u}}{D t}-\nabla \cdot\left[-p \boldsymbol{I}+\frac{1}{G a^{1 / 2}}\left(\nabla \boldsymbol{u}+\nabla \boldsymbol{u}^{T}\right)\right]-\boldsymbol{g} & =0, \\
\nabla \cdot \boldsymbol{u} & =0
\end{aligned}
$$


válidas em um domínio $\Omega \subset \mathbb{R}^{2}$. Na interface gás/líquido envolvendo um gás de massa específica desprezível, a tensão na superfície livre, $\Gamma$, satisfaz as Eqs. (2.10) e (2.11) escritas abaixo:

$$
\begin{aligned}
& (\boldsymbol{\sigma n}) \cdot \boldsymbol{n}=\frac{\gamma \kappa}{E O}, \\
& (\boldsymbol{\sigma n}) \cdot \boldsymbol{m}=0 .
\end{aligned}
$$

Para discretizar as equações do modelo no sentido do método dos elementos finitos, é necessário transformar o problema em um problema variacional. Considere o espaço de dimensão infinita

$$
L^{2}(\Omega)=\left\{v: \Omega \rightarrow \mathbb{R}, \int_{\Omega} v^{2} d \Omega<+\infty\right\}
$$

e o espaço de Sobolev

$$
H^{1}(\Omega)=\left\{v \in L^{2}(\Omega) ; \frac{\partial v}{\partial x_{i}} \in L^{2}(\Omega), i=1, \cdots, m\right\} .
$$

Define-se o subespaço $H^{1}(\Omega)^{n}$ sendo, $H^{1}(\Omega)^{n}=\left\{\boldsymbol{v}=\left(v_{1}, \cdots, v_{n}\right), v_{i} \in H^{1}(\Omega), \forall i=1, \cdots, n\right\}$, onde $H^{1}(\Omega)^{n}$ é o produto cartesiano de $n$ subespaços $H^{1}(\Omega)$. Sejam $H^{1}(\Omega)^{2}=H^{1}(\Omega) \times H^{1}(\Omega)$, $Q=L^{2}(\Omega)$ e $V=\left\{\boldsymbol{w} \in H^{1}(\Omega)^{2}: \boldsymbol{w}=\mathbf{0}\right.$ em $\left.\mathcal{S}\right\}$, onde $\mathcal{S}$ representa o contorno rígido (interface sólido/líquido), para obter a formulação variacional do problema dado pelas Eqs. (3.1)-(3.2), basta multiplicar a Eq. (3.1) por uma função teste $\boldsymbol{w} \in V$ arbitrária e integrar o resultado no domínio. Para os cálculos realizados neste capítulo será adotado $\boldsymbol{w}=\mathbf{0} \mathrm{em} \mathcal{S}$, por simplicidade. Contudo quando os ângulos de contato forem inseridos no modelo, esta condição deverá ser alterada como será visto no capítulo 4. Assim, o problema agora consiste em obter uma solução $\boldsymbol{u} \in V$ de forma que

$$
\int_{\Omega} \boldsymbol{w} \cdot\left\{\frac{D \boldsymbol{u}}{D t}-\nabla \cdot\left[-p \boldsymbol{I}+\frac{1}{G a^{1 / 2}}\left(\nabla \boldsymbol{u}+\nabla \boldsymbol{u}^{T}\right)\right]-\boldsymbol{g}\right\} d \Omega=0
$$

e também

$$
\underbrace{\int_{\Omega} q(\nabla \cdot \boldsymbol{u}) d \Omega}_{d(q, \boldsymbol{u})}=0
$$

para todo $q \in Q$. Desenvolvendo (3.7) vem

$$
\int_{\Omega} \boldsymbol{w} \cdot\left(\frac{D \boldsymbol{u}}{D t}\right) d \Omega-\int_{\Omega} \boldsymbol{w} \cdot \nabla \cdot\left[-p \boldsymbol{I}+\frac{1}{G a^{1 / 2}}\left(\nabla \boldsymbol{u}+\nabla \boldsymbol{u}^{T}\right)\right] d \Omega-\int_{\Omega} \boldsymbol{w} \cdot \boldsymbol{g} d \Omega=0
$$

Aplicando o teorema de integração por partes de Green na integral do termo de tensões totais, obtém-se

$$
\begin{aligned}
\int_{\Omega} \boldsymbol{w} \cdot \nabla \cdot\left[-p \boldsymbol{I}+\frac{1}{G a^{1 / 2}}\left(\nabla \boldsymbol{u}+\nabla \boldsymbol{u}^{T}\right)\right] d \Omega=\int_{\Omega} p \nabla \cdot \boldsymbol{w} d \Omega+ \\
-\frac{1}{G a^{1 / 2}} \int_{\Omega} \nabla \boldsymbol{w}:\left[\nabla \boldsymbol{u}+\nabla \boldsymbol{u}^{T}\right] d \Omega+\underbrace{\int_{\partial \Omega} \boldsymbol{w} \cdot(\boldsymbol{\sigma} \cdot \boldsymbol{n}) d(\partial \Omega)}_{\text {cond. de cont. natural }},
\end{aligned}
$$


onde o operador ': ' representa o produto escalar entre dois tensores, e $\partial \Omega$ é o contorno de $\Omega$, com $\partial \Omega=\Gamma \cup \mathcal{S}$. Assim, a Eq. (3.9) pode ser reescrita como

$$
\begin{aligned}
\int_{\Omega} \boldsymbol{w} \cdot\left(\frac{D \boldsymbol{u}}{D t}\right) d \Omega-\int_{\Omega} p \nabla \cdot \boldsymbol{w} d \Omega+\frac{1}{G a^{1 / 2}} \int_{\Omega} \nabla \boldsymbol{w}:\left[\nabla \boldsymbol{u}+\nabla \boldsymbol{u}^{T}\right] d \Omega+ \\
\quad-\int_{\Omega} \boldsymbol{w} \cdot \boldsymbol{g} d \Omega-\int_{\partial \Omega} \boldsymbol{w} \cdot(\boldsymbol{\sigma} \cdot \boldsymbol{n}) d(\partial \Omega)=0 .
\end{aligned}
$$

Utilizando (3.3), a última integral do lado esquerdo da Eq. (3.11) pode ser escrita como

$$
\int_{\partial \Omega} \boldsymbol{w} \cdot(\boldsymbol{\sigma} \cdot \boldsymbol{n}) d(\partial \Omega)=\int_{\Gamma} \frac{\gamma \kappa}{E O} \boldsymbol{w} \cdot \boldsymbol{n} d \Gamma
$$

pois como $\boldsymbol{w}=\mathbf{0}$ em $\mathcal{S}$, a integral $\int_{\mathcal{S}} \boldsymbol{w} \cdot(\boldsymbol{\sigma} \cdot \hat{n}) d \mathcal{S}=0$, onde $\hat{n}$ corresponde ao vetor normal à superfície sólida. Assim, a Eq. (3.11) pode ser reescrita como

$$
\begin{aligned}
& \underbrace{\int_{\Omega} \boldsymbol{w} \cdot\left(\frac{D \boldsymbol{u}}{D t}\right) d \Omega}_{m\left(\frac{D u}{D t}, \boldsymbol{w}\right)}-\underbrace{\int_{\Omega} p \nabla \cdot \boldsymbol{w} d \Omega}_{g(p, \boldsymbol{w})}+\frac{1}{G a^{1 / 2}} \underbrace{\int_{\Omega} \nabla \boldsymbol{w}:\left[\nabla \boldsymbol{u}+\nabla \boldsymbol{u}^{T}\right] d \Omega}_{k(\boldsymbol{u}, \boldsymbol{w})}+ \\
& -\underbrace{\int_{\Omega} \boldsymbol{w} \cdot \boldsymbol{g} d \Omega}_{m(\boldsymbol{g}, \boldsymbol{w})}-\underbrace{\int_{\Gamma} \frac{\gamma \kappa}{E_{O}} \boldsymbol{w} \cdot \boldsymbol{n} d \Gamma}_{\hat{m}(\gamma \kappa \boldsymbol{n}, \boldsymbol{w})}=0
\end{aligned}
$$

Utilizando as formas integrais definidas sob as chaves nas Eqs. (3.8) e (3.13), o problema pode ser escrito na forma fraca como segue: "Encontrar soluções $\boldsymbol{u}(\boldsymbol{x}, t) \in V$ e $p(\boldsymbol{x}, t) \in Q$ tais que

$$
\begin{aligned}
m\left(\frac{D \boldsymbol{u}}{D t}, \boldsymbol{w}\right)-g(p, \boldsymbol{w})+\frac{1}{G a^{1 / 2}} k(\boldsymbol{u}, \boldsymbol{w})-m(\boldsymbol{g}, \boldsymbol{w})-\frac{1}{E O} \hat{m}(\gamma \kappa \boldsymbol{n}, \boldsymbol{w}) & =0 \\
d(q, \boldsymbol{u}) & =0
\end{aligned}
$$

para todo $\boldsymbol{w} \in V$ e $q \in Q$ "'.

\subsection{Discretização espacial}

O primeiro passo na discretização de qualquer problema a ser resolvido numericamente é a discretização do domínio. No caso do método de elementos finitos, o domínio $\Omega$ é discretizado (dividido) por um número finito, $E$, de elementos, $\Omega^{e}$, de forma que, $\Omega=\cup_{e=1}^{E} \Omega^{e}$, com elementos não sobrepostos, $\Omega^{e} \cap \Omega^{f}=\emptyset, \forall e, f=1, \cdots, E, e \neq f$. O domínio pode ser discretizado por elementos poligonais ou por elementos curvos, com o devido tratamento numérico, porém a utilização de domínios poligonais é mais comum, devido à facilidade de implementação (Sousa, 2005). Há também a possibilidade de utilizar malhas mistas, ou seja, quando diferentes tipos de elementos discretizam o mesmo domínio. Em duas dimensões as escolhas óbvias para elementos 
são quadriláteros ou triângulos (simplexos). No presente trabalho, o domínio $\Omega$ é discretizado por uma malha não estruturada de elementos finitos triangulares, na Fig. 3.1(b) pode ser vista uma triangulação do domínio $\Omega$ em 3.1(a). Cada elemento é formado através da conexão de um certo número de nós (vértices), o número de vértices de um elemento depende do tipo de elemento (ou da função de interpolação).

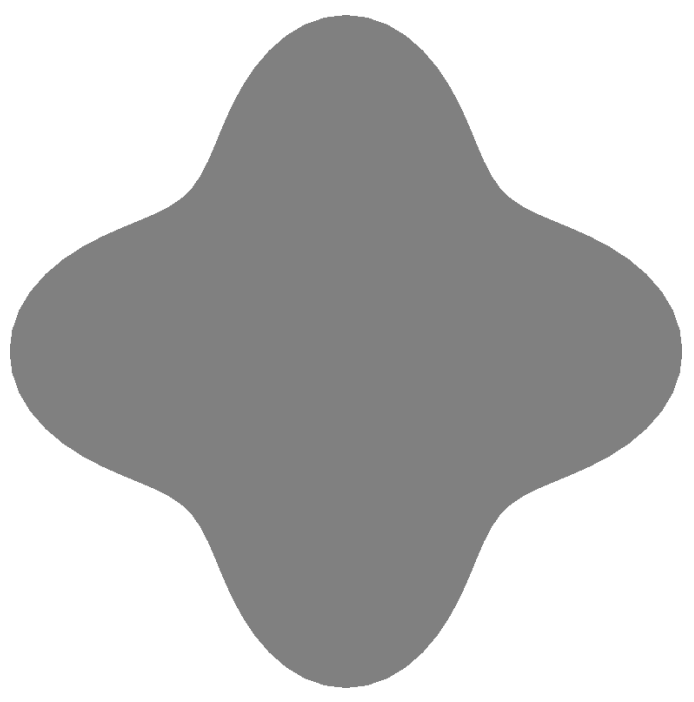

(a) Domínio $\Omega$.

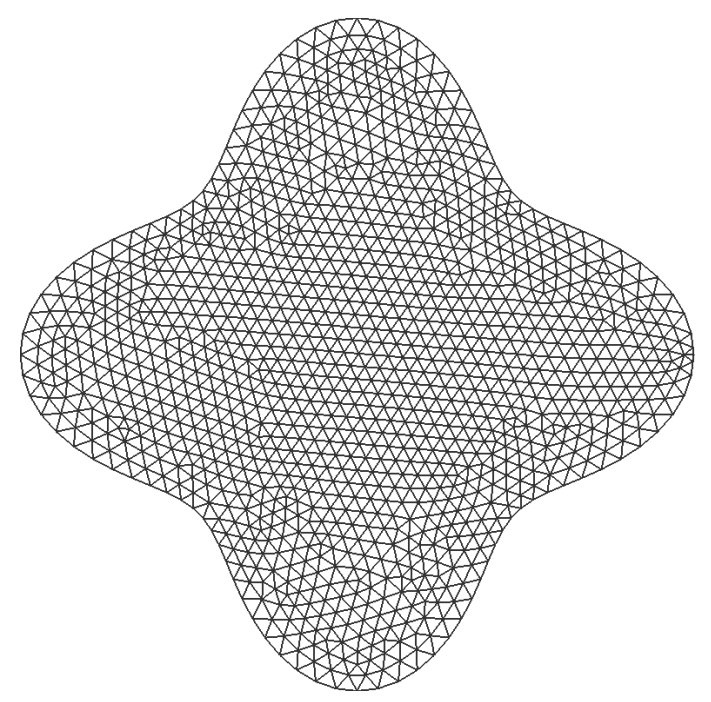

(b) Triangulação $T(\Omega)$.

Figura 3.1: Exemplo de uma triangulação $T$ de um domínio $\Omega$.

A utilização de triângulos é justificada, pois um dos principais objetivos é a implementação de um método de malha dinâmica. A qualidade de malhas simplexiais em 2D, como por exemplo malhas baseadas em triangulações de Delaunay, é garantida por várias propriedades geométricas e relações vindas de uma teoria bem estabelecida (Shewchuk, 1999, 2002; Chew, 1989).

\subsubsection{Tipos de elementos para escoamentos de fluidos}

Como foi visto na seção 3.2, o domínio $\Omega$ é discretizado por uma malha não estruturada de elementos finitos triangulares. Para as equações de Navier-Stokes, é necessário calcular funções de interpolação para mais de uma variável ao mesmo tempo, como velocidade e pressão. Devido ao acoplamento entre estas duas grandezas nas equações, a combinação entre elas não pode ser arbitrária no método de Galerkin. Existe uma vasta literatura sobre a escolha do tipo de elemento, principalmente no que diz respeito aos testes que devem ser feitos para identificar elementos que são ou não válidos para o problema (Sousa, 2005).

O método para solução das equações de Navier-Stokes implementado, utiliza uma formulação 
ALE, sendo discretizado pelo método de elementos finitos sobre uma malha que se move em relação ao espaço. A malha é movimentada através do transporte de seus vértices, e foi construída com elementos finitos do tipo mini-elemento ou elemento $P_{1}^{+}-P_{1}$ (Arnold et al., 1984), que satisfaz a condição inf-sup de Babuška-Brezzi. Cada elemento possui 4 graus de liberdade para as velocidades, utilizando-se funções de interpolação lineares mais um termo cúbico ("bolha”), definida como sendo 1 no centróide e 0 nas fronteiras do triângulo, e 3 para as pressões, utilizando-se funções de interpolação lineares.

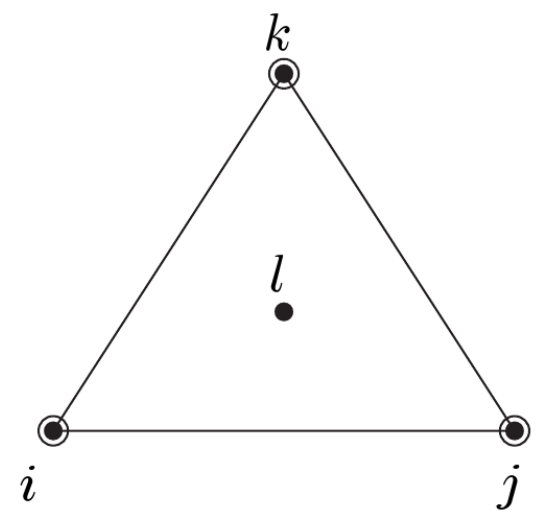

Figura 3.2: Mini-elemento com 4 pontos de velocidade e 3 pontos de pressão.

\subsubsection{Funções de interpolação para elementos triangulares}

Apesar de ser possível a determinação de funções de interpolação em coordenadas globais para o triângulo, a utilização de coordenadas locais simplifica e padroniza o processo de solução. Considere um ponto $P$ dentro de um triângulo como mostrado na Fig. 3.3. As coordenadas locais $L_{i}$, $L_{j}$ e $L_{k}$ deste ponto podem ser obtidas através do cálculo apropriado das áreas. Por exemplo, $L_{i}$ é definido como a razão entre a distância do ponto $P$ ao lado ' $j k$ ' $(O P)$ e a distância do nó $i$ ao lado ‘ $j k ’(Q R)$. Assim,

$$
L_{i}=\frac{O P}{Q R}
$$

Similarmente, $L_{j}$ e $L_{k}$ são também definidos. O valor de $L_{i}$ é também equivalente a razão entre a área $\left(A_{i}\right)$, oposta ao nó $i$, e a área total do triângulo, que é,

$$
L_{i}=\frac{A_{i}}{A}=\frac{0.5(O P)(j k)}{0.5(Q R)(j k)}=\frac{O P}{Q R}
$$




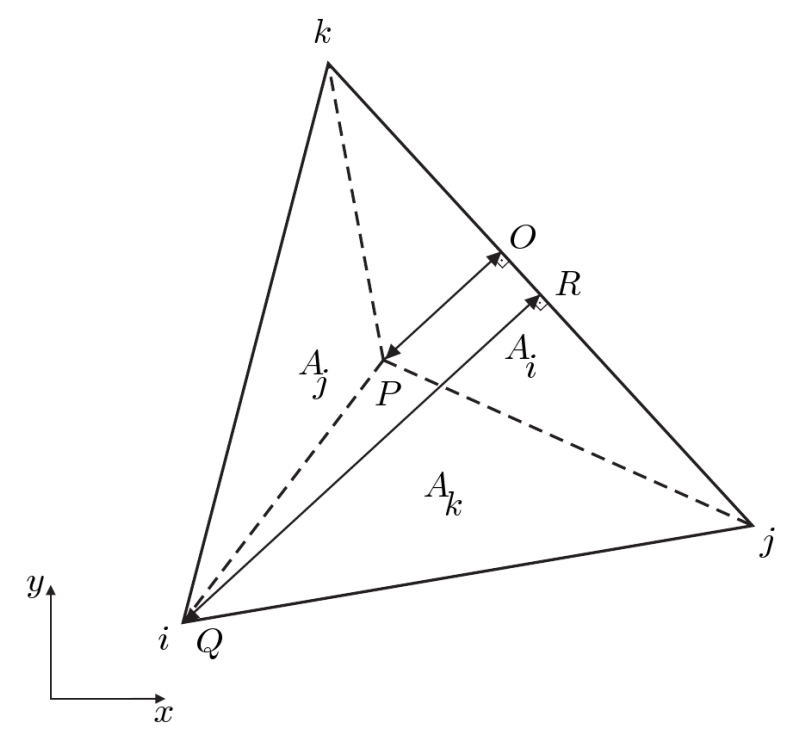

Figura 3.3: Coordenadas baricêntricas de um elemento triangular e determinação de funções de interpolação.

Assim, a coordenada local $L_{i}$ varia de 0 sobre ' $j k$ ' a 1 sobre o nó $i$, ou seja, qualquer ponto sobre a aresta ' $j k$ ' tem coordenada $L_{i}=0$, e se o ponto coincide com o vértice $i$, então, $L_{i}=1$, uma vez que $A_{i}=A$. Da Fig. 3.3 é claro que

$$
\begin{aligned}
A_{i}+A_{j}+A_{k} & =A \\
\frac{A_{i}}{A}+\frac{A_{j}}{A}+\frac{A_{k}}{A} & =1 .
\end{aligned}
$$

Note que, a posição de qualquer ponto dentro do triângulo pode ser representada pelas coordenadas locais $\left(L_{i}, L_{j}, L_{k}\right)$, também chamadas de coordenadas baricêntricas. Da Eq. 3.19 obtêm-se

$$
L_{i}+L_{j}+L_{k}=1
$$

A relação entre o sistema de coordenadas global $(x, y)$ e o sistema de coordenadas local $\left(L_{i}, L_{j}, L_{k}\right)$ é dado pelas equações

$$
\begin{aligned}
& x=L_{i} x_{i}+L_{j} x_{j}+L_{k} x_{k}, \\
& y=L_{i} y_{i}+L_{j} y_{j}+L_{k} y_{k},
\end{aligned}
$$

que podem ser resolvidas para obter $L_{i}$ em termos de $x$ e $y$ como

$$
\begin{aligned}
L_{i} & =\frac{1}{2 A}\left(a_{i}+b_{i} x+c_{i} y\right), \\
L_{j} & =\frac{1}{2 A}\left(a_{j}+b_{j} x+c_{j} y\right), \\
L_{k} & =\frac{1}{2 A}\left(a_{k}+b_{k} x+c_{k} y\right),
\end{aligned}
$$


onde as constantes $a, b$ e $c$ são dadas em termos das coordenadas nodais

$$
\begin{gathered}
a_{i}=x_{j} y_{k}-x_{k} y_{j} ; b_{i}=y_{j}-y_{k} ; c_{i}=x_{k}-x_{j} \\
a_{j}=x_{k} y_{i}-x_{i} y_{k} ; b_{j}=y_{k}-y_{i} ; c_{j}=x_{i}-x_{k} \\
a_{k}=x_{i} y_{j}-x_{j} y_{i} ; b_{k}=y_{i}-y_{j} ; c_{k}=x_{j}-x_{i}
\end{gathered}
$$

e a área $A$ é dada por

$$
A=\frac{1}{2}\left|\begin{array}{ccc}
1 & x_{i} & y_{i} \\
1 & x_{j} & y_{j} \\
1 & x_{k} & y_{k}
\end{array}\right| .
$$

Das Eqs. (3.23) as seguintes relações para as derivadas podem ser obtidas

$$
\begin{aligned}
& \frac{\partial L_{i}}{\partial x}=\frac{b_{i}}{2 A} ; \frac{\partial L_{i}}{\partial y}=\frac{c_{i}}{2 A} \\
& \frac{\partial L_{j}}{\partial x}=\frac{b_{j}}{2 A} ; \frac{\partial L_{j}}{\partial y}=\frac{c_{j}}{2 A} \\
& \frac{\partial L_{k}}{\partial x}=\frac{b_{k}}{2 A} ; \frac{\partial L_{k}}{\partial y}=\frac{c_{k}}{2 A} .
\end{aligned}
$$

Um resultado sobre integração em coordenadas de área, importante para a discretização por elementos triangulares, é dado por

$$
\int_{A} L_{i}^{m} L_{j}^{n} L_{k}^{p} d A=\frac{m ! n ! p !}{(m+n+p+2) !} 2 A,
$$

cuja prova pode ser encontrada em Davies (1980).

As funções de interpolação para o mini-elemento, podem ser escritas em função das coordenadas baricêntricas da seguinte forma:

$$
\begin{aligned}
\phi_{s} & =L_{s}-9 L_{i} L_{j} L_{k}, \quad s=i, j, k \\
\phi_{l} & =27 L_{i} L_{j} L_{k} .
\end{aligned}
$$

Para o mini-elemento, as funções de interpolação para a pressão são lineares $\left(L_{i}, L_{j}, L_{k}\right)$ e para a velocidade são as funções $\phi_{s}$ e $\phi_{l}$. Observe que $\phi_{l}$ corresponde ao nó no centróide do elemento, e vale um nesse ponto e zero na fronteira do elemento. Observe também que as funções $\phi$ não são lineares, mas sim lineares mais um termo cúbico.

\subsection{Discretização temporal}

O método semi-lagrangeano foi utilizado para discretizar a derivada material, $D \boldsymbol{u} / D t$, que aparece na Eq. (3.1). A ideia básica é acompanhar a trajetória de uma partícula de fluido ao longo de 
uma malha sobre o escoamento. A derivada material é discretizada através de um esquema implícito de primeira ordem no tempo para cada ponto $\boldsymbol{x}$ do domínio, ou seja:

$$
\frac{\partial \boldsymbol{u}}{\partial t}+((\boldsymbol{u}-\hat{\boldsymbol{u}}) \cdot \nabla) \boldsymbol{u}=\frac{D \boldsymbol{u}}{D t} \approx \frac{\boldsymbol{u}^{n+1}(\boldsymbol{x})-\boldsymbol{u}^{n}\left(X\left(\boldsymbol{x}, t_{n+1}, t_{n}\right)\right)}{\Delta t}
$$

onde $\boldsymbol{u}^{n+1}(\boldsymbol{x})$ corresponte à velocidade da partícula de fluido no ponto $\boldsymbol{x}$ do domínio no instante $t_{n+1}$, e $\boldsymbol{u}^{n}\left(X\left(\boldsymbol{x}, t_{n+1}, t_{n}\right)\right)$ corresponde à velocidade desta mesma partícula de fluido que, no instante $t_{n}$, ocupava a posição $X\left(\boldsymbol{x}, t_{n+1}, t_{n}\right)$, ou seja, $X\left(\boldsymbol{x}, t_{n+1}, t_{n}\right)$ define a posição ocupada, ao tempo $t_{n}$, pela partícula de fluido, que ao tempo $t_{n+1}$, ocupa a posição $\boldsymbol{x}$, e pode ser encontrada utilizando a velocidade no tempo $t_{n}$, da seguinte forma:

$$
X\left(\boldsymbol{x}, t_{n+1}, t_{n}\right)=\boldsymbol{x}-\left(\boldsymbol{u}^{n}(\boldsymbol{x})-\hat{\boldsymbol{u}}(\boldsymbol{x})\right) \Delta t,
$$

onde $\hat{\boldsymbol{u}}(\boldsymbol{x})=\hat{\boldsymbol{u}}$. Na formulação lagrangeana a velocidade do domínio de referência, $\hat{\boldsymbol{u}}(\boldsymbol{x})$, é igual a velocidade do domínio material $\boldsymbol{u}^{n}(\boldsymbol{x})$, ou seja, se $\hat{\boldsymbol{u}}(\boldsymbol{x})=\boldsymbol{u}^{n}(\boldsymbol{x})$, então $X\left(\boldsymbol{x}, t_{n+1}, t_{n}\right)=\boldsymbol{x}$ e portanto, a velocidade da partícula no ponto $X\left(\boldsymbol{x}, t_{n+1}, t_{n}\right)$ será $\boldsymbol{u}^{n}\left(X\left(\boldsymbol{x}, t_{n+1}, t_{n}\right)\right)=\boldsymbol{u}^{n}(\boldsymbol{x})$. No caso da formulação euleriana, onde $\hat{\boldsymbol{u}}(\boldsymbol{x})=\mathbf{0}$, o ponto $X\left(\boldsymbol{x}, t_{n+1}, t_{n}\right)$ estará na posição $\boldsymbol{x}-\boldsymbol{u}^{n}(\boldsymbol{x}) \Delta t$, o cálculo da velocidade $\boldsymbol{u}\left(X\left(\boldsymbol{x}, t_{n+1}, t_{n}\right)\right)$ é feito por uma interpolação linear entre os pontos vizinhos. A interpolação depende da localização do ponto $X\left(\boldsymbol{x}, t_{n+1}, t_{n}\right)$ dentro do domínio, pois este ponto poderá estar localizado sobre uma aresta, sobre um vértice, no interior de um elemento ou fora do domínio. Quando a velocidade do domínio de referência for diferente de zero e também diferente da velocidade do domínio material, o cálculo da velocidade no ponto $X\left(\boldsymbol{x}, t_{n+1}, t_{n}\right)$ poderá ser feito através da Eq. (3.31). Substituindo a derivada material $D \boldsymbol{u} / D t$ na Eq. (3.13) pela aproximação dada na Eq. (3.30), obtém-se

$$
\begin{array}{r}
\int_{\Omega} \boldsymbol{w} \cdot\left[\frac{\boldsymbol{u}^{n+1}(\boldsymbol{x})-\boldsymbol{u}^{n}\left(X\left(\boldsymbol{x}, t_{n+1}, t_{n}\right)\right)}{\Delta t}\right] d \Omega-\int_{\Omega} p^{n+1}(\boldsymbol{x}) \nabla \cdot \boldsymbol{w} d \Omega \\
+\frac{1}{G a^{1 / 2}} \int_{\Omega} \nabla \boldsymbol{w}:\left[\nabla \boldsymbol{u}^{n+1}(\boldsymbol{x})+\left(\nabla \boldsymbol{u}^{n+1}(\boldsymbol{x})\right)^{T}\right] d \Omega+ \\
\quad-\int_{\Omega} \boldsymbol{w} \cdot \boldsymbol{g} d \Omega-\int_{\Gamma} \frac{\gamma \kappa}{E_{O}} \boldsymbol{w} \cdot \boldsymbol{n} d \Gamma=0 .
\end{array}
$$

Para simplificar a notação considere, $\overline{\boldsymbol{u}}^{n}=\boldsymbol{u}^{n}\left(X\left(\boldsymbol{x}, t_{n+1}, t_{n}\right)\right), \boldsymbol{u}^{n+1}=\boldsymbol{u}^{n+1}(\boldsymbol{x})$ e $p^{n+1}=$ $p^{n+1}(\boldsymbol{x})$. Após a discretização temporal a formulação variacional dada pelas Eqs. (3.8) e (3.13) pode ser escrita como: 


$$
\begin{aligned}
\int_{\Omega} \boldsymbol{w} \cdot\left(\frac{\boldsymbol{u}^{n+1}-\overline{\boldsymbol{u}}^{n}}{\Delta t}\right) d \Omega- & \int_{\Omega} p^{n+1} \nabla \cdot \boldsymbol{w} d \Omega \\
+\frac{1}{G a^{1 / 2}} \int_{\Omega} \nabla \boldsymbol{w}:\left[\nabla \boldsymbol{u}^{n+1}+\left(\nabla \boldsymbol{u}^{n+1}\right)^{T}\right] & d \Omega-\int_{\Omega} \boldsymbol{w} \cdot \boldsymbol{g} d \Omega \\
- & +\int_{\Gamma} \frac{\gamma \kappa}{E o} \boldsymbol{w} \cdot \boldsymbol{n} d \Gamma=0, \\
\int_{\Omega} q\left(\nabla \cdot \boldsymbol{u}^{n+1}\right) d \Omega & =0 .
\end{aligned}
$$

\subsection{Método de Galerkin}

Sejam as equações de Navier-Stokes Eqs. (3.1)-(3.2), e sua discretização temporal dada pelas Eqs. (3.33)-(3.34), o método de Galerkin será utilizado para discretizá-las no espaço. Seja $\Omega_{h}=$ $T(\Omega)$ o domínio $\Omega$ discretizado por elementos finitos, limitado por $\partial \Omega_{h}$ que é linear por partes. Escolhendo-se espaços de dimensão finita adequados $V_{h} \subset V$ e $Q_{h} \subset Q$, que são gerados pelas funções de interpolação do mini-elemento (3.28) e (3.29), a formulação variacional discreta das equações de Navier-Stokes (3.1)-(3.2) é dada por: "Encontrar $\boldsymbol{u}_{h}^{n+1} \in V_{h}$ e $p_{h}^{n+1} \in Q_{h}$ de forma que:

$$
\begin{aligned}
\int_{\Omega_{h}} \boldsymbol{w}_{h} \cdot\left(\frac{\boldsymbol{u}_{h}^{n+1}-\overline{\boldsymbol{u}}_{h}^{n}}{\Delta t}\right) d \Omega-\int_{\Omega_{h}} p_{h}^{n+1} \nabla \cdot \boldsymbol{w}_{h} d \Omega & \\
+\frac{1}{G a^{1 / 2}} \int_{\Omega_{h}} \nabla \boldsymbol{w}_{h}:\left[\nabla \boldsymbol{u}_{h}^{n+1}+\nabla\left(\boldsymbol{u}_{h}^{n+1}\right)^{T}\right] d \Omega-\int_{\Omega_{h}} \boldsymbol{w}_{h} \cdot \boldsymbol{g}_{h} d \Omega & + \\
-\frac{1}{E O} \int_{\Gamma_{h}} \gamma \kappa \boldsymbol{w}_{h} \cdot \boldsymbol{n}_{h} d \Gamma & =0 \\
\int_{\Omega_{h}} q_{h} \nabla \cdot \boldsymbol{u}_{h}^{n+1} d \Omega & =0
\end{aligned}
$$

para todo $\boldsymbol{w}_{h} \in V_{h}$ e $q_{h} \in Q_{h}$ ". Sendo $\boldsymbol{u}_{h}^{n+1}=\left(u_{h}^{n+1}, v_{h}^{n+1}\right)$ o vetor velocidade discreto e $\boldsymbol{n}_{h}=$ $\left(n_{x, h}, n_{y, h}\right)$ o vetor normal à superfície discreta linear por partes $\partial \Omega_{h}$. A partir de agora, para simplificar a notação considere $\boldsymbol{u}_{h}$ e $p_{h}$ no instante $t_{n+1}$ e $\overline{\boldsymbol{u}}_{h}$ no instante $t_{n}$.

Considere as Eqs. (3.35)-(3.36) desenvolvidas em um sistema cartesiano bidimensional. Sejam

$$
\boldsymbol{u}_{h}=\left(u_{h}, v_{h}\right), \quad \overline{\boldsymbol{u}}_{h}=\left(\bar{u}_{h}, \bar{v}_{h}\right), \quad \boldsymbol{g}_{h}=\left(g_{x, h}, g_{y, h}\right), \quad \boldsymbol{w}_{h}=\left(w_{x, h}, w_{y, h}\right), \quad \boldsymbol{n}_{h}=\left(n_{x, h}, n_{y, h}\right) .
$$


A equação (3.35) torna-se

$$
\begin{aligned}
& \int_{\Omega_{h}}\left[w_{x, h}\left(\frac{u_{h}-\bar{u}_{h}}{\Delta t}\right)+w_{y, h}\left(\frac{v_{h}-\bar{v}_{h}}{\Delta t}\right)\right] d \Omega-\int_{\Omega_{h}}\left(p_{h} \frac{\partial w_{x, h}}{\partial x}+p_{h} \frac{\partial w_{y, h}}{\partial y}\right) d \Omega \\
&+\frac{1}{G a^{1 / 2}} \int_{\Omega_{h}}\left[\left(\frac{\partial w_{x, h}}{\partial x} \frac{\partial u_{h}}{\partial x}+\frac{\partial w_{y, h}}{\partial x} \frac{\partial v_{h}}{\partial x}+\frac{\partial w_{x, h}}{\partial y} \frac{\partial u_{h}}{\partial y}+\frac{\partial w_{y, h}}{\partial y} \frac{\partial v_{h}}{\partial y}\right)\right] d \Omega \\
&+ \frac{1}{G a^{1 / 2}} \int_{\Omega_{h}}\left[\left(\frac{\partial w_{x, h}}{\partial x} \frac{\partial u_{h}}{\partial x}+\frac{\partial w_{y, h}}{\partial x} \frac{\partial u_{h}}{\partial y}+\frac{\partial w_{x, h}}{\partial y} \frac{\partial v_{h}}{\partial x}+\frac{\partial w_{y, h}}{\partial y} \frac{\partial v_{h}}{\partial y}\right)\right] d \Omega+ \\
&-\int_{\Omega_{h}}\left(w_{x, h} g_{x, h}+w_{y, h} g_{y, h}\right) d \Omega-\frac{1}{E o} \int_{\Gamma_{h}} \gamma \kappa\left(w_{x, h} n_{x, h}+w_{y, h} n_{y, h}\right) d \Gamma=0 .
\end{aligned}
$$

Pela formulação variacional do problema é necessário determinar soluções $\boldsymbol{u}_{h}=\left(u_{h}, v_{h}\right) \in V_{h}$ e $p_{h} \in Q_{h}$ de modo que a Eq. (3.38) seja verdadeira para todo $\boldsymbol{w}_{h}=\left(w_{x, h}, w_{y, h}\right) \in V_{h}$. No entanto sendo satisfeitas as expressões na direção $x$

$$
\begin{aligned}
\int_{\Omega_{h}} w_{x, h}\left(\frac{u_{h}-\bar{u}_{h}}{\Delta t}\right) d \Omega-\int_{\Omega_{h}} p_{h} \frac{\partial w_{x, h}}{\partial x} d \Omega & \\
+\frac{1}{G a^{1 / 2}} \int_{\Omega_{h}}\left(\frac{\partial w_{x, h}}{\partial x} \frac{\partial u_{h}}{\partial x}+\right. & \left.\frac{\partial w_{x, h}}{\partial y} \frac{\partial u_{h}}{\partial y}+\frac{\partial w_{x, h}}{\partial x} \frac{\partial u_{h}}{\partial x}+\frac{\partial w_{x, h}}{\partial y} \frac{\partial v_{h}}{\partial x}\right) d \Omega+ \\
& \quad-\int_{\Omega_{h}} w_{x, h} g_{x, h} d \Omega-\frac{1}{E_{o}} \int_{\Gamma_{h}} \gamma \kappa w_{x, h} n_{x, h} d \Gamma=0
\end{aligned}
$$

e na direção $y$,

$$
\begin{aligned}
\int_{\Omega_{h}} w_{y, h} & \left(\frac{v_{h}-\bar{v}_{h}}{\Delta t}\right) d \Omega-\int_{\Omega_{h}} p_{h} \frac{\partial w_{y, h}}{\partial y} d \Omega \\
+\frac{1}{G a^{1 / 2}} \int_{\Omega_{h}}\left(\frac{\partial w_{y, h}}{\partial x} \frac{\partial v_{h}}{\partial x}+\right. & \left.\frac{\partial w_{y, h}}{\partial y} \frac{\partial v_{h}}{\partial y}+\frac{\partial w_{y, h}}{\partial x} \frac{\partial u_{h}}{\partial y}+\frac{\partial w_{y, h}}{\partial y} \frac{\partial v_{h}}{\partial y}\right) d \Omega+ \\
& \quad-\int_{\Omega_{h}} w_{y, h} g_{y, h} d \Omega-\frac{1}{E_{o}} \int_{\Gamma_{h}} \gamma \kappa w_{y, h} n_{y, h} d \Gamma=0
\end{aligned}
$$

para quaisquer $w_{x, h} \in V_{h}$ e $w_{y, h} \in V_{h}$ então a Eq. (3.38) é satisfeita. Assim pode-se trabalhar com as equações nas direções $x$ e $y$ separadamente sem perda de generalidade. Como neste trabalho as equações são resolvidas de maneira acoplada, não há a necessidade da separação das equações nas direções $x$ e $y$. Contudo, os cálculos daqui em diante serão feitos dessa maneira, para aproveitar a analogia de notação nas direções $x$ e $y$, e facilitar a definição do operador de montagem de matriz feita adiante.

Para a equação da continuidade em (3.15), tem-se

$$
\int_{\Omega_{h}} q_{h}\left(\frac{\partial u_{h}}{\partial x}+\frac{\partial v_{h}}{\partial y}\right) d \Omega=0
$$

Considere $N_{V}, N_{P}$ e $N_{E}$ os números de incógnitas respectivamente para a velocidade (o mesmo número de pontos nas direções $x$ e $y$, sendo as condições de contorno de Dirichlet e tensão superficial impostas posteriormente), $N_{P}$ o número de pontos de pressão e $N_{E}$ o número de elementos na malha de elementos finitos que discretiza o domínio $\Omega_{h}$. 
Sejam $\left\{\phi_{1}, \cdots, \phi_{N_{V}}\right\}$ base de $H_{h}^{1}(\Omega) \subset H^{1}(\Omega)$ e $\left\{\psi_{1}, \cdots, \psi_{N_{P}}\right\}$ base de $Q_{h}$, o método de Galerkin consiste em fazer as seguintes substituições nas Eqs. (3.39)-(3.40):

$$
\begin{aligned}
u_{h}(\boldsymbol{x}, t) & \approx \sum_{s=1}^{N_{V}} \phi_{s}(\boldsymbol{x}) u_{s}(t), \\
v_{h}(\boldsymbol{x}, t) & \approx \sum_{s=1}^{N_{V}} \phi_{s}(\boldsymbol{x}) v_{s}(t), \\
p_{h}(\boldsymbol{x}, t) & \approx \sum_{r=1}^{N_{P}} \psi_{r}(\boldsymbol{x}) p_{r}(t),
\end{aligned}
$$

onde $\phi_{s}(\boldsymbol{x})$ representam funções de interpolação utilizadas para a velocidade e $\psi_{r}(\boldsymbol{x})$ as funções de interpolação para a pressão. Considere também

$$
\begin{aligned}
g_{x, h}(\boldsymbol{x}, t) & \approx \sum_{s=1}^{N_{V}} \phi_{s}(\boldsymbol{x}) g_{x, s}(t), \\
g_{y, h}(\boldsymbol{x}, t) & \approx \sum_{s=1}^{N_{V}} \phi_{s}(\boldsymbol{x}) g_{y, s}(t),
\end{aligned}
$$

como sendo aproximações para os termos de gravidade.

A Eq. (3.38) é normalmente avaliada em todos os nós livres de velocidade e portanto as funções teste $w_{x, h}$ e $w_{y, h}$ são substituídas por funções de interpolação $\phi_{s}=\phi_{s}(x), s=1, \cdots, N_{V}$. Aplicando este procedimento para as direções $x$ e $y$ e restringindo-se as funções de interpolação nodais a cada elemento " $e$ ", na direção $x$ tem-se

$$
\begin{aligned}
\sum_{e} \int_{\Omega_{e}} \sum_{i, j \in e}\left[\frac{u_{j}-\bar{u}_{j}}{\Delta t}\right] \phi_{i}^{e} \phi_{j}^{e} d \Omega-\sum_{e} \int_{\Omega_{e}} \sum_{i, k \in e} \frac{\partial \phi_{i}^{e}}{\partial x} \psi_{k}^{e} p_{k} d \Omega \\
+\frac{1}{G a^{1 / 2}} \sum_{e} \int_{\Omega_{e}} \sum_{i, j \in e}\left(\frac{\partial \phi_{i}^{e}}{\partial x} \frac{\partial \phi_{j}^{e}}{\partial x} u_{j}+\frac{\partial \phi_{i}^{e}}{\partial y} \frac{\partial \phi_{j}^{e}}{\partial y} u_{j}+\frac{\partial \phi_{i}^{e}}{\partial x} \frac{\partial \phi_{j}^{e}}{\partial x} u_{j}+\frac{\partial \phi_{i}^{e}}{\partial y} \frac{\partial \phi_{j}^{e}}{\partial x} v_{j}\right) d \Omega+ \\
\quad-\sum_{e} \int_{\Omega_{e}} \sum_{i, j \in e} \phi_{i}^{e} \phi_{j}^{e} g_{x, j} d \Omega-\frac{1}{E o} \sum_{e} \int_{\Gamma^{e}} \gamma \kappa n_{x} \sum_{i \in e} \phi_{i}^{e} d \Gamma=0
\end{aligned}
$$

na direção $y$

$$
\begin{aligned}
\sum_{e} \int_{\Omega_{e}} \sum_{i, j \in e}\left[\frac{v_{j}-\bar{v}_{j}}{\Delta t}\right] \phi_{i}^{e} \phi_{j}^{e} d \Omega-\sum_{e} \int_{\Omega_{e}} \sum_{i, k \in e} \frac{\partial \phi_{i}^{e}}{\partial y} \psi_{k}^{e} p_{k} d \Omega \\
+\frac{1}{G a^{1 / 2}} \sum_{e} \int_{\Omega_{e}} \sum_{i, j \in e}\left(\frac{\partial \phi_{i}^{e}}{\partial x} \frac{\partial \phi_{j}^{e}}{\partial x} v_{j}+\frac{\partial \phi_{i}^{e}}{\partial y} \frac{\partial \phi_{j}^{e}}{\partial y} v_{j}+\frac{\partial \phi_{i}^{e}}{\partial x} \frac{\partial \phi_{j}^{e}}{\partial y} u_{j}+\frac{\partial \phi_{i}^{e}}{\partial y} \frac{\partial \phi_{j}^{e}}{\partial y} v_{j}\right) d \Omega+ \\
\quad-\sum_{e} \int_{\Omega_{e}} \sum_{i, j \in e} \phi_{i}^{e} \phi_{j}^{e} g_{y, j} d \Omega-\frac{1}{E o} \sum_{e} \int_{\Gamma^{e}} \gamma \kappa n_{y} \sum_{i \in e} \phi_{i}^{e} d \Gamma=0 .
\end{aligned}
$$

A Eq. (3.41) é avaliada nos nós livres de pressão e portanto a função peso $q_{h}$ é aproximada pelas funções de interpolação associadas à pressão $\psi_{r}(\boldsymbol{x})$, restringindo-se as funções de interpolação a 
cada elemento " $e$ ", tem-se

$$
\sum_{e} \int_{\Omega_{e}} \sum_{j, k \in e}\left(\frac{\partial \phi_{j}^{e}}{\partial x} u_{j}+\frac{\partial \phi_{j}^{e}}{\partial y} v_{j}\right) \psi_{k}^{e} d \Omega=0
$$

As Eqs. (3.47), (3.48) e (3.49) podem ser representadas na forma de um sistema de equações algébricas.

$$
\begin{aligned}
\mathcal{M}_{x} \frac{\mathbf{U}-\overline{\mathbf{U}}}{\Delta t}-\mathcal{G}_{x} \mathbf{p}+\frac{1}{G a^{1 / 2}}\left[\left(2 \mathcal{K}_{x x}+\mathcal{K}_{y y}\right) \mathbf{U}+\mathcal{K}_{x y} \mathbf{V}\right]-\mathcal{M}_{x} \mathbf{G}_{x}= & \boldsymbol{f}_{x} \\
\mathcal{M}_{y} \frac{\mathbf{V}-\overline{\mathbf{V}}}{\Delta t}-\mathcal{G}_{y} \mathbf{p}+\frac{1}{G a^{1 / 2}}\left[\mathcal{K}_{y x} \mathbf{U}+\left(2 \mathcal{K}_{y y}+\mathcal{K}_{x x}\right) \mathbf{V}\right]-\mathcal{M}_{y} \mathbf{G}_{y}= & \boldsymbol{f}_{y} \\
\mathcal{D}_{x} \mathbf{U}+\mathcal{D}_{y} \mathbf{V}= & 0
\end{aligned}
$$

onde $\mathbf{U}=\left[u_{1}, \cdots, u_{N_{V}}\right]^{T}, \mathbf{V}=\left[v_{1}, \cdots, v_{N_{V}}\right]^{T}, \overline{\mathbf{U}}=\left[\bar{u}_{1}, \cdots, \bar{u}_{N_{V}}\right]^{T}, \overline{\mathbf{V}}=\left[\bar{v}_{1}, \cdots, \bar{v}_{N_{V}}\right]^{T}$, $\mathbf{p}=\left[p_{1}, \cdots, p_{N_{P}}\right]^{T}, \mathbf{G}_{x}=\left[g_{1}^{x}, \cdots, g_{N_{V}}^{x}\right]^{T}, \mathbf{G}_{y}=\left[g_{1}^{y}, \cdots, g_{N_{V}}^{y}\right]^{T}, \boldsymbol{f}_{x}=\left[f_{1}^{x}, \cdots, f_{N_{V}}^{x}\right]^{T}$ e $\boldsymbol{f}_{y}=$ $\left[f_{1}^{y}, \cdots, f_{N_{V}}^{y}\right]^{T}$ são os vetores dos valores nodais para as variáveis de velocidade, pressão, gravidade e tensão superficial. As matrizes desse sistema são dadas por

$$
\begin{array}{lllll}
\mathcal{M}_{x}=\mathcal{A}_{x}\left(\mathbf{m}^{e}\right), & \mathcal{M}_{y}=\mathcal{A}_{y}\left(\mathbf{m}^{e}\right), & \mathcal{K}_{x x}=\mathcal{A}_{x}\left(\mathbf{k}_{x x}^{e}\right), & \mathcal{K}_{x y}=\mathcal{A}_{x}\left(\mathbf{k}_{x y}^{e}\right), & \mathcal{K}_{y x}=\mathcal{A}_{y}\left(\mathbf{k}_{y x}^{e}\right), \\
\mathcal{K}_{y y}=\mathcal{A}_{y}\left(\mathbf{k}_{y y}^{e}\right), & \mathcal{G}_{x}=\mathcal{A}_{x}\left(\mathbf{g}_{x}^{e}\right), & \mathcal{G}_{y}=\mathcal{A}_{y}\left(\mathbf{g}_{y}^{e}\right), & \mathcal{D}_{x}=\mathcal{A}_{x}\left(\mathbf{d}_{x}^{e}\right), & \mathcal{D}_{y}=\mathcal{A}_{y}\left(\mathbf{d}_{y}^{e}\right) .
\end{array}
$$

O operador $\mathcal{A}$ monta as submatrizes de elemento nas matrizes do sistema de equações, respeitando a correspondência entre índices globais e locais. As matrizes definidas no elemento são dadas por

$$
\begin{array}{cccc}
\mathbf{k}_{x x, i j}^{e} & =\int\left(\frac{\partial \phi_{i}^{e}}{\partial x} \frac{\partial \phi_{j}^{e}}{\partial x}+\frac{\partial \phi_{i}^{e}}{\partial x} \frac{\partial \phi_{j}^{e}}{\partial x}\right) d \Omega, & \mathbf{k}_{x y, i j}^{e}=\int\left(\frac{\partial \phi_{i}^{e}}{\partial x} \frac{\partial \phi_{j}^{e}}{\partial x}+\frac{\partial \phi_{i}^{e}}{\partial y} \frac{\partial \phi_{j}^{e}}{\partial x}\right) d \Omega, & \mathbf{m}_{i j}^{e}=\int \phi_{i}^{e} \phi_{j}^{e} d \Omega, \\
\mathbf{k}_{y x, i j}^{e}=\int\left(\frac{\partial \phi_{i}^{e}}{\partial y} \frac{\partial \phi_{j}^{e}}{\partial y}+\frac{\partial \phi_{i}^{e}}{\partial x} \frac{\partial \phi_{j}^{e}}{\partial y}\right) d \Omega, & \mathbf{k}_{y y, i j}^{e}=\int\left(\frac{\partial \phi_{i}^{e}}{\partial y} \frac{\partial \phi_{j}^{e}}{\partial y}+\frac{\partial \phi_{i}^{e}}{\partial y} \frac{\partial \phi_{j}^{e}}{\partial y}\right) d \Omega, & \mathbf{g}_{x, i k}^{e}=\int \frac{\partial \phi_{i}^{e}}{\partial x} \psi_{k}^{e} d \Omega, \\
\mathbf{g}_{y, i k}^{e}=\int \frac{\partial \phi_{i}^{e}}{\partial y} \psi_{k}^{e} d \Omega, & \mathbf{d}_{x, k j}^{e}=\int \frac{\partial \phi_{j}^{e}}{\partial x} \psi_{k}^{e} d \Omega, & \mathbf{d}_{y, k j}^{e}=\int \frac{\partial \phi_{j}^{e}}{\partial y} \psi_{k}^{e} d \Omega,
\end{array}
$$

$\operatorname{com} i=1, \cdots, 4, j=1, \cdots, 4, k=1, \cdots, 3$ e as integrais calculadas em um elemento finito $\Omega^{e}$.

As dimensões das matrizes que aparecem no sistema (3.50) são $N_{V} \times N_{P}$ para $\mathcal{G}_{x}$ e $\mathcal{G}_{y}, N_{P} \times N_{V}$ para $\mathcal{D}_{x}$ e $\mathcal{D}_{y}$ e $N_{V} \times N_{V}$ para as outras. A partir do sistema (3.50) é possível escrever o sistema de equações de forma mais compacta, acoplando as velocidades nas direções $x$ e $y$, e retornando à notação no tempo, resulta em

$$
\begin{aligned}
\mathbb{M} \frac{\mathbf{u}^{n+1}-\overline{\mathbf{u}}^{n}}{\Delta t}-\mathbb{G} \mathbf{p}^{n+1}+\frac{1}{G a^{1 / 2}} \mathbb{K} \mathbf{u}^{n+1}-\mathbb{M g} & =\boldsymbol{f} \\
\mathbb{D} \mathbf{u}^{n+1} & =0
\end{aligned}
$$


onde $\mathbf{u}^{n+1}=\left[u_{1}^{n+1}, \cdots, u_{N_{V}}^{n+1}, v_{1}^{n+1}, \cdots, v_{N_{V}}^{n+1}\right]^{T}, \overline{\mathbf{u}}^{n+1}=\left[\bar{u}_{1}^{n+1}, \cdots, \bar{u}_{N_{V}}^{n+1}, \bar{v}_{1}^{n+1}, \cdots, \bar{v}_{N_{V}}^{n+1}\right]^{T}, \mathbf{g}=$ $\left[g_{1}^{x}, \cdots, g_{N_{V}}^{x}, g_{1}^{y}, \cdots, g_{N_{V}}^{y}\right]^{T}, \mathbf{p}^{n+1}=\left[p_{1}^{n+1}, \cdots, p_{N_{P}}^{n+1}\right]^{T}$ e $\boldsymbol{f}=\left[f_{1}^{x}, \cdots, f_{N_{V}}^{x}, f_{1}^{y}, \cdots, f_{N_{V}}^{y}\right]^{T}$, e as matrizes dadas por

$$
\begin{array}{cc}
\mathbb{M}=\left[\begin{array}{cc}
\mathcal{M}_{x} & \mathbf{0} \\
\mathbf{0} & \mathcal{M}_{y}
\end{array}\right]_{2 N_{V} \times 2 N_{V}} & \mathbb{K}=\left[\begin{array}{ll}
\mathcal{K}_{x x} & \mathcal{K}_{x y} \\
\mathcal{K}_{y x} & \mathcal{K}_{y y}
\end{array}\right]_{2 N_{V} \times 2 N_{V}} \\
\mathbb{G}=\left[\begin{array}{l}
\mathcal{G}_{x} \\
\mathcal{G}_{y}
\end{array}\right]_{2 N_{V} \times N_{P}} & \mathbb{D}=\left[\begin{array}{ll}
\mathcal{D}_{x} & \mathcal{D}_{y}
\end{array}\right]_{N_{P} \times 2 N_{V}}
\end{array}
$$

\subsection{Resolução do sistema}

Os métodos para solução das equações de Navier-Stokes para escoamentos de fluidos podem ser, de maneira geral classificados em métodos segregados e métodos acoplados. Os métodos segregados buscam o desacoplamento entre pressão-velocidade, separando o sistema linear multidimensional em problemas mais simples. Já os métodos acoplados buscam resolver o sistema completo de equações (pressão-velocidade) a cada ciclo computacional e será descrito nesta seção.

\subsubsection{Método acoplado}

Sejam as equações de Navier-Stokes (3.51)-(3.52), discretizadas no espaço pelo método de elementos finitos e discretizadas no tempo por um esquema semi-lagrangeano, tais equações são dadas por

$$
\begin{aligned}
\mathbb{M}\left(\frac{\mathbf{u}^{n+1}-\overline{\mathbf{u}}^{n}}{\Delta t}\right)-\mathbb{G}^{n+1}+\frac{1}{G a^{1 / 2}} \mathbb{K} \mathbf{u}^{n+1}-\mathbb{M g} & =\boldsymbol{f}, \\
\mathbb{D} \mathbf{u}^{n+1} & =0
\end{aligned}
$$

reescrevendo a Eq. (3.53) da seguinte forma

$$
\left(\frac{\mathbb{M}}{\Delta t}+\frac{1}{G a^{1 / 2}} \mathbb{K}\right) \mathbf{u}^{n+1}-\mathbb{G} \mathbf{p}^{n+1}=\underbrace{\mathbb{M g}+\frac{1}{\Delta t} \mathbb{M} \overline{\mathbf{u}}^{n}+\boldsymbol{f}}_{\boldsymbol{r}^{n}}
$$

que juntamente com a Eq. (3.54) formam um sistema de equações que pode ser escrito na forma matricial

$$
\left[\begin{array}{ll}
\mathbb{B} & \mathbb{G} \\
\mathbb{D} & \mathbf{0}
\end{array}\right]\left[\begin{array}{l}
\mathbf{u}^{n+1} \\
\mathbf{p}^{n+1}
\end{array}\right]=\left[\begin{array}{c}
\boldsymbol{r}^{n} \\
0
\end{array}\right]
$$


A matriz $\mathbb{B}$ é dada por $\mathbb{B}=(\Delta t)^{-1} \mathbb{M}+G a^{-1 / 2} \mathbb{K}$, e o lado direito representa as grandezas conhecidas no tempo $n$, mais as condições de contorno que são as contribuições dos valores conhecidos de velocidade.

$\mathrm{O}$ sistema pode ser resolvido diretamente para se obter as soluções $\mathbf{u}^{n+1}$ e $\mathbf{p}^{n+1}$ de forma acoplada. Apesar de a matriz ser simétrica, pois $\mathbb{G}=\mathbb{D}^{T}$, e $\mathbb{B}$ é simétrica, ela não é definida positiva. E o sistema linear é resolvido através do método direto LU. 


\section{Cálculo da tensão superficial e ângulo de}

\section{contato}

Este capítulo trata do cálculo da tensão superficial e da estratégia de imposição direta de ângulo de contato e imposição do ângulo de contato através da condição de Navier Generalizada.

\subsection{Cálculo da tensão superficial}

Para calcular o efeito da tensão superficial, é necessário apenas calcular a curvatura $\kappa$, pois como pode ser visto na Eq. (2.19) o coeficiente $\gamma$ e o parâmetro adimensional Eo são conhecidos. A geometria diferencial dá ao conceito de curvatura $2 D$, pelo menos três interpretações distintas: $(i)$ a taxa de variação angular do campo tangente à forma. (ii) a magnitude da aceleração centrípeta de uma partícula que percorre a forma com velocidade constante e (iii) o inverso dos raios dos círculos que melhor se ajustam localmente à forma (Kreyszig, 1991).

O raio de curvatura da interface necessita ser estimado afim de avaliar os efeitos da tensão superficial na Eq. (2.19). Como a interface é explicitamente representada por vértices e arestas da malha (veja Fig. 4.1(a)), o raio de curvatura pode ser obtido de maneira bastante natural construindo um único círculo que passe por três vértices adjacentes (Fig. 4.1(b)), com isso consegue-se encontrar o raio, $R$, e consequentemente a curvatura $\kappa$, sendo

$$
\kappa=\frac{1}{R}
$$




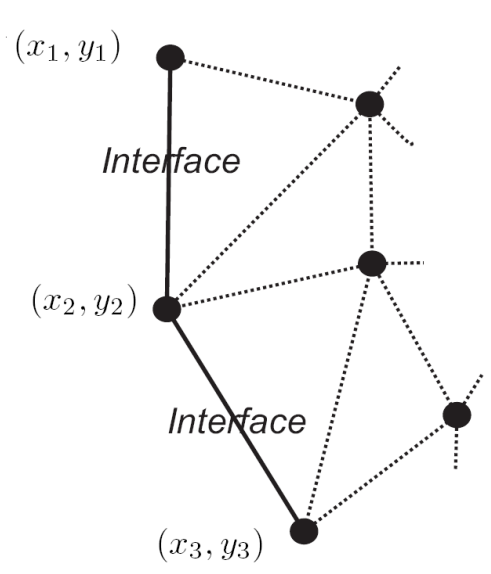

(a)

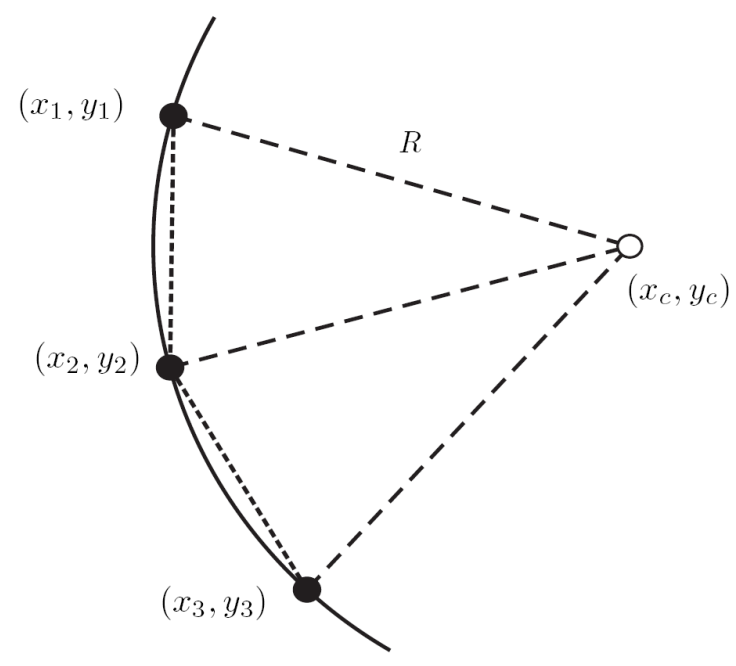

(b)

Figura 4.1: Em (a) está ilustrada a representação explicita da interface por vértices e arestas da malha. Em (b) o único círculo que passa por $\left(x_{1}, y_{1}\right),\left(x_{2}, y_{2}\right)$ e $\left(x_{3}, y_{3}\right)$, sendo $\left(x_{c}, y_{c}\right)$ as coordenadas do centro do círculo e $R$ o raio.

A normal à interface líquido/gás no ponto $\boldsymbol{p}_{2}=\left(x_{2}, y_{2}\right)$ é então calculada por,

$$
\boldsymbol{n}_{h}=\frac{\boldsymbol{p}_{2}-\boldsymbol{p}_{c}}{\left\|\boldsymbol{p}_{2}-\boldsymbol{p}_{c}\right\|}
$$

onde $\boldsymbol{p}_{c}=\left(x_{c}, y_{c}\right)$. A curvatura calculada e a normal $\boldsymbol{n}_{h}$ são então utilizadas para aplicar as condições de contorno na superfície livre.

\subsection{Imposição direta do ângulo de contato através da condição de Navier (NBC)}

A estratégia de imposição do ângulo de contato consiste em aproximar uma curvatura no ponto de contato, considerando-se uma extensão virtual da superfície livre $\Gamma$, que possua a inclinação correta $\theta_{S}$. Desta forma, a tensão superficial no ângulo de contato tenderá a alinhar a superfície livre com a superfície virtual, impondo o ângulo desejado.

Para o cálculo desta curvatura, calcula-se geometricamente um círculo que passe pelo ponto de contato e pelo vértice de superfície livre adjacente, e cuja tangente ao círculo no ponto de contato possua a inclinação $\theta_{S}$ desejada. Uma vez calculado o círculo, a Eq. (4.1) é utilizada para calcular a curvatura. Um esquema do cálculo geométrico pode ser visto na Fig. 4.2.

Quando o ponto $\left(x_{1}, y_{1}\right)$ está alinhado com a tangente, o raio de curvatura tende a ser muito 


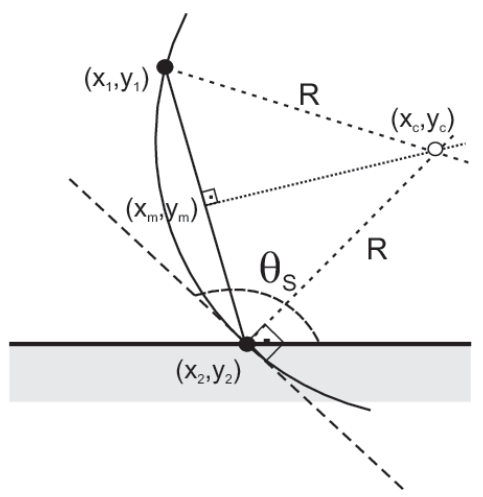

Figura 4.2: Cálculo da curvatura em um ponto de contato utilizando-se um vértice de superfície livre e a inclinação $\theta_{S}$ da superfície virtual. Neste exemplo, a tensão superficial deslocará o ponto de contato para a direita, para alinhar o segmento da superfície livre com o segmento virtual.

grande, neste caso a curvatura é considerada nula, ou seja, $\kappa=0$.

\subsubsection{Formulação contínua do problema}

As equações de Navier-Stokes (2.17)-(2.18) são válidas em um domínio $\Omega \in \mathbb{R}^{2}$, limitado por um contorno $\partial \Omega=\Gamma \cup \mathcal{S}$ e $\partial \Gamma=\Gamma \cap \mathcal{S}$ (veja Fig. 4.3), onde $\Gamma$ representa a superfície livre (interface líquido/gás), $\mathcal{S}$ contorno rígido (interface sólido/líquido) e $\partial \Gamma$ os pontos de contato (interface tripla sólido/líquido/gás).

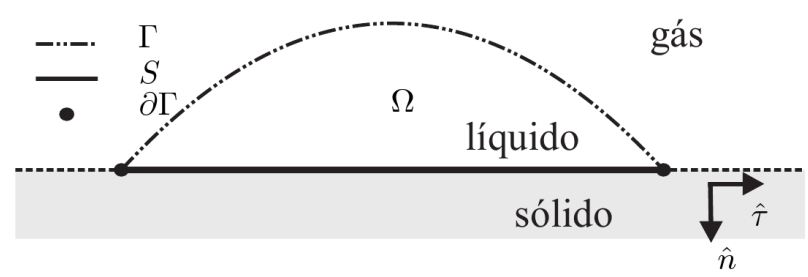

Figura 4.3: Domínio $\Omega$ de uma gota apoiada, limitado pelo contorno $\partial \Omega=\Gamma \cup \mathcal{S}$.

$\mathrm{Na}$ interface gás/líquido envolvendo um gás de massa específica e viscosidade desprezível, e também no ponto de contato, a tensão na superfície livre, satisfaz as Eqs. (2.19)-(2.20). No contorno rígido $\mathcal{S}$, na interface sólido/líquido, é imposta uma condição de contorno conhecida como condição de Navier (NBC), dada por:

$$
\begin{array}{r}
\left(\boldsymbol{u}-\boldsymbol{u}_{w}\right) \cdot \hat{n}=0, \\
\left(\boldsymbol{u}-\boldsymbol{u}_{w}\right) \cdot \hat{\tau}+\beta \boldsymbol{\sigma} \hat{n} \cdot \hat{\tau}=0,
\end{array}
$$


onde $\beta$ é o coeficiente de escorregamento, $\hat{n}$ e $\hat{\tau}$ correspondem respectivamente ao vetor normal e tangencial à superfície sólida, $\boldsymbol{u}$ é o campo de velocidades, $\boldsymbol{u}_{w}$ é a velocidade da parede.

A condição na Eq. (4.3) é a condição de não penetração do fluido, ou seja, o fluido não pode penetrar em uma superfície sólida impermeável, sendo assim a componente normal da velocidade é zero. A condição na Eq. (4.4) é a condição de contorno de fricção, ou seja, na interface sólido líquido, as velocidades tangenciais do fluido são proporcionais a tensão tangencial correspondente. Dependendo da escolha de $\beta$, diferentes condições de contorno são obtidas.

1. não escorregamento (no-slip), se $\beta=0$,

2. escorregamento com atrito, se $0<\beta<\infty$,

3. escorregamento livre (free slip), se $\beta=\infty$.

Para uma interpretação do comprimento de escorregamento, veja a Fig. 4.2.1. Por exemplo, no caso de escoamentos de cisalhamento, escorregamento parcial, $\beta$ pode ser interpretado como a distância fictícia a superfície sólida.

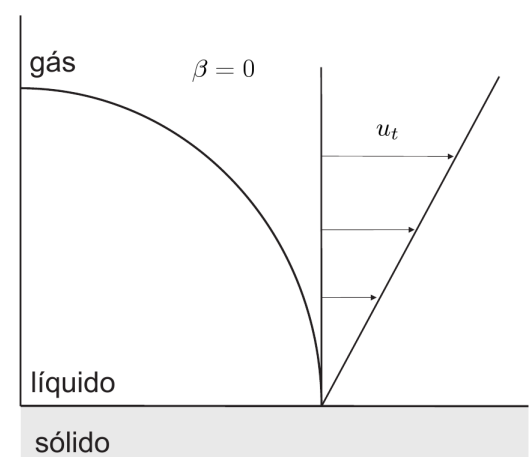

(a) Não escorregamento

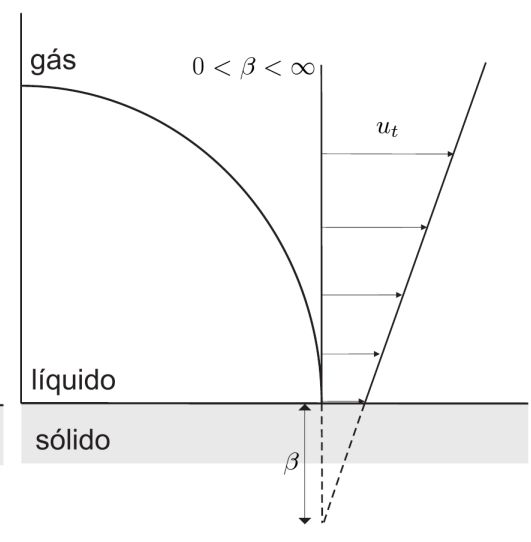

(b) Escorregamento com atrito

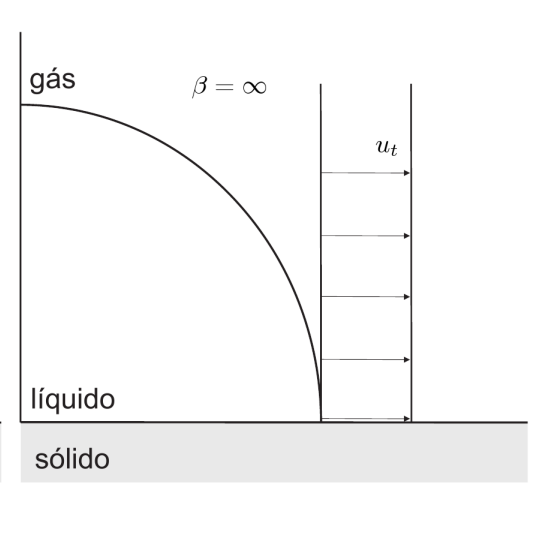

(c) Escorregamento livre

Figura 4.4: Interpretação do comprimento de escorregamento $\beta$. As setas indicam a magnitude da componente tangencial da velocidade $\boldsymbol{u}$ (Ganesan and Tobiska, 2009).

Nos pontos de contato $\partial \Gamma$, é imposta além da Eq. (2.19), a condição de Navier dada acima pelas Eqs. (4.3)-(4.4).

\subsubsection{Formulação variacional}

Retornando à Eq. (3.11) na seção 3.1 correspondente à formulação variacional, e utilizando as condições de contorno (2.19)-(2.20) e (4.3)-(4.4) a integral no contorno dada pelo último termo do 
lado esquerdo será escrita agora como

$$
\begin{aligned}
\int_{\partial \Omega} \boldsymbol{w} \cdot(\boldsymbol{\sigma} \cdot \boldsymbol{n}) d(\partial \Omega) & =\int_{\Gamma} \boldsymbol{w} \cdot(\boldsymbol{\sigma} \cdot \boldsymbol{n}) d \Gamma+\int_{\mathcal{S}} \boldsymbol{w} \cdot(\boldsymbol{\sigma} \cdot \hat{n}) d \mathcal{S} \\
& =\int_{\Gamma} \frac{\gamma \kappa}{E O} \boldsymbol{w} \cdot \boldsymbol{n} d \Gamma-\frac{1}{\beta} \int_{\mathcal{S}} \boldsymbol{w} \cdot\left(\boldsymbol{u}-\boldsymbol{u}_{w}\right) d \mathcal{S}
\end{aligned}
$$

Note que este termo agora depende da incógnita $\boldsymbol{u}$, o que resulta em uma modificação das matrizes do problema discretizado.

\subsection{Imposição do ângulo de contato através da condição de Navier Generalizada (GNBC)}

Considere o problema de dois fluidos separados por uma interface material $\Gamma$ em um domínio $\Omega \subset \mathbb{R}^{2}$. Suponhamos de maneira geral que o domínio $\Omega$ está dividido em subdomínios disjuntos $\Omega_{1}$ e $\Omega_{2}$ por uma curva $\Gamma$, tal que $\mathcal{S} \cap \Gamma \neq \emptyset$, sendo $\mathcal{S}$ o contorno sólido, que pode ser visto na Fig. 4.5. O domínio $\Omega$ é formado pela união entre os subdomínios $\Omega_{1}$ e $\Omega_{2}$, ou seja, $\Omega=\Omega_{1} \cup \Omega_{2}$ e $\Gamma=\Omega_{1} \cap \Omega_{2}$.

A condição de contorno de Navier Generalizada (Generalized Navier Boundary Condition GNBC, em inglês) foi proposta recentemente por Qian et al. (2003, 2006), sendo utilizada em métodos de diferenças finitas. Neste trabalho a condição de contorno GNBC é imposta em um método de elementos finitos com uma formulação ALE, sobre $\mathcal{S}$, tal como Gerbeau and Lelièvre (2009), que é dada por,

$$
\begin{aligned}
\left(\boldsymbol{u}-\boldsymbol{u}_{w}\right) \cdot \hat{n} & =0, \\
\left(\boldsymbol{u}-\boldsymbol{u}_{w}\right) \cdot \hat{\tau}+\beta \boldsymbol{\sigma} \hat{n} \cdot \hat{\tau}+\beta \gamma\left(\boldsymbol{m} \cdot \boldsymbol{t}_{\mathcal{S}}-\cos \theta_{S}\right) \boldsymbol{t}_{\mathcal{S}} \cdot \hat{\tau} \delta_{\partial \Gamma} & =0,
\end{aligned}
$$

para qualquer vetor $\hat{\tau}$, tangente a $\mathcal{S}$. Nas Eqs. (4.6) e (4.7), $\boldsymbol{u}$ é o campo de velocidades, $\boldsymbol{u}_{w}$ é a velocidade da parede, $\beta$ é o coeficiente de escorregamento, $\boldsymbol{t}_{\mathcal{S}}$ é um vetor tangente a $\mathcal{S}, \theta_{S}$ é o ângulo de contato estático e $\delta_{\partial \Gamma}$ é uma distribuição delta de Dirac, de forma que $\int_{\Gamma} \varphi \delta_{\partial \Gamma} d \Gamma=\int_{\partial \Gamma} \varphi d l$.

A primeira equação indica a não penetração (não escorregamento) do fluido, além do mais, será considerado que $\boldsymbol{u}_{w} \cdot \hat{n}=0$. Por outro lado, a segunda condição incorpora a diferença entre o ângulo de contato dinâmico, $\cos \theta=\boldsymbol{m} \cdot \boldsymbol{t}_{\mathcal{S}}$ na Eq. (4.7), e o ângulo de contato estático, $\theta_{S}$, sendo $\theta_{S}$ um dado do problema. Obviamente, esta contribuição desaparece quando $\partial \Gamma=\emptyset$. Neste caso, deve-se notar que para $\beta=0$, o qual ocorre na maioria das aplicações, esta condição de contorno se reduz à condição clássica de não escorregamento. Contudo, quando $\partial \Gamma \neq \emptyset$, a Eq. (4.7) deve ser 


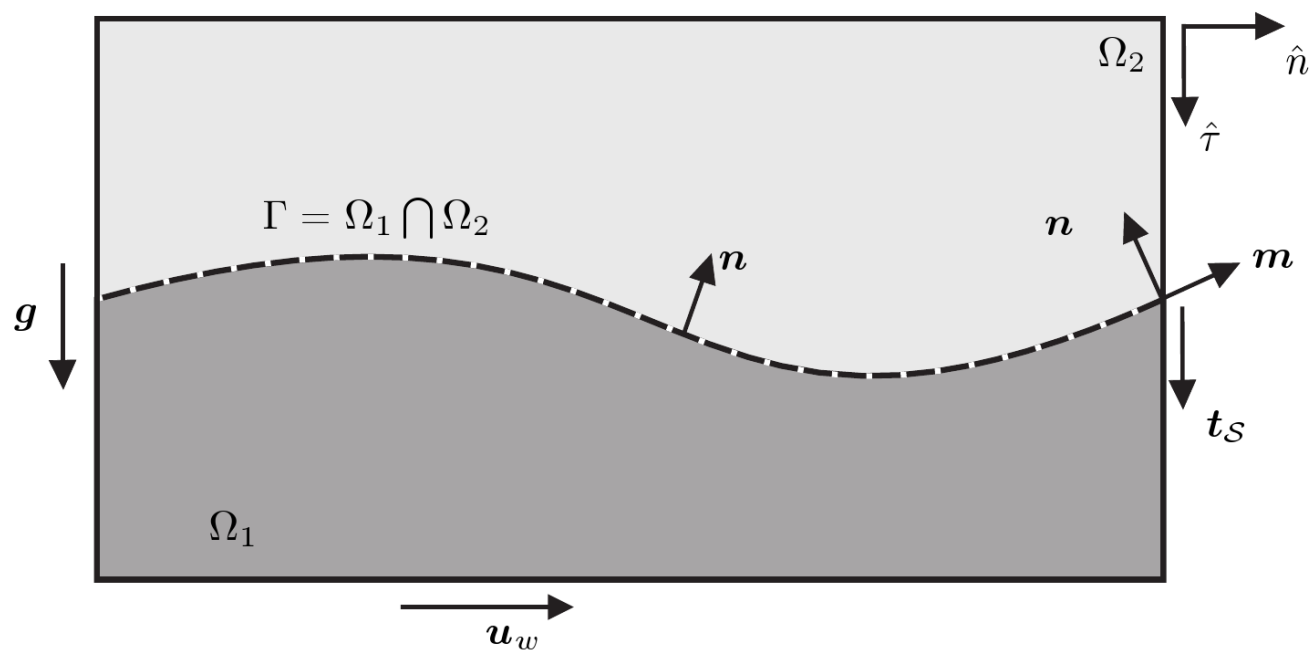

Figura 4.5: Domínio computacional $\Omega$ e interface $\Gamma$. Indicam-se os vetores utilizados para a condição de contorno GNBC.

considerada, para evitar a contradição de ter uma linha de contato que deve-se movimentar, com a condição de não escorregamento (Ausas et al., 2009).

\subsubsection{Formulação contínua do problema}

As equações de Navier-Stokes (2.17)-(2.18) são válidas em um domínio $\Omega \in \mathbb{R}^{2}$, limitado por um contorno $\partial \Omega=\Gamma \cup \mathcal{S}$ e $\partial \Gamma=\Gamma \cap \mathcal{S}$ (veja Fig. 4.6), onde $\Gamma$ representa a superfície livre (interface líquido/gás), $\mathcal{S}$ contorno rígido (interface sólido/líquido) e $\partial \Gamma$ os pontos de contato (interface tripla sólido/líquido/gás).

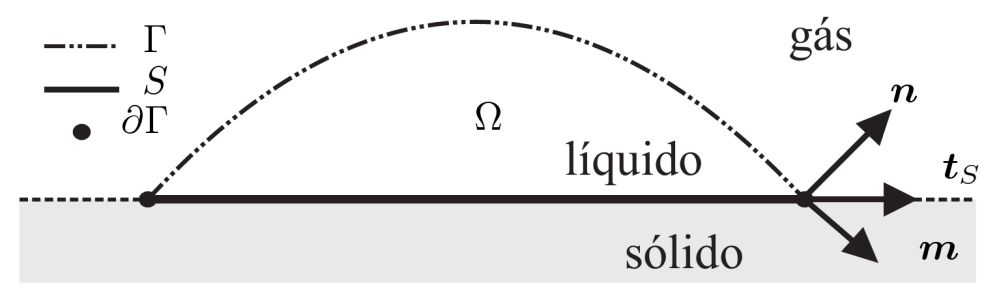

Figura 4.6: Domínio $\Omega$, limitado pelo contorno $\partial \Omega=\Gamma \cup \mathcal{S}$ e $\partial \Gamma=\Gamma \cap \mathcal{S}$. Os vetores $\boldsymbol{t}_{\mathcal{S}}, \boldsymbol{m}$ e $\boldsymbol{n}$ representam respectivamente a tangente ao contorno rígido $\mathcal{S}$, a tangente e a normal à superfície livre $\Gamma$.

$\mathrm{Na}$ interface gás/líquido envolvendo um gás de massa específica e viscosidade desprezível, e também no ponto de contato, a tensão na superfície livre, satisfaz as Eqs. (2.19)-(2.20) em $\Gamma$. 
A condição de contorno GNBC (4.6)-(4.7), é considerada sobre $\mathcal{S}$, no contorno rígido (na interface sólido/líquido), e nos pontos de contato (interface tripla sólido/líquido/gás).

\subsubsection{Formulação variacional}

De maneira semelhante a realizada na subseção 4.2.1, retorna-se a Eq. (3.11) e utilizando as condições de contorno (2.19)-(2.20) e (4.6)-(4.7) a integral no contorno dada pelo último termo do lado esquerdo será escrita agora como

$$
\int_{\partial \Omega} \boldsymbol{w} \cdot(\boldsymbol{\sigma} \cdot \boldsymbol{n}) d(\partial \Omega)=\int_{\Gamma} \boldsymbol{w} \cdot(\boldsymbol{\sigma} \cdot \boldsymbol{n}) d \Gamma+\int_{\mathcal{S}} \boldsymbol{w} \cdot(\boldsymbol{\sigma} \cdot \hat{n}) d \mathcal{S}
$$

e, utilizando (2.19), a primeira integral do lado direito da Eq. (4.8) pode ser escrita como

$$
\int_{\Gamma} \boldsymbol{w} \cdot(\boldsymbol{\sigma} \cdot \boldsymbol{n}) d \Gamma=\int_{\Gamma} \frac{\gamma \kappa}{E_{O}} \boldsymbol{w} \cdot \boldsymbol{n} d \Gamma
$$

sendo $\boldsymbol{n}$ o vetor normal à superfície discreta linear por partes $\Gamma$. A condição de contorno GNBC, é aplicada na segunda integral do lado direito da Eq. (4.8), de forma que

$$
\begin{aligned}
\int_{\mathcal{S}} \boldsymbol{w} \cdot(\boldsymbol{\sigma} \cdot \hat{n}) d \mathcal{S} & =\int_{\mathcal{S}} \boldsymbol{w} \cdot\left[-\frac{1}{\beta}\left(\boldsymbol{u}-\boldsymbol{u}_{w}\right)-\gamma\left(\boldsymbol{m} \cdot \boldsymbol{t}_{\mathcal{S}}-\cos \theta_{S}\right) \boldsymbol{t}_{\mathcal{S}} \cdot \delta_{\partial \Gamma}\right] d \mathcal{S} \\
& =-\frac{1}{\beta} \int_{\mathcal{S}} \boldsymbol{w} \cdot\left(\boldsymbol{u}-\boldsymbol{u}_{w}\right) d \mathcal{S}+ \\
& -\int_{\partial \Gamma} \boldsymbol{w} \cdot \gamma\left(\boldsymbol{m} \cdot \boldsymbol{t}_{\mathcal{S}}-\cos \theta_{S}\right) \boldsymbol{t}_{\mathcal{S}} d l
\end{aligned}
$$

No caso $2 D$, a integral sobre $\partial \Gamma$ (que são os pontos de contato) é simplesmente a avaliação do integrando nestes pontos. 


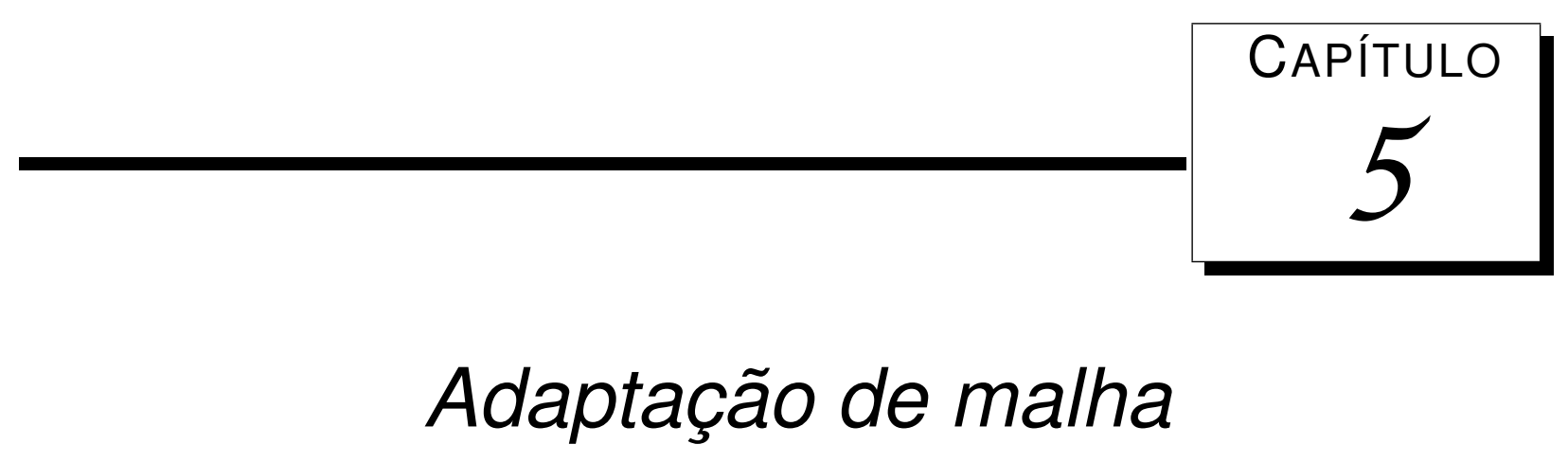

Este capítulo descreve a estratégia de adaptação de malhas dinâmicas não estruturadas de elementos finitos. A malha inicial é uma triangulação, e para garantir boas propriedades de qualidade, tal malha de elementos finitos é obtida através de uma triangulação de Delaunay através do software EasyMesh, proposto por Niceno (2001). Em um ambiente onde a malha se movimenta, o controle de malha se faz necessário, (veja Fig. 5.1(a)-(c)), pois elementos ruins podem aparecer durante a simulação, comprometendo a aproximação por elementos finitos. Para evitar este problema, (veja Fig. 5.1(d)-(f)), o procedimento adotado neste trabalho consiste na verificação das arestas de cada elemento, que devem satisfazer o seguinte critério: um triângulo é candidato a ter sua forma alterada, se o comprimento, $l$, de uma de suas arestas for maior do que $l_{\max }$ ou menor do que $l_{\min }$, onde $l_{\max }$ e $l_{\min }$ são determinados segundo alguma norma de qualidade.

As estratégias de melhoramento de malha adotatas neste trabalho são aplicadas em malhas uniformes. Quando a malha apresentar regiões com diferentes níveis de refinamento, é necessário adotar um procedimento diferenciado que não será abordado neste trabalho.

\subsection{Triangulação de Delaunay}

Seja $T$ um conjunto de elementos $t_{i}$, para $i=1, \cdots n$ com $t_{i} \cap t_{j}=\emptyset$ ou $t_{i} \cap t_{j}$ é uma aresta ou vértice comum a $t_{i}$ e $t_{j}$, uma triangulação de Delaunay de um conjunto de pontos $P=\left\{\boldsymbol{x}_{0}, \cdots, \boldsymbol{x}_{m}\right\} \subset \Omega$, em que $\Omega \subset \mathbb{R}^{d}$ define um domínio limitado e fechado, é a triangu- 


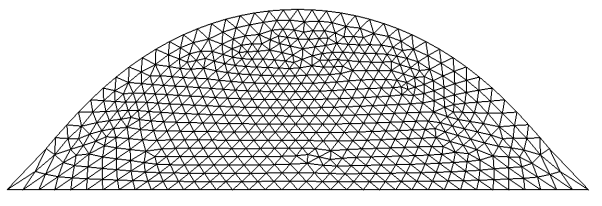

(a) $t_{i}$

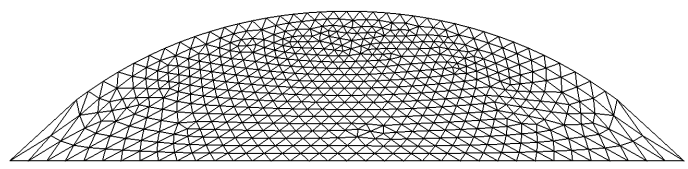

(b) $0.5 t_{f}$

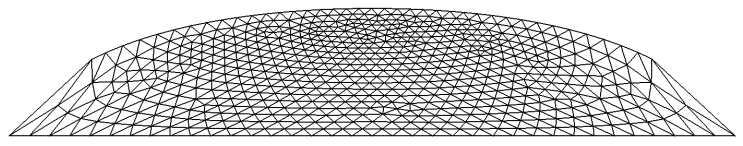

(c) $t_{f}$

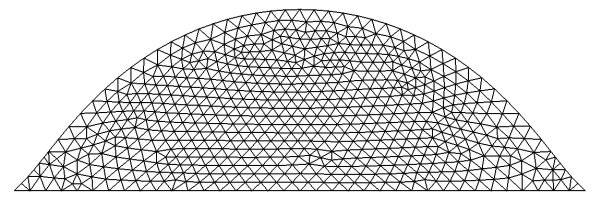

(d) $t_{i}$

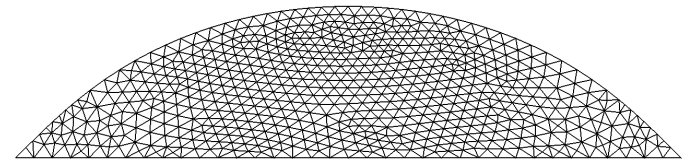

(e) $0.5 t_{f}$

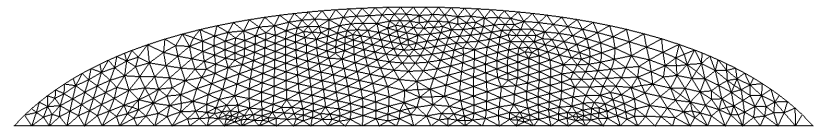

(f) $t_{f}$

Figura 5.1: Ilustração de um resultado sem controle de malha (a)-(c), o aparecimento de elementos ruins pode degradar a precisão do método. Com o controle de malha (d)-(f), o aparecimento de elementos ruins é evitado, $t_{i}$ é o tempo inicial e $t_{f}$ o tempo final.

lação cuja circunsfera de cada elemento de $T$ não possui nenhum ponto $P$ no seu interior. Esta triangulação é muito utilizada em várias áreas. Dentre os motivos que justificam tamanha popularidade, estão as boas propriedades da triangulação de Delaunay. Como exemplo, a maximização do ângulo mínimo no caso bidimensional, isto é, dentre todas as triangulações de $P$, a triangulação de Delaunay maximiza o menor ângulo da triangulação, tendendo a gerar triângulos de boa qualidade, no sentido de tentar minimizar o aparecimento de elementos muito finos, o que pode degradar a solução numérica por elementos finitos.

Uma triangulação de Delaunay possui as seguintes propriedades:

- A triangulação de Delaunay é única. Este fato decorre diretamente da dualidade existente entre triangulação de Delaunay e diagrama de Voronoi, que é uma decomposição única do espaço $\mathbb{R}^{d}$

- Todo elemento da triangulação possui circunsfera vazia, ou seja, sem pontos do conjunto $P$ em seu interior; 
- Dentre todas as triangulações possíveis de um conjunto de pontos em $\mathbb{R}^{2}$, a triangulação de Delaunay é a que maximiza o ângulo mínimo de todos os elementos, minimiza o maior circuncírculo da triangulação e minimiza o maior círculo mínimo da triangulação.

Maiores detalhes sobre triangulação Delaunay podem ser encontradas no livro de Edelsbrunner (2001) e nas notas de Shewchuk (1999).

\subsection{Flipping de arestas}

A troca de arestas (operação conhecida formalmente como flipping de arestas, Fig. 5.2) tem como objetivo melhorar a qualidade local dos elementos da malha. Esta operação é amplamente utilizada em métodos para geração de triangulações de Delaunay, os quais se baseiam no critério do circuncírculo vazio (Chew, 1989). Este critério é bem definido e facilmente computado para geração de triangulações isotrópicas em domínios bidimensionais planares.

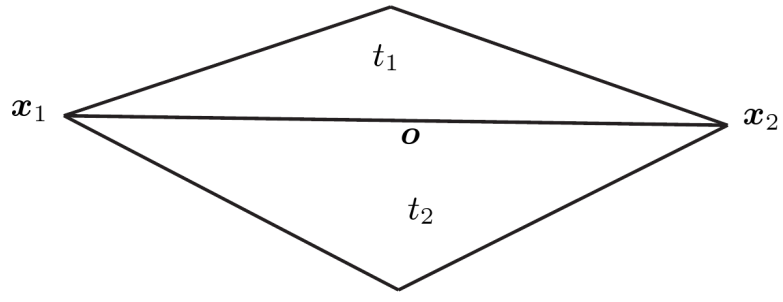

(a)

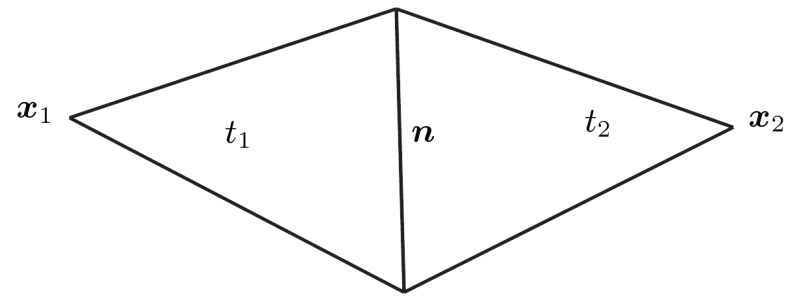

(b)

Figura 5.2: Flipping de uma aresta. Uma aresta $\boldsymbol{o}$, em (a), cujo comprimento é $l_{\boldsymbol{o}}$, é trocada por uma aresta $\boldsymbol{n}$ de comprimento $l_{\boldsymbol{n}}$.

Na Fig. 5.2 as arestas $\boldsymbol{o}$ e $\boldsymbol{n}$ são chamadas de "flipping" uma da outra. Se uma das arestas é externa ao quadrilátero formado pela união dos triângulos $t_{1}$ e $t_{2}$, então diz-se que a aresta interna não possui flipping.

Um algoritmo baseado em operações de flipping pode ser utilizado para construir triangulações que satisfaçam o critério de Delaunay a cada ciclo da simulação, garantindo a sua qualidade. Contudo, isso não é computacionalmente barato nem necessário, pois para manter a triangulação $T$ Delaunay, todas as arestas devem ser localmente Delaunay (Shewchuk, 1997). Seja uma aresta $\boldsymbol{e}$ compartilhada por dois triângulos $t_{1}$ e $t_{2}$, e $\boldsymbol{x}_{1}, \boldsymbol{x}_{2}$ os vértices opostos a $\boldsymbol{e}$ em $t_{1}$ e $t_{2}$, como na Fig. 5.3. A aresta $e$ é chamada de localmente Delaunay se o circuncírculo de $t_{1}$ não inclui $\boldsymbol{x}_{2} \mathrm{e}$ o circuncírculo de $t_{2}$ não inclui $\boldsymbol{x}_{1}$. Sendo assim, ou a aresta $\boldsymbol{e}$ é localmente Delaunay, ou possui flipping e seu flipping é localmente Delaunay (Sousa, 2005). 


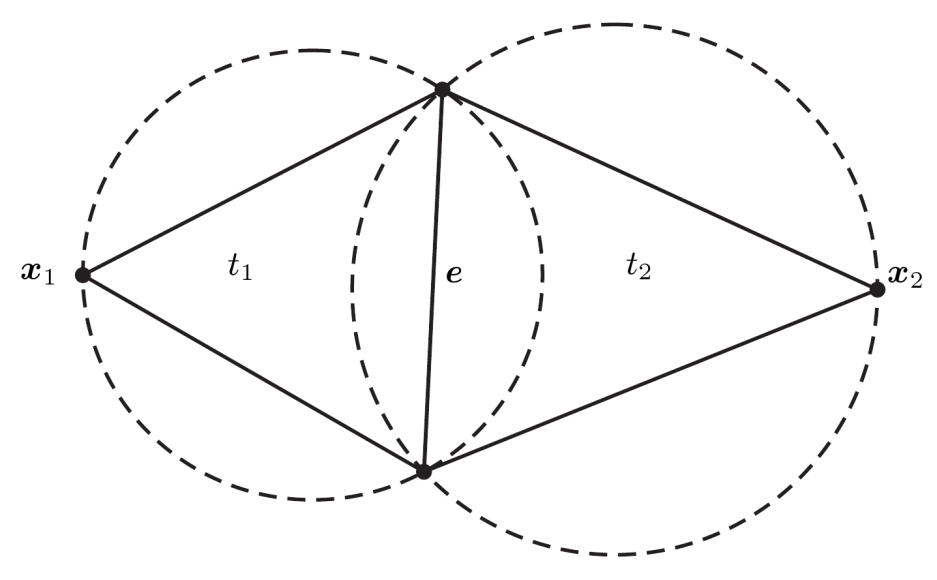

Figura 5.3: Definição de aresta $e$ localmente Delaunay.

Neste trabalho não há a necessidade de manter a malha Delaunay, pois como visto na seção 2.1.1, a velocidade da malha $\hat{\boldsymbol{u}}$, determina a movimentação dos pontos da malha de elementos finitos em uma formulação ALE, em que a velocidade elástica $\boldsymbol{u}_{e}$ (ver Eq. (2.3)), calculada através de uma estratégia de suavização laplaciana, tende a melhorar a qualidade dos triângulos internos. Com isso a opção escolhida neste trabalho evita o teste da aresta ser localmente Delaunay para realizar o flipping, o qual é substituído por um teste equivalente que determina se ocorrerá ou não o flipping da seguinte maneira:

- Dado na Fig. 5.2(a) o quadrilátero pertencente a triangulação cuja diagonal é a aresta $\boldsymbol{O}$ de comprimento $l_{\boldsymbol{o}}$, e seja a aresta $\boldsymbol{n}$ de comprimento $l_{\boldsymbol{n}}$ o flipping da aresta $\boldsymbol{o}$. A aresta $\boldsymbol{o}$ será trocada pelo seu flipping se o comprimento $l_{\boldsymbol{n}}$ da aresta $\boldsymbol{n}$ for menor que $0.9 l_{\boldsymbol{o}}$.

A ideia de trocar arestas que satisfazem estes critérios é melhorar a qualidade local da malha, sem a preocupação que a aresta $\boldsymbol{n}$ seja localmente Delaunay, pois como dito anteriormente o fato da malha ser movimentada pela velocidade $\hat{\boldsymbol{u}}$ tenderá a ajustar os vértices internos para uma melhor posição na triangulação.

\subsection{Inserção e remoção de pontos}

Em geral, como uma malha de superfície livre evolui com o tempo segundo a velocidade $\hat{\boldsymbol{u}}$ dada na subseção 2.1.1, haverá regiões da superfície livre que as arestas poderão aumentar ou diminuir de comprimento, o que pode gerar elementos distorcidos e prejudicar a precisão da aproximação por elementos finitos. Apesar do esquema de suavização laplaciana, a interface se move de acordo com a velocidade do escoamento, fazendo com que a distribuição de pontos mude drasticamente ao 
longo da simulação (Sousa, 2005). Com isso, para a qualidade da discretização da superfície livre ser mantida, será necessário aplicar um controle de malha que consiste em refinar e simplificar a malha de elementos finitos nas regiões críticas, e estas operações serão realizadas com a inserção e remoção de nós.

Dada uma malha inicial que seja uma triangulação de Delaunay de um domínio $\Omega$, o comprimento máximo, $l_{\max }$, e mínimo, $l_{\text {min }}$, das arestas da triangulação são determinados e serão utilizados nas estratégias de refinamento e simplificação. Como foi visto, manter a malha sempre Delaunay a todo passo é computacionalmente caro, e até desnecessário, bastando apenas que a qualidade dos elementos satisfaça algum critério de qualidade.

\subsubsection{Enriquecimento de malha}

O esquema de enriquecimento de malha aplicado neste trabalho, busca subdividir os elementos quando pelo menos uma de suas arestas atinja um tamanho maior que o permitido, com o objetivo de manter a malha com elementos uniformes.

Seja $l_{\boldsymbol{o}}$ o tamanho da aresta $\boldsymbol{o}$, esta é subdividida pela inserção de um novo vértice em seu centro sempre que $l_{\boldsymbol{o}}>\delta_{1} l_{\text {max }}$. Foram realizados testes com o parâmetro $\delta_{1} \in[0.9,1.1]$, e optou-se nos testes com adaptação de malha o valor de $\delta_{1}=1.1$. A Fig. 5.4 ilustra a inserção de um ponto no centro da aresta $\boldsymbol{o}$.

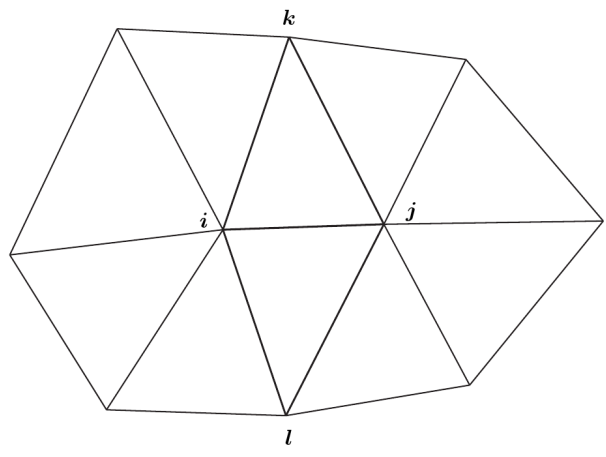

(a)

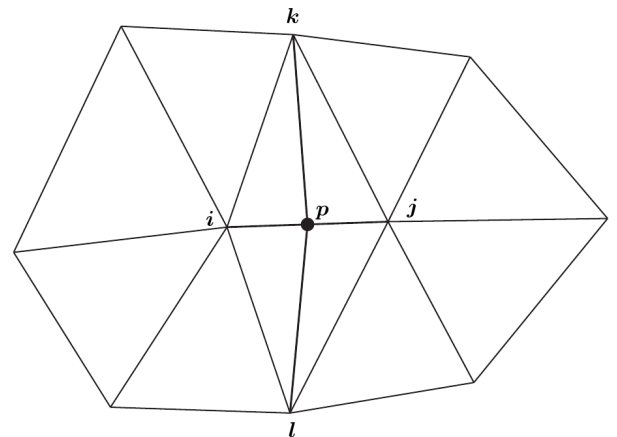

(b)

Figura 5.4: Refinamento de malha. A aresta em destaque em (a) é subdividida e a malha resultante pode ser vista em (b).

Pode ser escolhido algum valor de $\delta_{1}$ fora do intervalo $[0.9,1.1]$, a escolha vai depender do problema a ser simulado. 


\subsubsection{Simplificação de malha}

Dada uma malha inicial, a estratégia de remoção de pontos busca remover da triangulação arestas de tamanho $l$ tal que $l<\delta_{2} l_{\text {min }}$, os valores do parâmetro $\delta_{2}$ foram testados no intervalo [0.4, 0.6], e optou-se nos testes com adaptação de malha o valor de $\delta_{2}=0.5$, este valor foi escolhido com a intenção de realizar o colapso de arestas apenas quando o tamanho da aresta for $50 \%$ do tamanho da menor aresta pertencente a triangulação inicial. Dependendo do problema o parâmetro $\delta_{2}$ também pode ser escolhido fora do intervalo [0.4,0.6].

Há várias maneiras de se remover uma aresta de uma triangulação, como por exemplo, o colapso de seus vértices em um ponto médio ou ainda a remoção da aresta e de todos os seus vizinhos (Sousa, 2005). Neste trabalho optou-se por remover um dos vértices da aresta a ser eliminada, por exemplo o vértice $\boldsymbol{i}$, e movimentar o vértice $\boldsymbol{j}$ para o ponto médio $\boldsymbol{p}$ da aresta $\boldsymbol{i}-\boldsymbol{j}$ (Fig. 5.5), com o intuito de resumir o processo de remoção de arestas a um problema de remoção de um vértice da triangulação.

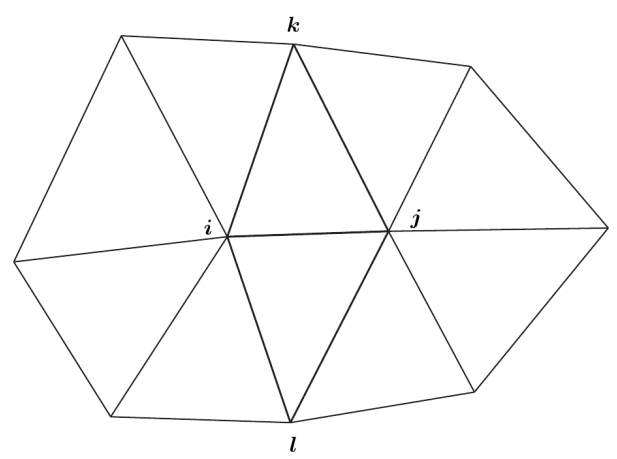

(a)

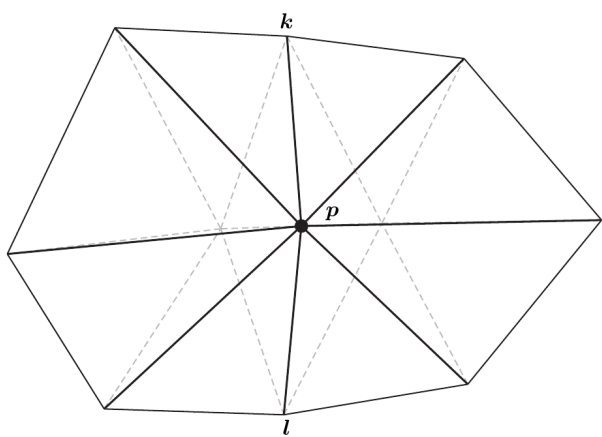

(b)

Figura 5.5: Simplificação de malha. A aresta em destaque em (a) é removida e a malha resultante pode ser vista em (b).

\subsection{Ilustração do esquema de adaptação de malha}

Nesta seção será ilustrado o procedimento de adaptação de malha, sem a preocupação com a física do problema de uma gota apoiada sobre uma superfície rígida. Na Fig. 5.6, está a dinâmica de uma gota apoiada, com ângulo de contato estático $\theta_{S}=90^{\circ} \mathrm{em}$ (i). Aqui, as arestas da malha de elementos finitos é dividida sempre que $l>0.1 l_{\max }$ e será eliminada através do colapso de arestas sempre que $l<0.05 l_{\min }$. 
A malha inicial em (a) é uma representação bem grosseira de uma gota apoiada, em (b) verificase que as arestas da malha inicial foram divididas e uma nova triangulação foi obtida, pode-se ver em (c) e (d) que as arestas são divididas enquanto são maiores que $0.1 l_{\max }$. Desde o início da simulação a malha vai se ajustando com operações de flipping, divisões e colapsos de arestas, a partir de (e) as operações de divisão e colapso de arestas praticamente não acontecem mais até atingir a forma final em (i). Durante todo o processo de adaptação de malha ocorre a suavização laplaciana, que melhorar a qualidade dos elementos.

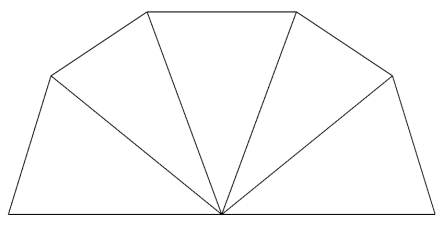

(a) $t_{i}$

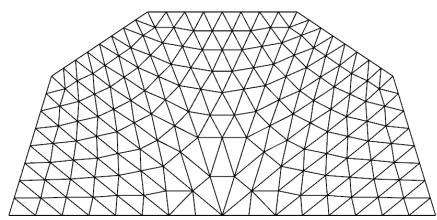

(d) $t_{i}+3 \delta t$

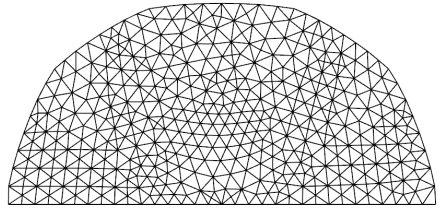

(g) $t_{i}+100 \delta t$

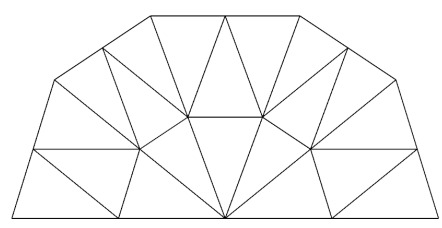

(b) $t_{i}+\delta t$

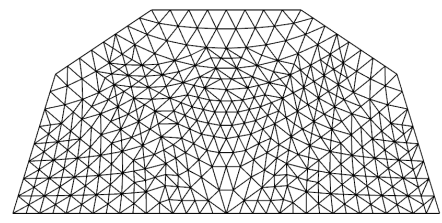

(e) $t_{i}+4 \delta t$

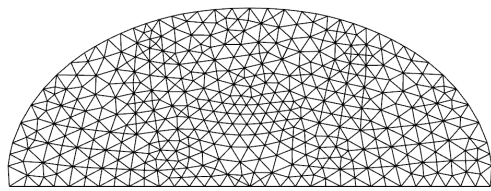

(h) $t_{i}+150 \delta t$

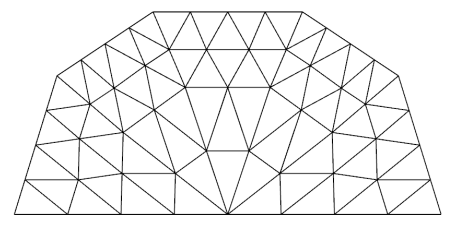

(c) $t_{i}+2 \delta t$

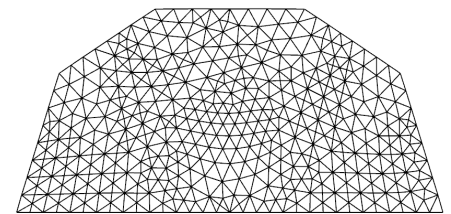

(f) $t_{i}+5 \delta t$

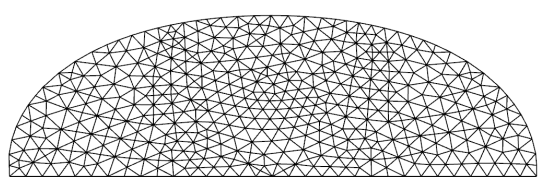

(i) $t_{f}=t_{i}+200 \delta t$

Figura 5.6: Controle de malha no caso de uma gota apoiada. Neste caso teste, o ângulo de contato estático $\theta_{S}=90^{\circ}$. 


\section{Validação e resultados numéricos}

Neste capítulo são apresentados os resultados numéricos obtidos a partir do programa UMeshFlow desenvolvido por Sousa (2005) em sua tese de doutorado, para o caso bidimensional, que é a implementação em linguagem orientada a objeto $\mathbf{C + +}$, foram acrescentados no código os métodos vistos até aqui. Os problemas foram simulados em um computador com processador Intel Core 2 Quad de $2.4 \mathrm{GHz}$ e 4 GB de memória Ram. Os resultados dos problemas acadêmicos: gota estática (subseção 6.2.1), gota oscilante (subseção 6.2.2) e validação da imposição direta do ângulo de contato (subseção 6.3), foram apresentados no trabalho (Silva and Sousa, 2009).

\subsection{Validação para escoamentos com superfícies livres}

\subsubsection{Vibração da superfície livre}

Ao caminhar com um recipiente contendo líquido, o movimento de uma pessoa deve ser cuidadoso para que não haja derramamento do líquido. A experiência mostra que, mesmo para deslocamentos muito pequenos do recipiente, a superfície do líquido pode se mover aumentando significativamente a amplitude das ondas superfície, culminando no transbordamento do líquido. No entanto, pode-se ajustar cuidadosamente a frequência do movimento para que o líquido não derrame.

Esta simples experiência ilustra um fenômeno conhecido como vibração da superfície livre (“sloshing”, em inglês), veja Fig. 6.1, que está relacionado com a formação de ondas na superfície de um líquido. Este fenômeno aparece em vários casos da prática de Engenharia, envolvendo 
tanques de líquidos (Pedroso et al., 2005), e foi utilizada para a validação da imposição de condições de contorno para a superfície livre sem os efeitos da tensão superficial, ou seja, para o caso onde $\gamma=0$, que consiste na verificação da frequência da oscilação e do amortecimento para pequenas amplitudes iniciais do perfil senoidal da superfície livre que é dado por

$$
s(x)=h+a_{0} \sin (\pi(0.5-x)),
$$

onde $a_{0}$ é a amplitude da perturbação senoidal do movimento e $h$ é a altura do nível do fluido dentro do tanque (Rabier and Medale, 2003).

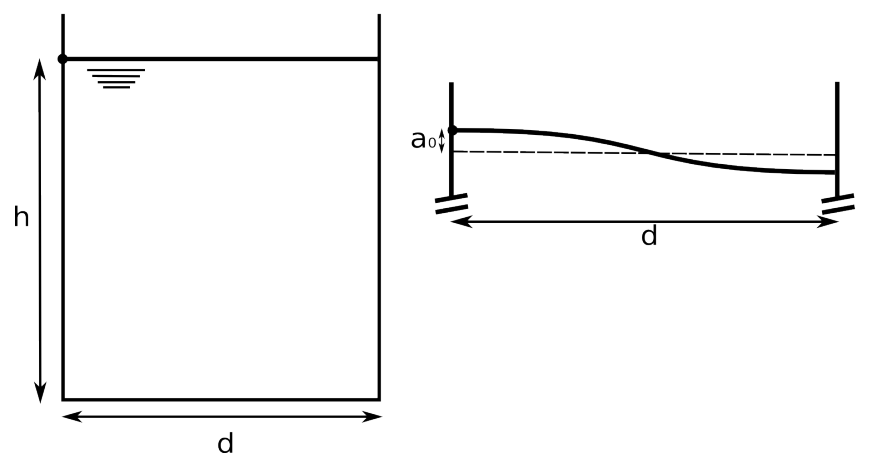

Figura 6.1: Ilustração das dimensões do tanque na simulação do problema de vibração da superfície livre, em que, $d$ é o comprimento da base do recipiente, $h$ a altura e $a_{0}$ representa a amplitude inicial da perturbação senoidal na superfície livre. O ponto, $\bullet$, à esquerda do perfil senoidal, foi monitorado como pode ser visto na Fig. (6.2).

O fluido é submetido à aceleração gravitacional, e forças viscosas que são responsáveis pelo amortecimento do movimento. As condições de contorno utilizadas foram: (i) de escorregamento nas fronteiras sólidas do tanque, dada pela Eq. (2.9) e; (ii) de não escorregamento - na interseção entre a parede vertical e horizontal. Uma solução analítica para este problema foi proposta por Prosperetti (1981).

$$
a(t)=\frac{4 \nu^{2} k^{4}}{8 \nu^{2} k^{4}+\omega_{0}^{2}} a_{0} \operatorname{erfc}\left(\sqrt{\nu k^{2} t}\right)+\sum_{i=1}^{4} \frac{z_{i}}{Z_{i}}\left(\frac{\omega_{0}^{2} a_{0}}{z_{i}^{2}-\nu k^{2}}\right) \exp \left[\left(z_{i}^{2}-\nu k^{2}\right) t\right] \operatorname{erfc}\left(z_{i} \sqrt{t}\right),
$$

onde $\nu$ é a viscosidade cinemática do fluido, $k$ é o número de onda, $\omega_{0}^{2}=g k$ é a frequência de oscilação, cada $z_{i}$ é uma raíz da seguinte equação algébrica

$$
z^{4}+2 k^{2} \nu z^{2}+4\left(k^{2} \nu\right)^{3 / 2} z+\nu^{2} k^{4}+\omega_{0}^{2}=0
$$

onde $Z_{1}=\left(z_{2}-z_{1}\right)\left(z_{3}-z_{1}\right)\left(z_{4}-z_{1}\right), Z_{2}=\left(z_{1}-z_{2}\right)\left(z_{3}-z_{2}\right)\left(z_{4}-z_{2}\right), Z_{3}=\left(z_{1}-z_{3}\right)\left(z_{2}-z_{3}\right)\left(z_{4}-z_{3}\right)$ e $Z_{4}=\left(z_{1}-z_{4}\right)\left(z_{2}-z_{4}\right)\left(z_{3}-z_{4}\right)$, e erfc $(x)=\frac{2}{\sqrt{\pi}} \int_{x}^{\infty} \exp \left(-t^{2}\right) d t=1-\operatorname{erf}(x)$, é o complementar da função erro erf $(x)$. Esta expressão é válida para perturbações de pequenas amplitudes. 
O problema foi simulado com os seguintes parâmetros: $h=1.5, d=1.0, a_{0}=0.01 \mathrm{e} \nu=0.01$. Na Fig. (6.2), pode-se ver a variação temporal da amplitude do ponto, em destaque, mais a esquerda do perfil senoidal da superfície livre Fig. (6.1).

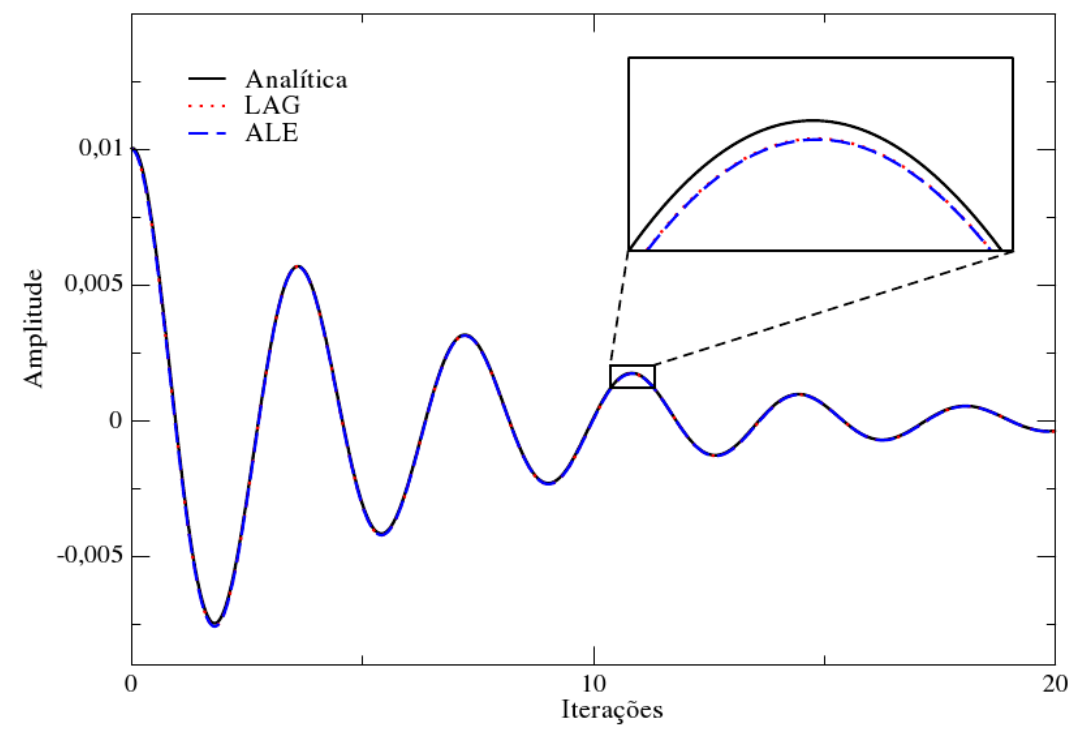

Figura 6.2: Comparação entre solução analítica e numérica calculada para a vibração da superfície livre. Os resultados foram simulados utilizando as estratégias Lagrangeana e ALE.

Os resultados obtidos numericamente capturaram bem a frequência e o decaimento da oscilação. Na Tab. 6.1, verifica-se a norma do erro entre a solução analítica e os resultados obtidos numericamente da amplitude nas estratégias lagrangeana (LAG) e ALE.

Tabela 6.1: Comparação entre a amplitude da curva analítica e numérica no problema de vibração da superfície livre. O erro $E$, foi calculado como a diferença máxima da coordenada $y$ entre a curva analítica e numérica, ou seja, $\|E\|_{\infty}=\max \left\{\left|y_{\text {ana }}-y_{\text {num }}\right|\right\}$.

\begin{tabular}{ll}
\hline Formulação & $\|E\|_{\infty}$ \\
\hline LAG & $0.1363 \%$ \\
ALE & $0.1918 \%$ \\
\hline
\end{tabular}

\subsection{Validação do cálculo da tensão superficial}

Esta seção apresenta a solução numérica de alguns problemas acadêmicos e comparam-se com a solução analítica. Primeiramente o problema de uma gota estática é investigado, em seguida é estudado o problema de uma gota oscilante no vácuo. 


\subsubsection{Gota estática}

A simulação de uma gota estática imersa no vácuo, sem a influência da gravidade, é feita com o intuito de validar o cálculo da tensão superficial agindo sobre a interface. A tensão superficial resulta do desbalanço de forças intermoleculares, nas quais existe a variação brusca da massa específica (Wolf et al., 2005). Sendo assim, a força resultante em uma molécula próxima à interface líquido/gás é diferente daquela sobre uma molécula que se encontra em uma região completamente homogênea (como foi visto na subseção 1.1.1). A expressão analítica para o salto de pressão na interface para uma gota em equilíbrio é dada abaixo pela fórmula de Young-Laplace (de Gennes et al., 2004),

$$
\Delta p=p_{i}-p_{e}=\gamma \kappa=\frac{\gamma}{R}
$$

onde $p_{i}$ é a pressão no interior da gota e $p_{e}$ é a pressão externa, neste caso $p_{e}=0, R$ é o raio de curvatura da gota. As simulações foram realizadas para uma gota de raio $R=1.0$, coeficiente de tensão superficial $\gamma=1.0$. Assim, a expressão analítica para a pressão no interior da gota é $p_{i}=1.0$. Para a velocidade, a solução exata corresponde a um campo de velocidades identicamente nulo. O passo no tempo $\Delta t=10^{-3}$.

Tabela 6.2: Comparação entre a pressão interna e dos erros cometidos em diferentes malhas de elementos finitos. Aqui, $N_{e}$ é o número de elementos em cada malha, $h$ é o espaçamento médio da malha, $p_{i}^{*}$ é o máximo da pressão interna nos nós obtida numericamente, $E=\left\|p_{i}^{*}-p_{i}\right\| /\left\|p_{i}\right\|$ é o erro relativo cometido na aproximação da pressão interna e $\boldsymbol{p}$ é a ordem de convergência.

\begin{tabular}{lllllll}
\hline Malha & $N_{e}$ & $h$ & $p_{i}^{*}$ & $E$ & $\boldsymbol{p}$ & $\max \{|u|,|v|\}$ \\
\hline 1 & 100 & 0.2500 & 0.996643 & 0.003357 & - & $3.426 \mathrm{E}-07$ \\
2 & 200 & 0.1768 & 0.998186 & 0.001814 & 1.7759 & $1.030 \mathrm{E}-08$ \\
3 & 400 & 0.1250 & 0.999191 & 0.000809 & 2.3299 & $2.918 \mathrm{E}-08$ \\
4 & 800 & 0.0884 & 0.999600 & 0.000400 & 2.0322 & $6.983 \mathrm{E}-09$ \\
5 & 1600 & 0.0625 & 0.999800 & 0.000020 & 2.0000 & $3.628 \mathrm{E}-09$ \\
\hline
\end{tabular}

Para avaliar a precisão do cálculo da curvatura, foi feito um estudo de convergência com os valores da pressão interna para as malhas utilizadas, sendo estes mostrados na Tab. 6.2, portanto pode-se constatar ordem de convergência quadrática para este exemplo. Adicionalmente, os valores máximos das velocidades residuais no escoamento também podem ser vistos na Tab. 6.2.

Pela lei de Young-Laplace, o efeito da tensão superfícial é aumentar a pressão interna, que pode ser modificada tanto pela variação da tensão superficial quanto pela variação do raio da gota. Em princípio, para um processo isotérmico, a tensão superficial não varia (Wolf et al., 2005). Para 


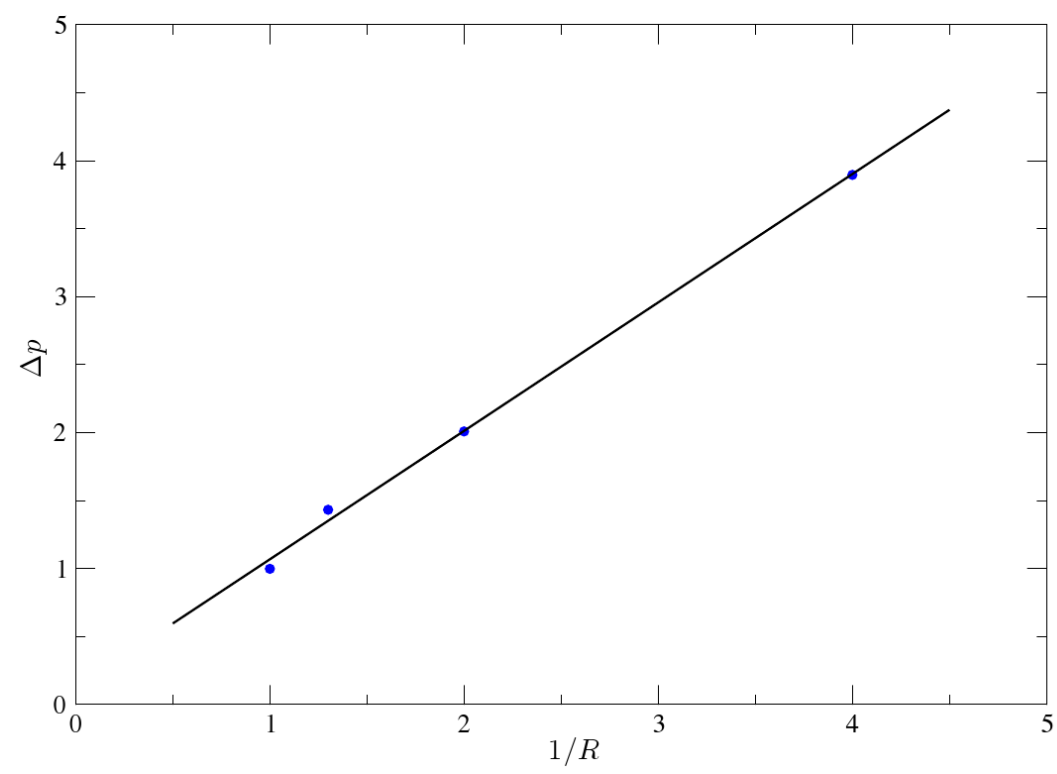

Figura 6.3: Verificação da lei de Young-Laplace. A tensão superficial $\gamma$, pode ser determinada através do coeficiente angular da reta ajustada por mínimos quadrados. Neste caso $\gamma$ calculado é dado por 0.94467 .

verificar a validade da lei de Young-Laplace, pode-se variar o raio da gota e obter a pressão interna correspondente, como pode ser visto na Fig. 6.3, onde a linearidade entre a pressão interna e o inverso do raio pode ser observada.

\subsubsection{Gota oscilante}

Esta validação consiste em avaliar a frequência de oscilação de uma gota de fluido. Como visto acima, gotas tendem a permanecer esféricas (ou circulares no caso bidimensional), ponto de equilíbrio entre as forças de tensão interfacial. Sendo o raio de uma gota inicialmente perturbado, esta oscila até atingir o equilíbrio, a amplitude do movimento é amortecida pela viscosidade.

A frequência $\omega$, de oscilação analítica de pequenas amplitudes de uma gota é encontrada em (Lamb, 1945)

$$
\omega_{n}^{2}=\frac{\left(n^{3}-n\right) \gamma}{\left(\rho_{L}+\rho_{G}\right) R^{3}}
$$

onde $R$ é o raio da gota (não perturbado), $\gamma$ é o coeficiente de tensão superficial, $n$ caracteriza o modo de oscilação, e os subscritos $L$ e $G$ indicam a fase líquida e gasosa. Lamb (1945), também encontrou que a amplitude da oscilação deverá decair como uma função do tempo,

$$
A_{n}(t)=A_{0} e^{-t / \tau_{n}}
$$


onde

$$
\tau_{n}=\frac{R^{2}\left(\rho_{L}+\rho_{G}\right)}{2 n\left((n-1) \nu_{L}+(n+1) \nu_{G}\right)},
$$

e $A_{0}$ representa a amplitude inicial. O perfil da gota líquida é dado em coordenadas polares $(r, \theta)$ por

$$
r=R+A_{0} \cos (n \theta)
$$

O teste realizado consiste em uma gota com raio não perturbado, $R=1.0$, massa específica $\rho=1.0$, viscosidade cinemática $\nu=0.01$ imersa no vácuo, ou seja, com $\rho_{G}=0, \nu_{G}=0$. Dois casos testes são apresentados neste exemplo, o primeiro tem-se $A_{0}=0.02$ e o segundo caso, tem-se $A_{0}=0.2$, ambos com dois modos de oscilação $(n=2)$. Para as duas simulações o tamanho do passo no tempo é $\Delta t=10^{-3}$.

O período é definido como $T_{n}=2 \pi / \omega$, no caso que $n=2, \rho=1.0$ e $R=1.0$, tem-se a partir da Eq. (6.5) que $T_{2}=2.5651$.

Tabela 6.3: Comparação entre o período, $T_{n}$, analítico e numérico $\left(T_{2}^{*}(1)\right.$ para $A_{0}=0.02$ e $T_{2}^{*}$ (2) para $A_{0}=0.2$ ), no caso de uma gota líquida bidimensional. Para $n=2, \rho=1.0$ e $R=1.0$, tem-se $T_{2}=2.5651, \mathrm{~N}_{\text {ele }}$ é o número de elementos na malha, $h$ é o espaçamento médio da malha, $E=\left\|T_{n}^{*}-T_{n}\right\| /\left\|T_{n}\right\|$ é o erro relativo cometido na aproximação do período de oscilação e $\boldsymbol{p}$ é a ordem de convergência. A identificação (1) refere-se a gota cuja amplitude de oscilação é $A=0.02$ e (2) para $A=0.2$.

\begin{tabular}{lccccccccc}
\hline Malha & $\mathrm{N}_{\text {ele }}$ & $h(1)$ & $T_{2}^{*}(1)$ & $E(1)$ & $\boldsymbol{p}(1)$ & $h(2)$ & $T_{2}^{*}(2)$ & $E(2)$ & $\boldsymbol{p}(2)$ \\
\hline 1 & 160 & 0.2503 & 2.616 & 0.0198 & - & 2.5000 & 2.7829 & 0.0849 & - \\
2 & 320 & 0.1770 & 2.597 & 0.0124 & 1.3503 & 1.7678 & 2.7013 & 0.0531 & 1.3541 \\
3 & 640 & 0.1252 & 2.581 & 0.0062 & 2.0000 & 1.2500 & 2.6657 & 0.0392 & 0.8757 \\
4 & 1280 & 0.0885 & 2.573 & 0.0031 & 2.0000 & 0.8839 & 2.6390 & 0.0288 & 0.8896 \\
5 & 2560 & 0.0626 & 2.569 & 0.0015 & 2.0946 & 0.6250 & 2.6167 & 0.0201 & 1.0377 \\
\hline
\end{tabular}

Pode ser visto na Tab. 6.3, que para pequenas amplitudes de oscilações $\left(A_{0}=0.02\right)$ e viscosidade $(\nu=0.01)$, obtém-se excelentes resultados numéricos com ordem de convergência quadrática $(\boldsymbol{p}=2.0)$. Como é esperado, para o caso com amplitude moderada $\left(A_{0}=0.2\right)$, os resultados numéricos estão mais distantes da solução analítica, com ordem de convergência linear $(\boldsymbol{p}=1.0)$. Estes resultados estão compatíveis com os obtidos em Saksono and Perić (2006b). Verifica-se na Fig. 6.5 a comparação do período de oscilação e amortecimento entre a solução analítica e numérica. 


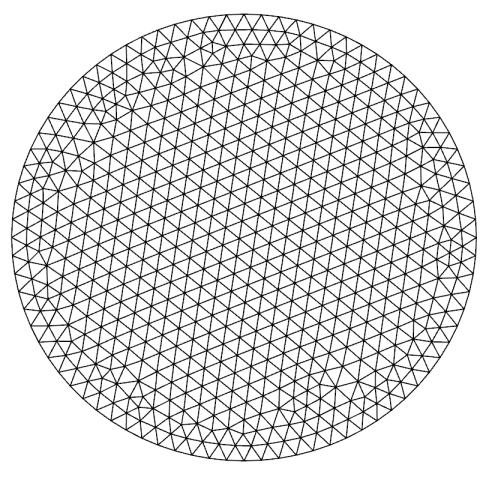

(a) $A_{0}=0.02$

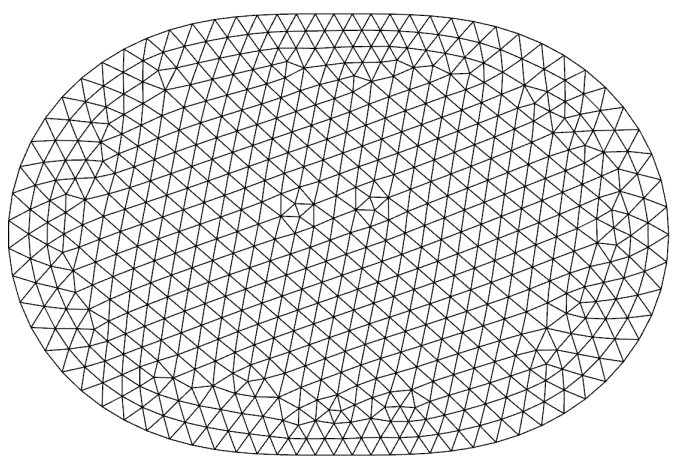

(b) $A_{0}=0.2$

Figura 6.4: Representação da malha 4 de elementos finitos de uma gota com amplitudes $A_{0}=0.02$ em (a) e $A_{0}=0.2 \mathrm{em}$ (b).

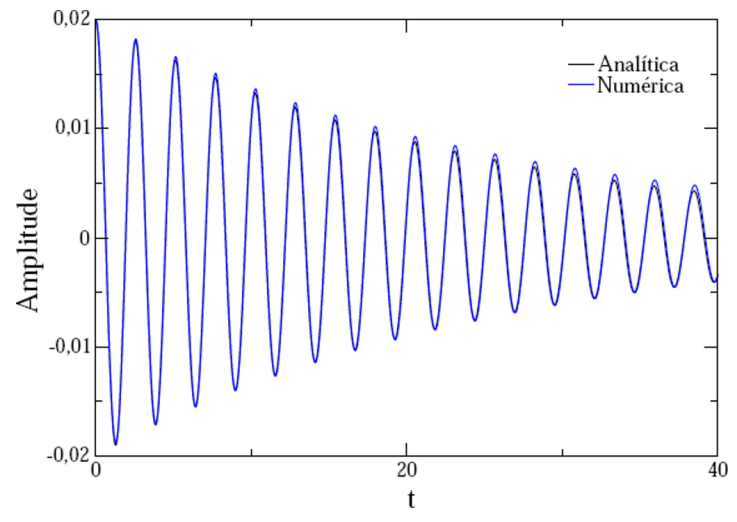

(a) $A_{0}=0.02 R$

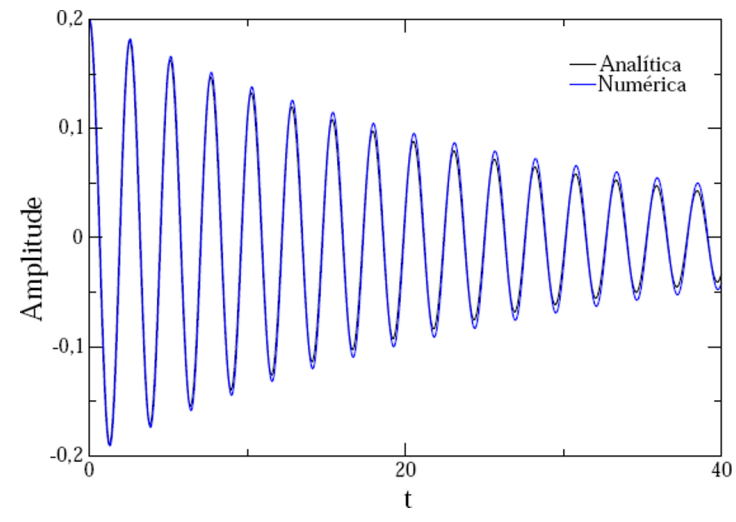

(b) $A_{0}=0.2 R$

Figura 6.5: Evolução da amplitude no tempo, ilustrando o amortecimento devido a viscosidade.

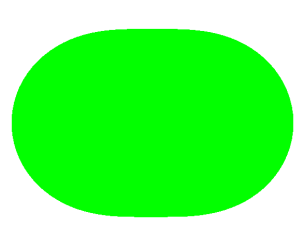

(a) inicial

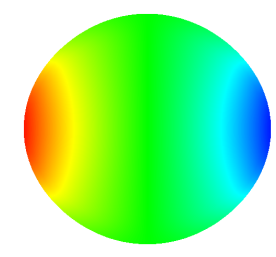

(b) intermediário

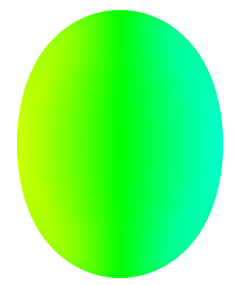

(c) intermediário

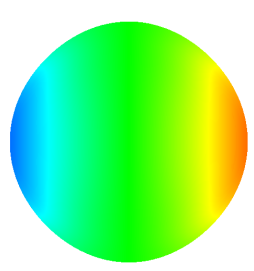

(d) intermediário

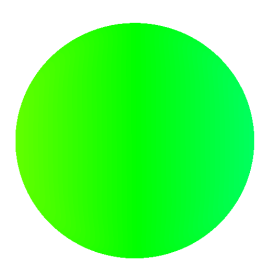

(e) estacionário

Figura 6.6: Inversão no sentido da velocidade $u$ no escoamento em (b) e (d), caracterizando oscilação. A cor azul representa o sinal negativo da velocidade, e em vermelho o sinal positivo. 


\subsection{Validação da imposição direta do ângulo de contato com condição de Navier (NBC)}

Para a validação da implementação do ângulo de contato, foi utilizado um modelo de gota apoiada sem a presença de forças externas, como o efeito da gravidade atuando sobre o domínio. Quando a aceleração da gravidade é nula, a solução analítica consiste em um arco de circunferência com raio $R$ calculado a partir do ângulo de contato estático $\theta_{S}$ prescrito e da altura máxima do fluido $h$. Assim as coordenadas do centro da circunferência, $X_{c}=\left(x_{c}, y_{c}\right)$, e raio são:

$$
x_{c}=0.0 ; y_{c}=-\frac{h \cos \left(\theta_{S}\right)}{1-\cos \left(\theta_{S}\right)} ; R=\frac{h}{1-\cos \left(\theta_{S}\right)} \text {. }
$$

O modelo utilizado nesta validação, consiste de uma gota inicialmente apoiada sobre a superfície sólida, sendo um segmento circular com raio $R=1.0$, e grandezas adimensionais, $G a=1.0$ e $E_{o}=1.0$, com passo no tempo $\Delta t=10^{-3}$. Foram simulados três valores para o ângulo de contato estático $\theta_{S}, 45^{\circ}, 90^{\circ}$ e $135^{\circ}$ com cinco malhas de elementos finitos para cada ângulo, sendo a primeira malha, com um menor número de elementos (aproximadamente $N_{e} \approx 160$ elementos) e a última, com aproximadamente $N_{e} \approx 2560$ elementos, e os resultados numéricos dos estados estacionários comparados com a solução analítica para cada caso.

O erro foi obtido da seguinte forma:

$$
E\left(x^{*}, y^{*}\right)=\left(x^{*}-x_{c}\right)^{2}+\left(y^{*}-y_{c}\right)^{2}-R^{2},
$$

onde $\left(x^{*}, y^{*}\right)$ são as coordenadas numéricas da gota. Os erros são reportados na Tab. 6.4, onde pode-se observar a convergência sob refinamento de malha.

Tabela 6.4: Teste de convergência para a imposição direta do ângulo de contato, com o refinamento das malhas. Dobrando o número de elementos $N_{e}$ da malha, corresponde a dividir o espaçamento $h$ por $\sqrt{2}$, sendo $\boldsymbol{p}$ é a ordem de convergência e $E_{\text {max }}=\|E\|_{\infty}$ a norma do erro.

\begin{tabular}{ll|cc|cc|cc}
\hline Malha & $\mathrm{N}_{e}$ & \multicolumn{2}{|c|}{$45^{\circ}$} & \multicolumn{2}{c|}{$90^{\circ}$} & \multicolumn{2}{c}{$135^{\circ}$} \\
& & $E_{\text {max. }}$ & $\boldsymbol{p}$ & $E_{\text {max. }}$ & $\boldsymbol{p}$ & $E_{\text {max. }}$ & $\boldsymbol{p}$ \\
\hline 1 & 160 & $1.4426 \mathrm{E}-2$ & - & $4.6573 \mathrm{E}-2$ & - & $3.9124 \mathrm{E}-2$ & - \\
2 & 320 & $1.0584 \mathrm{E}-2$ & 0.8936 & $3.0494 \mathrm{E}-2$ & 1.2219 & $2.5556 \mathrm{E}-2$ & 1.2287 \\
3 & 640 & $6.5319 \mathrm{E}-3$ & 1.3927 & $2.3536 \mathrm{E}-2$ & 0.7473 & $1.9941 \mathrm{E}-2$ & 0.7158 \\
4 & 1280 & $4.5910 \mathrm{E}-3$ & 1.0174 & $1.7665 \mathrm{E}-2$ & 0.8279 & $9.4805 \mathrm{E}-3$ & 2.1454 \\
5 & 2560 & $3.2589 \mathrm{E}-3$ & 0.9888 & $9.0562 \mathrm{E}-3$ & 1.9278 & $6.1316 \mathrm{E}-3$ & 1.2573 \\
\hline
\end{tabular}




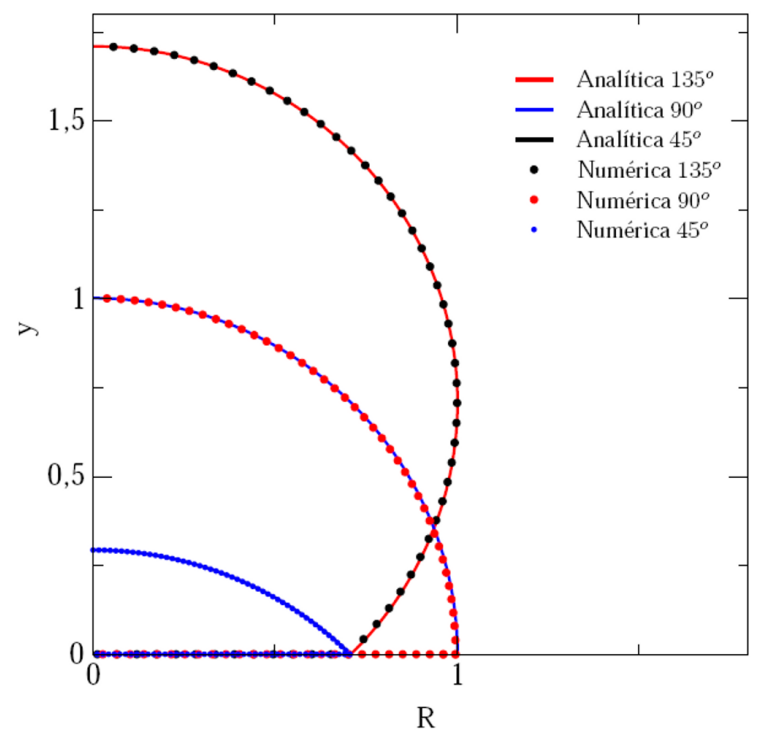

Figura 6.7: Validação da imposição direta do ângulo de contato, com aceleração da gravidade nula, para os seguintes valores de $\theta_{S}: 45^{\circ}, 90^{\circ}$ e $135^{\circ}$.

Pode-se observar, na Fig. 6.7, a comparação dos resultados numéricos com os arcos de circunferência para cada ângulo de contato.

Quando os efeitos da gravidade são importantes, uma solução pseudo-analítica pode ser obtida da solução de um sistema de equações diferenciais ordinárias como função do comprimento de arco $s$,

$$
\frac{d x}{d s}=\cos (\theta), \quad \frac{d y}{d s}=\sin (\theta), \quad \frac{d \theta}{d s}=\frac{p_{0}+\rho g y}{\gamma}
$$

onde $\theta$ é o ângulo formado entre a tangente à curva na posição correspondente à $s$ e o eixo horizontal (Mangiavacchi et al., 2005; O’Brien, 1991). O método de Runge-Kutta de quarta ordem foi utilizado para resolver o sistema de equações acima, com um passo de integração $\delta s=0.0001$.

O modelo utilizado nesta validação, consiste de uma gota incialmente apoiada sobre a superfície sólida, sendo um segmento circular com área $A=\pi$, e grandezas adimensionais, $G a=1.0 \mathrm{e}$ $E_{O}=1.0$, com passo no tempo $\Delta t=10^{-3}$.

Foram simulados três valores para o ângulo de contato estático $\theta_{S}, 45^{\circ}, 90^{\circ}$ e $135^{\circ}$ com aproximadamente $N_{e} \approx 1280$ elementos, onde o perfil inicial da gota evolui no tempo até o estado estacionário, que pode ser visto na Fig. 6.8, comparado com a solução pseudo-analítica dada pela Eq. (6.11).

Como pode ser observado, os resultados para os problemas sem e com influência dos efeitos da gravidade são bem satisfatórios, o que valida a estratégia de imposição direta do ângulo de contato proposta neste trabalho. 


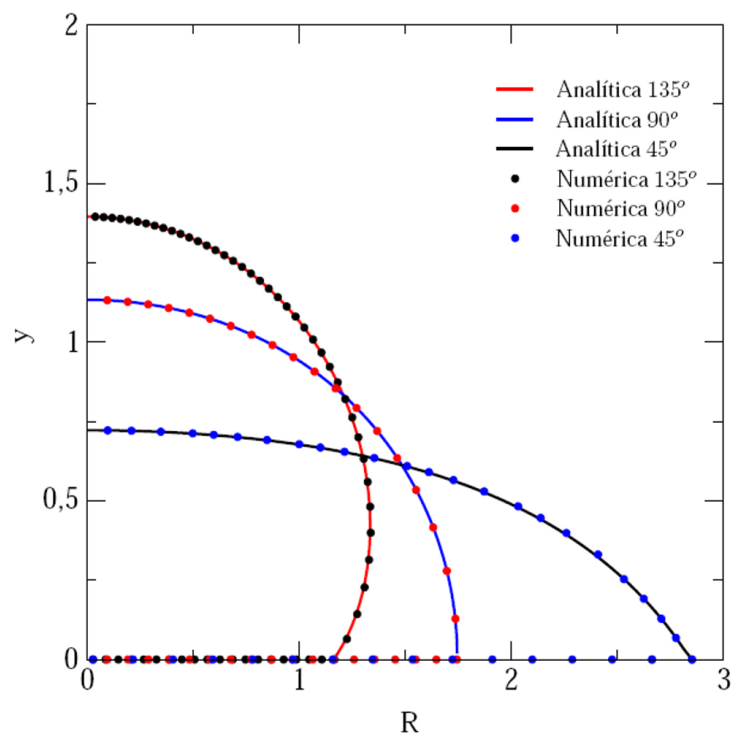

Figura 6.8: Validação do ângulo de contato com aceleração da gravidade.

\subsection{Validação da imposição do ângulo de contato com condição de Navier generalizada (GNBC)}

O problema da gota apoiada sobre uma superfície sólida é novamente investigado, mas dessa vez apenas sob o efeito da gravidade, com intuito de avaliar a condição de contorno GNBC. A solução pseudo-analítica é obtida através da solução do sistema de equações diferenciais ordinárias como função do comprimento de $\operatorname{arco} s$, dado pelas equações em (6.11).

Neste exemplo numérico (veja Fig. 6.9) é estudada a utilização da condição de contorno GNBC apresentada no capítulo 4. Para este problema, é considerada uma gota líquida inicialmente apoiada sobre a superfície sólida, sendo um segmento circular com área $A=\pi$, centrado em $[0,0]$ e grandezas adimensionais, $G a=1.0$ e $E o=1.0$, com passo no tempo $\Delta t=10^{-3}$. Assim como no problema anterior, também foram simulados três valores para o ângulo de contato estático $\theta_{S}$, $45^{\circ}, 90^{\circ}$ e $135^{\circ}$ com aproximadamente $N_{e} \approx 1280$ elementos, onde o perfil inicial da gota evolui no tempo até atingir o estado estacionário, que pode ser visto na Fig. 6.10, comparado com a solução pseudo-analítica dada pela Eq. (6.11).

Assim como no caso da seção 6.3, em que o ângulo de contato foi obtido através da imposição direta da curvatura utilizando uma superfície virtual, pode ser observado na Fig. 6.10 que os resultados alcançados através da condição GNBC, que foi imposta de forma variacional nas equações de Navier-Stokes são bem satisfatórios nos testes de ângulo de contato em equilíbrio, o que valida a estratégia de imposição do ângulo de contato para o ponto tríplice utilizando a GNBC. 


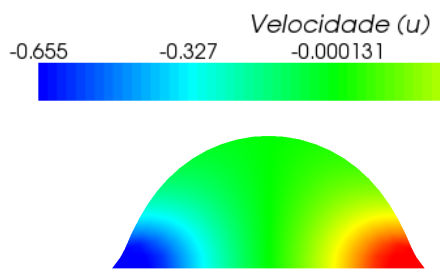

(b) intermediário

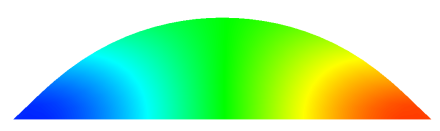

(e) intermediário

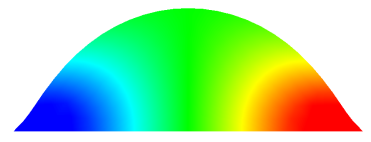

(c) intermediário

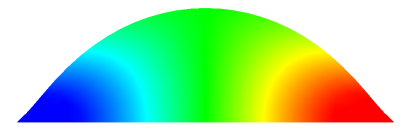

(d) intermediário

Figura 6.9: Evolução de uma gota apoiada sobre uma superfície sólida. A gota inicialmente em (a) possui um ângulo de contato de $90^{\circ}$, sendo imposto um ângulo de contato $\theta_{S}=45^{\circ} \mathrm{em}$ (c).

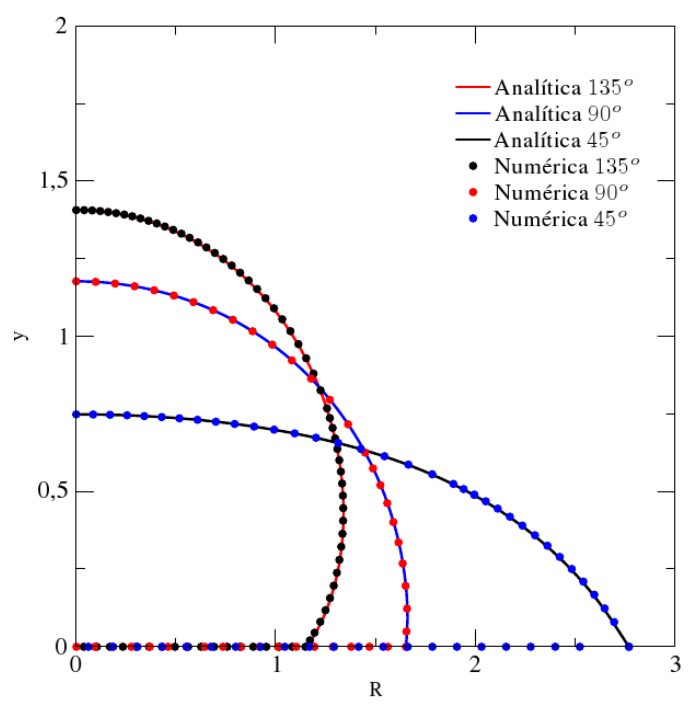

Figura 6.10: Validação da imposição do ângulo de contato com a utilização da condição GNBC.

Na Fig. 6.11 pode ser visto o comportamento do espalhamento da gota apoiada para diferentes ângulos de contato iniciais, nota-se que inicialmente a evolução de cada caso é completamente dependente das condições iniciais impostas através de $\theta_{0}$. Após passar por uma região transitória inicial, verifica-se que os casos considerados exibem aproximadamente o mesmo comportamento. 


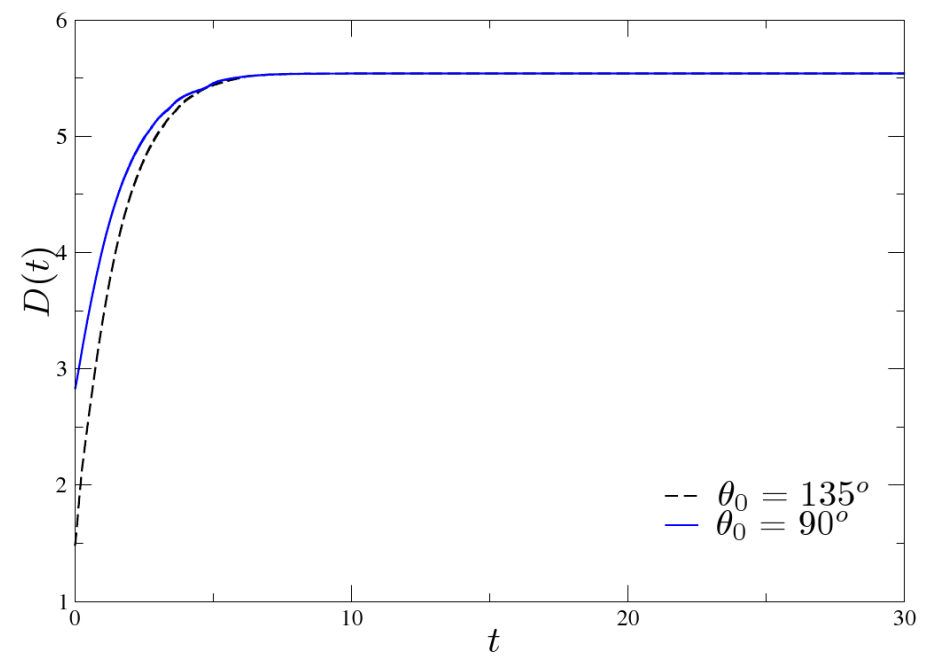

Figura 6.11: Variação temporal do diâmetro da região apoiada sobre a superfície sólida para diferentes formas iniciais, $\theta_{0}=135^{\circ}$ e $\theta_{0}=90^{\circ}$.

\subsection{Comportamento dinâmico da imposição do ângulo de contato}

O teste numérico da gota oscilante visto na subseção 6.2.2 é repetido nesta seção, a gota da Fig. 6.4(a) é dividida ao meio e apoiada sobre uma superfície sólida. Os pontos em contato com a superfície sólida estão sujeitos a condição de escorregamento livre, com ângulo de contato imposto $\theta_{S}=90^{\circ}$.

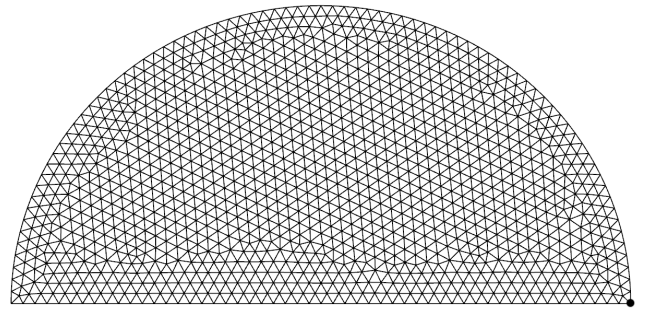

(a) $A_{0}=0.02$

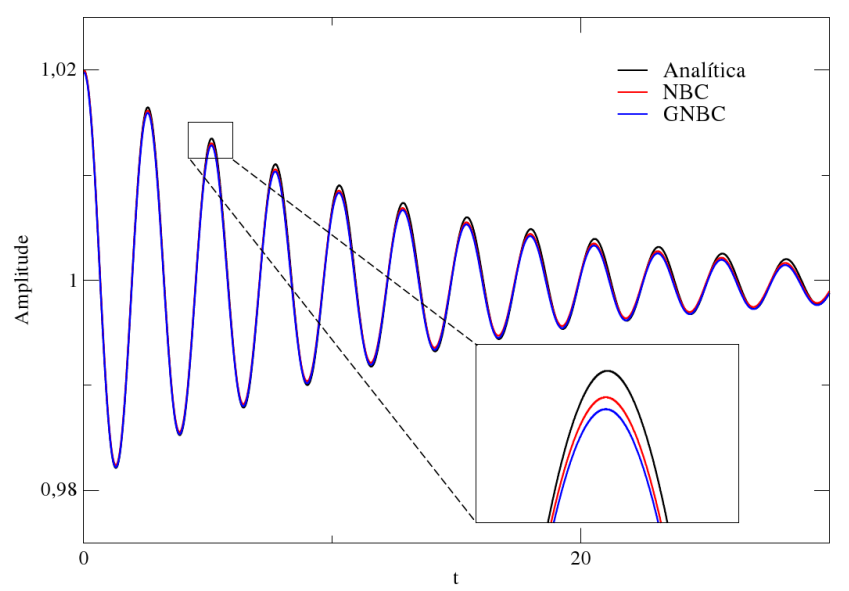

(b) Variação da posição $x$ do ponto de contato.

Figura 6.12: Evolução temporal da posição $x$ do ponto de contato.

A coordenada $x$ da posição do ponto de contato em destaque na Fig. 6.12(a) é monitorada, e 
como esperado, ocorre a oscilação deste ponto em torno da coordenada de equilíbrio $x=1.0$. Podese verificar a concordância entre as estratégias de imposição do ângulo de contato. Os resultados numéricos foram comparados com a solução analítica para pequenas amplitudes dada pelas Eqs. 6.5-6.6.

\subsection{Simulações com linhas de contato dinâmicas}

Os resultados obtidos nesta seção utilizam a condição de contorno de Navier Generalizada (GNBC), vista na seção 4.3, com o objetivo de simular situações dinâmicas, tais como: o caso de uma gota escorrendo na parede e a simulação da convecção em um canal ou tubo capilar.

\subsubsection{Gota escorrendo}

Gotas deslizando sobre superfícies inclinadas não é apenas um tópico de interessante, mas igualmente relevante em muitas aplicações tecnológicas e biológicas. Tais como em processos de cobertura por tinturas, remoção de óleo aderido à superfícies sólidas, gotas escorrendo em folhas ou janelas, dentre outros.

O problema da histerese, quando o ângulo de avanço é diferente do ângulo de retrocesso, foi aproximado impondo diferentes ângulos de contato nas partes anterior e posterior da gota. Com o intuito de simular uma gota escorrendo sobre uma superfície inclinada, a representação da superfície sólida será considerada neste trabalho sempre na horizontal, porém com diferentes vetores gravidade é possível representar diferentes configurações da superfície. 


\section{- Gravidade nula e plano horizontal}

No primeiro teste realizado serão impostos os seguintes ângulos de contato $\theta_{1}=45^{\circ}$ e $\theta_{2}=135^{\circ}$, sendo o primeiro correspondente ao ponto de contato do lado esquerdo da gota $\left(P C_{1}\right)$ e o segundo, ao ponto de contato do lado direito da gota $\left(P C_{2}\right)$, ou seja, o ângulo de contato $\theta_{i}$ corresponde ao ponto de contato $P C_{i}$. Inicialmente é considerada uma gota líquida apoiada sobre a superfície sólida, sendo um segmento circular com área $A=\pi$, centrado em $[0,0]$ com ângulos iniciais $\theta_{1}=$ $\theta_{2}=90^{\circ}$ e grandezas adimensionais, $G a=1.0$ e $E o=1.0$, com passo no tempo $\Delta t=10^{-3}$. A Fig. 6.13 ilustra a situação simulada aqui.

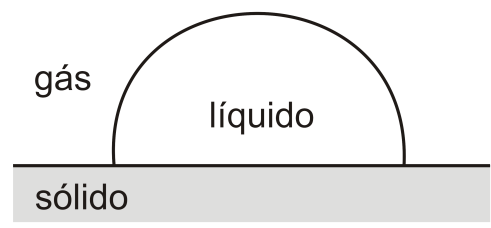

Figura 6.13: Gota sobre um plano horizontal na ausência de gravidade, ou seja, $\boldsymbol{g}=[0,0]$.

Neste teste a gota não sofre influência das forças gravitacionais e está sujeita apenas aos efeitos da tensão superficial. Com o desbalanço das forças de tensão superficial no ponto de contato a gota deverá se movimentar no sentido do menor ângulo de contato $\theta$, neste caso, para o lado esquerdo, o que pode ser observado na Fig. 6.14. Quando o ângulo de contato $\theta_{1}=45^{\circ}$ é imposto no ponto de contato $P C_{1}$ a tendência das arestas da superfície livre nesta região é tomar a forma que satisfaça esta imposição "puxando" o ponto de contato para o lado esquerdo, isto é, para fora do domínio da gota, ocorrendo um maior espalhamento. Por outro lado no ponto de contato $P C_{2}$, o contorno na superfície livre se ajusta ao ângulo de contato imposto $\theta_{2}=135^{\circ}$, ocorrendo um espalhamento menor, "puxando" o fluido para dentro do domínio, como consequência, nesta situação, não há equilíbrio, e o resultado será o deslocamento da gota sobre a superfície para o lado esquerdo.

Esse exemplo ilustra o fato de que, na presença de um campo gravitacional em um plano inclinado, esta gota pode ficar estacionária, situação de equilíbrio entre as forças gravitacionais e de tensão superficial, mais forças de fricção. Este efeito de gotas paradas em superfícies inclinadas ou verticais pode ser facilmente observado na natureza. 


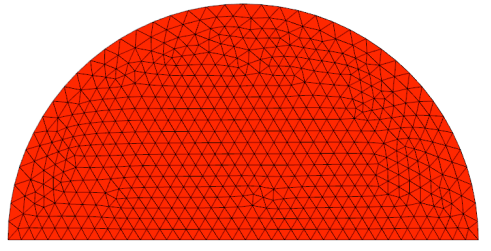

(a)

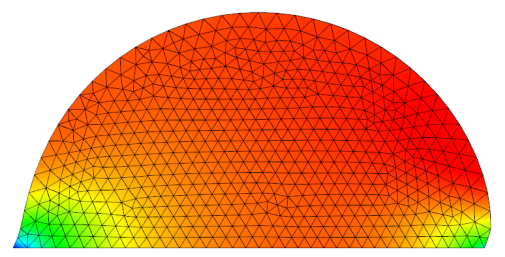

(b)

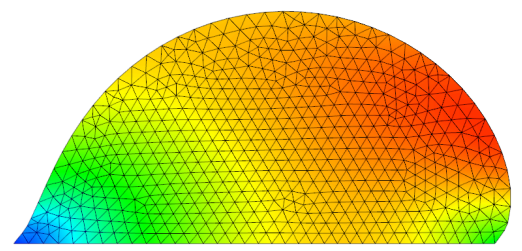

(c)

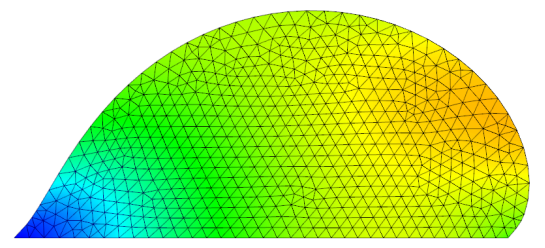

(d)

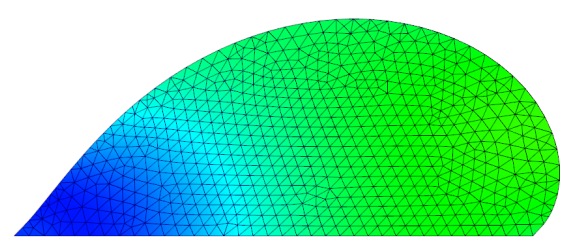

(e)

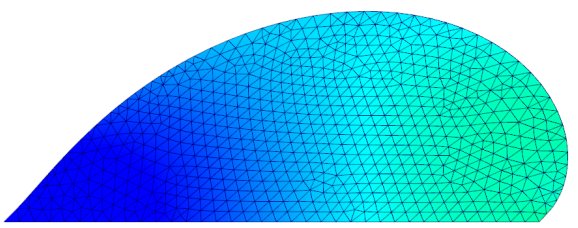

(f)

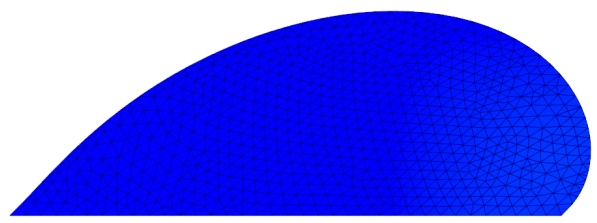

$(\mathrm{g})$

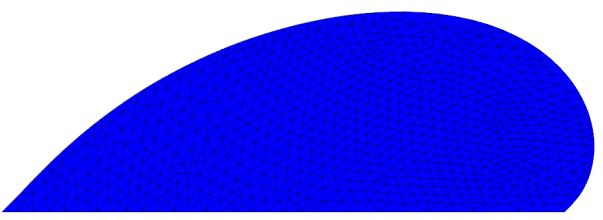

(h)

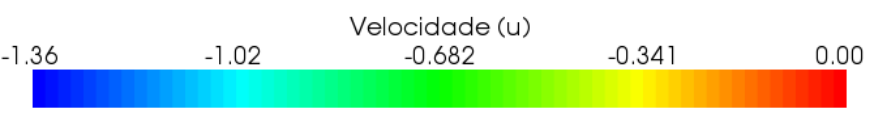

Figura 6.14: Gota escorrendo sobre uma superfície horizontal sem os efeitos gravitacionais.

\section{- Gota sob efeito da gravidade em um plano inclinado}

Agora considera-se o caso de um plano inclinado a um ângulo de $45^{\circ}$, sob o efeito de um campo gravitacional vertical. Tal efeito pode ser alcançado também considerando-se um plano horizontal com campo gravitacional oblíquo a um ângulo de $45^{\circ}$ (veja a Fig. 6.15).

Da mesma forma que os casos anteriores, inicialmente a gota encontra-se apoiada sobre a superfície sólida, sendo um segmento circular com área $A=\pi$, centrado em $[0,0]$ com ângulos iniciais $\theta_{1}=\theta_{2}=90^{\circ}$ e grandezas adimensionais, $G a=1.0$ e $E o=1.0$, com passo no tempo $\Delta t=10^{-3}$. São impostos ângulos de contato distintos $\theta_{1}=45^{\circ}$ e $\theta_{2}=135^{\circ}$, sendo o primeiro correspondente ao ponto de contato do lado esquerdo da gota $\left(P C_{1}\right)$ e o segundo, ao ponto de contato do lado direito da gota $\left(P C_{2}\right)$, porém neste caso, a gota se move para a direita no sentido do $P C_{2}$ (veja Fig. 6.16) 


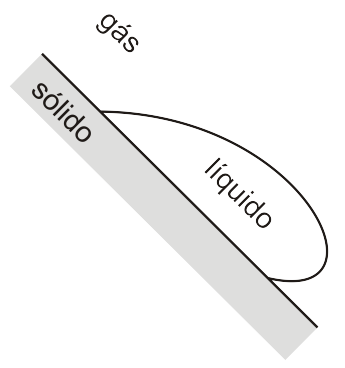

Figura 6.15: Gota sobre um plano inclinado a um ângulo de $45^{\circ}$.

e não no sentido do $P C_{1}$, devido à força gerada pelo campo gravitacional.

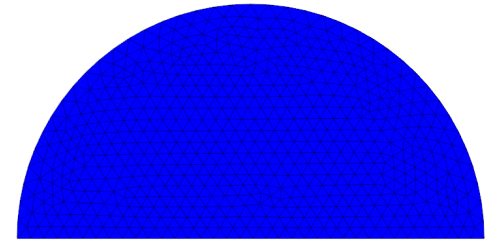

(a)

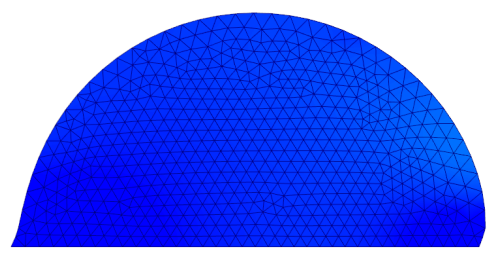

(b)

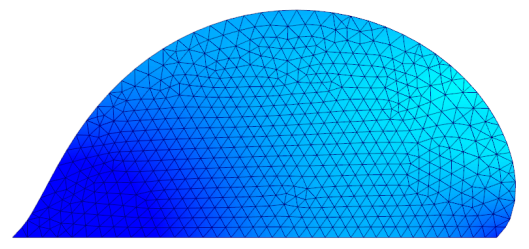

(c)

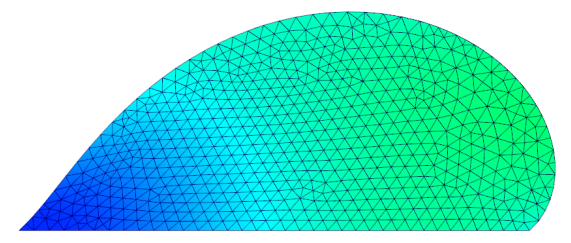

(d)

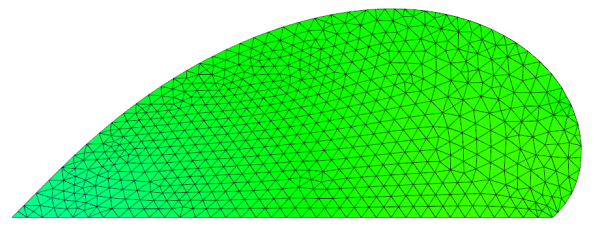

(e)

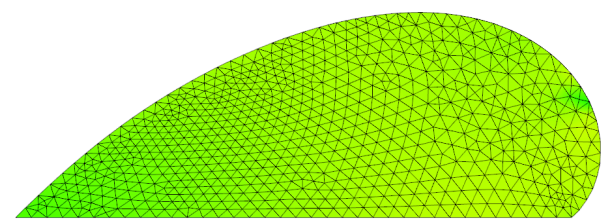

(f)

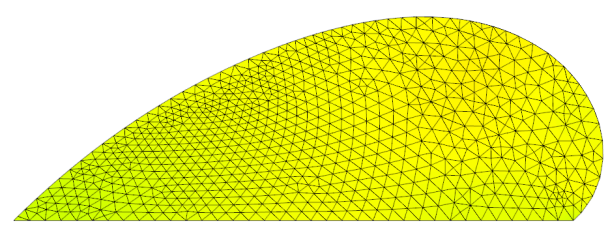

(g)

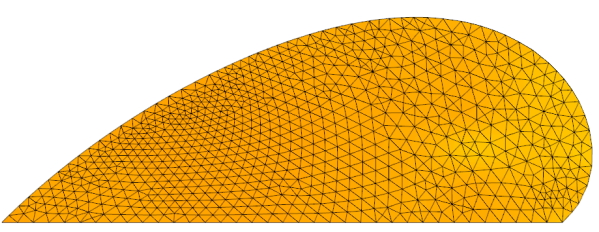

(h)

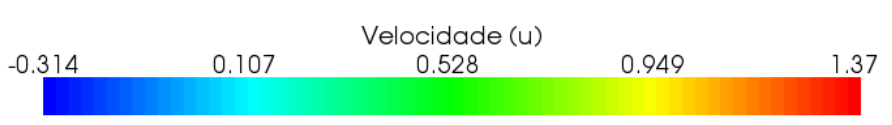

Figura 6.16: Gota escorrendo sob um plano inclinado. 


\subsubsection{Escoamento em um tubo capilar}

Serão apresentados aqui, os resultados da simulação do escoamento em um tubo capilar com ângulo de contato no ponto tríplice. Tubos capilares possuem aplicações em áreas bastante diferentes como a microeletrônica e a indústria petroquímica, também são utilizados em bombas capilares de uso aeroespacial, na exploração de petróleo, a sua extração é fortemente influenciada por efeitos capilares no interior dos reservatórios.

A Fig. 6.17 ilustra o domínio de um tubo capilar de comprimento infinito, com um bloco líquido em seu interior, bem como os quatro pontos de contato, denominados $P C_{1}, P C_{2}, P C_{3}$ e $P C_{4}$. Os ângulos de contato iniciais para estes pontos de contato são todos iguais a $90^{\circ}$ e considera-se as grandezas adimensionais $G a=1.0$ e $E o=1.0$, com passo no tempo $\Delta t=10^{-3}$, as coordenadas dos pontos de contato são $P C_{1}=(0,0), P C_{2}=(3,0), P C_{3}=(3,1)$ e $P C_{4}=(0,1)$. Os ângulos de contato impostos para os pontos $P C_{1}$ e $P C_{4}$ são $\theta_{1}=45^{\circ}$ e $\theta_{4}=45^{\circ}$, para os pontos $P C_{2}$ e $P C_{3}$ os ângulos são $\theta_{2}=135^{\circ}$ e $\theta_{3}=135^{\circ}$, o bloco líquido não está sujeito aos efeitos gravitacionais, estando apenas sob os efeitos da tensão superficial.

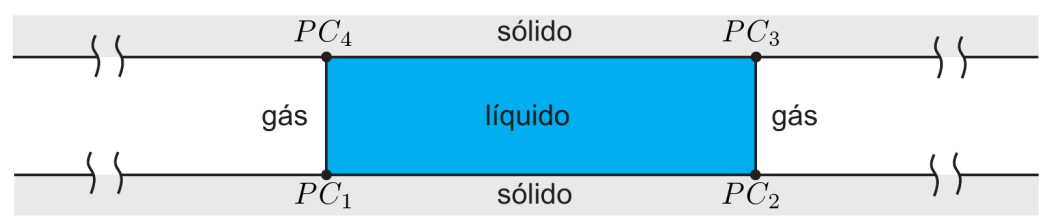

Figura 6.17: Identificação dos pontos de contato $P C_{1}, P C_{2}, P C_{3}$ e $P C_{4}$ no caso do escoamento em um tubo capilar.

Devido ao desbalanço das forças de tensão superficial, o bloco líquido irá se movimentar no sentido dos pontos de contato $P C_{1}$ e $P C_{4}$, ou seja, da direita para a esquerda, como pode ser visto na Fig. (6.18). 


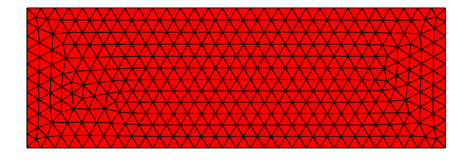

(a)

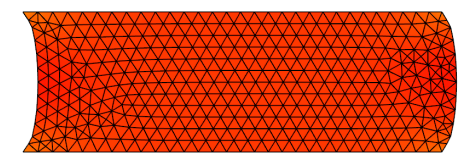

(b)

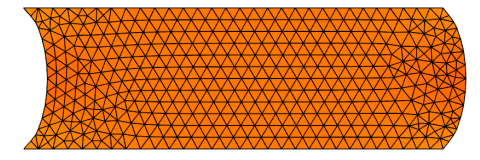

(c)

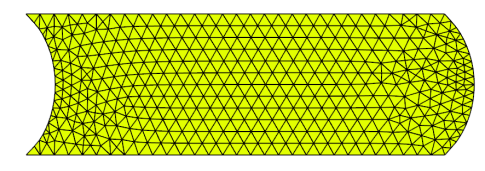

(d)

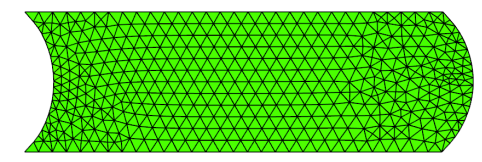

(e)

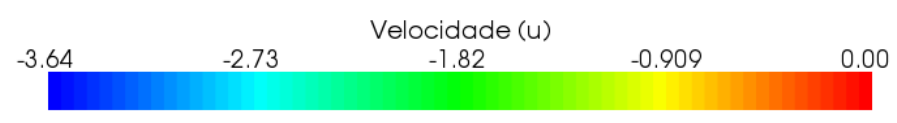

Figura 6.18: Escoamento em um tubo capilar.

Neste teste, quando o ângulo de contato $\theta_{1}=45^{\circ}$ é imposto no ponto de contato $P C_{1}$ a tendência da superfície livre nesta região é tomar a forma que satisfaça esta imposição "puxando" o fluido para fora do domínio, ocorrendo um maior espalhamento, e no ponto de contato $P C_{4}$ acontece o mesmo. Por outro lado nos pontos de contato $P C_{2}$ e $P C_{3}$, o contorno na superfície livre se ajustam ao ângulo de contato imposto, ocorrendo um espalhamento menor, "puxando" o fluido para dentro do domínio. 


\subsubsection{Escoamento em um tubo capilar ligado a uma gota}

O teste do escoamento em tubo capilar com uma gota, consiste em uma gota em contato com um tubo capilar de comprimento infinito, ou seja, possui o comprimento muito maior que a largura do tubo. Este teste é motivado pela semelhança com a geometria de um viscosímetro, e tem como objetivo aplicar o ângulo de contato em um escoamento capilar induzido pela tensão superficial sem os efeitos da gravidade, o escoamento no sentido oposto a gota, faz com que o fluido da gota seja drenado para o canal capilar. Há neste teste, quatro pontos de contato, sendo dois deles na parede do tubo capilar $\left(P C_{1}\right.$ e $\left.P C_{4}\right)$ e os outros dois $\left(P C_{2}\right.$ e $\left.P C_{3}\right)$ são os pontos de contato entre a gota e a parede vertical como está ilustrado na Fig. 6.19. Os ângulos de contato iniciais para estes pontos de contato são todos iguais a $90^{\circ}$ e considera-se as grandezas adimensionais $G a=1.0$ e $E o=1.0$, com passo no tempo $\Delta t=10^{-3}$, e as coordenadas dos pontos de contato são $P C_{1}=(0,-0.5)$, $P C_{2}=(3,-1), P C_{3}=(3,1)$ e $P C_{4}=(0,0.5)$.

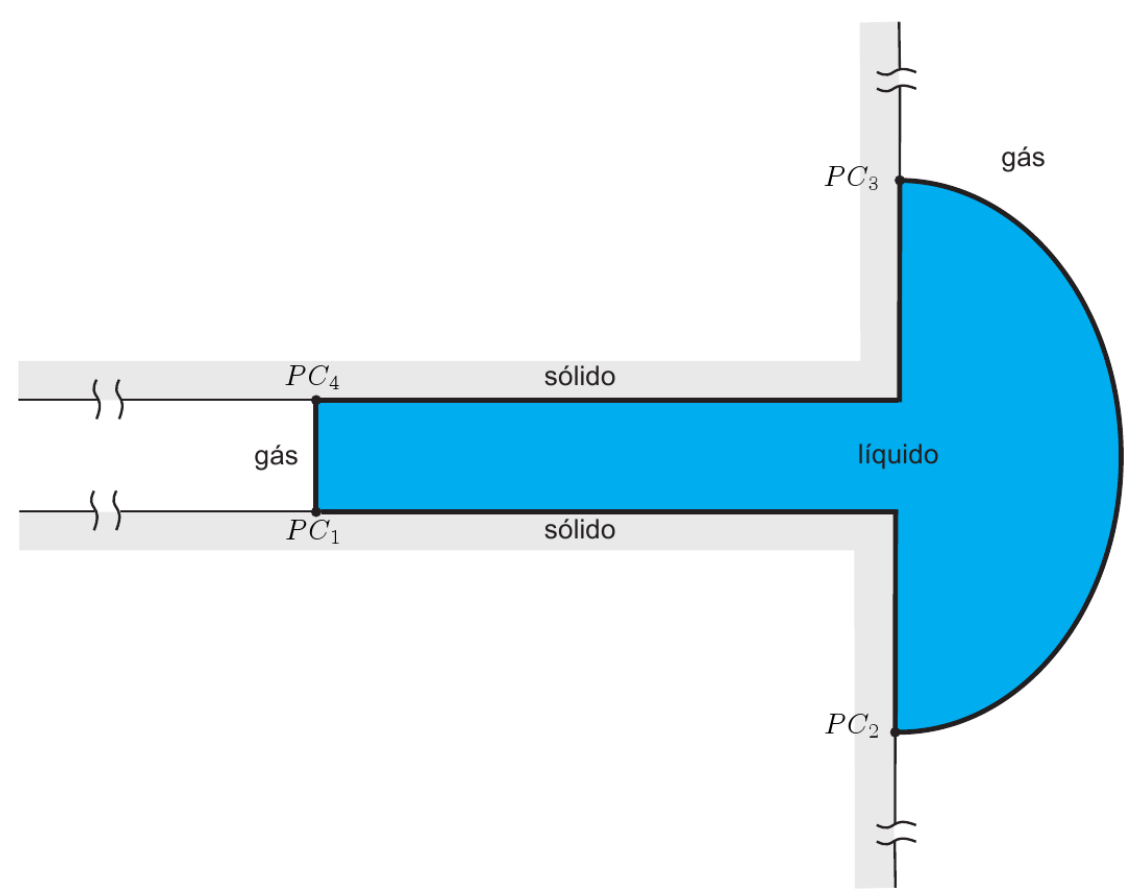

Figura 6.19: Identificação dos pontos de contato $P C_{1}$ e $P C_{2}$ no caso da gota apoiada sobre uma superfície.

A dinâmica deste teste é devida aos efeitos da tensão superficial. Os ângulos de contato são impostos para cada ponto de contato, sendo $\theta_{1}=\theta_{4}$ e $\theta_{2}=\theta_{3}$. Foram realizados testes com diferentes ângulos de contato, nas Figs. 6.20, 6.21 e 6.22, mostram três testes com diferentes valores para os ângulos $\theta_{2}$ e $\theta_{3}$. 
- Caso 1: $\theta_{1}=45^{\circ}, \theta_{2}=90^{\circ}, \theta_{3}=90^{\circ}, \theta_{4}=45^{\circ}$.

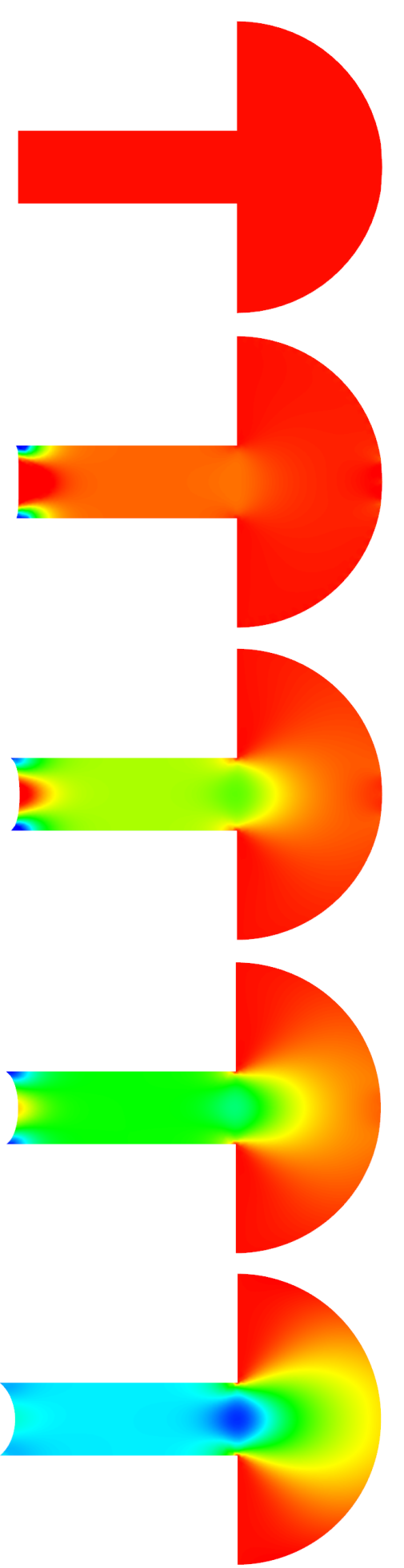

(a)-(e)

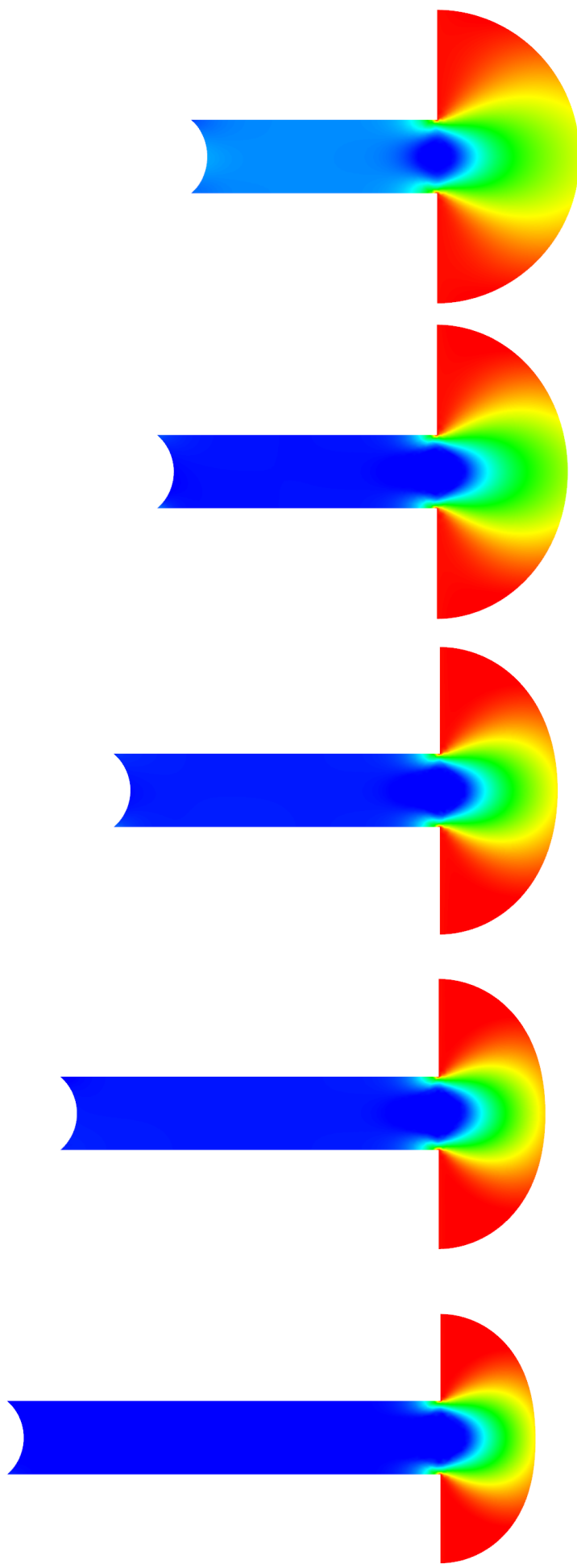

(f)-(j)

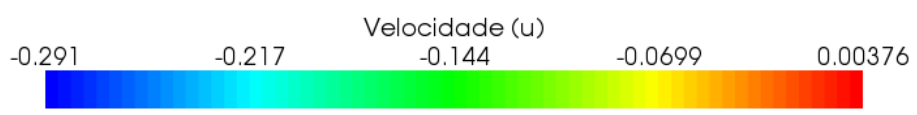

Figura 6.20: Escoamento em um tubo capilar com uma gota. 
- Caso 2: $\theta_{1}=45^{\circ}, \theta_{2}=135^{\circ}, \theta_{3}=135^{\circ}, \theta_{4}=45^{\circ}$.
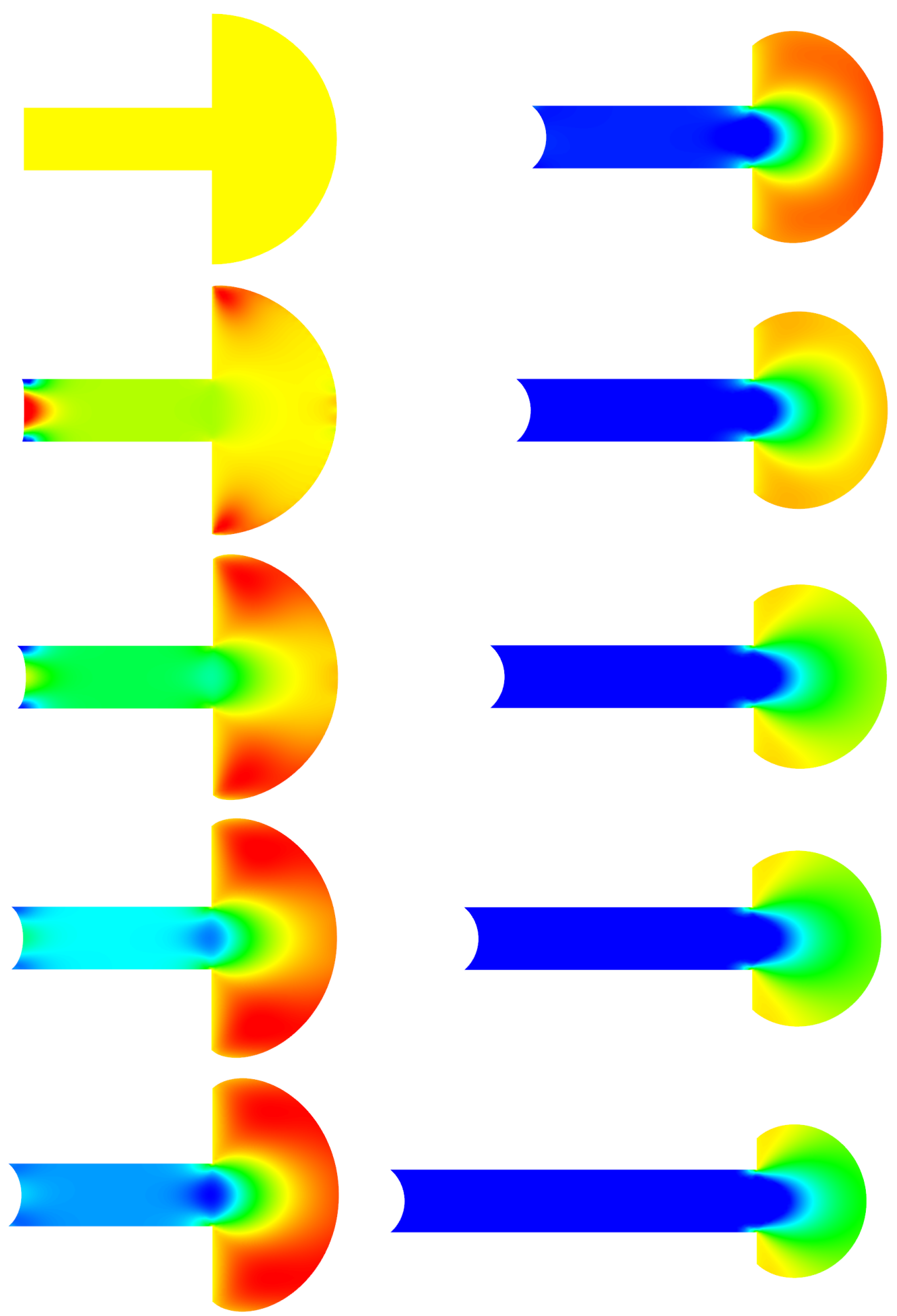

(a)-(e)

(f)-(j)

\begin{tabular}{|c|c|c|c|}
\hline-0.279 & -0.185 & $\begin{array}{c}\text { Velocidade (u) } \\
-0.0918\end{array}$ & 0.00176 \\
\hline
\end{tabular}

Figura 6.21: Escoamento em um tubo capilar com uma gota. 
- Caso 3: $\theta_{1}=45^{\circ}, \theta_{2}=60^{\circ}, \theta_{3}=60^{\circ}, \theta_{4}=45^{\circ}$.
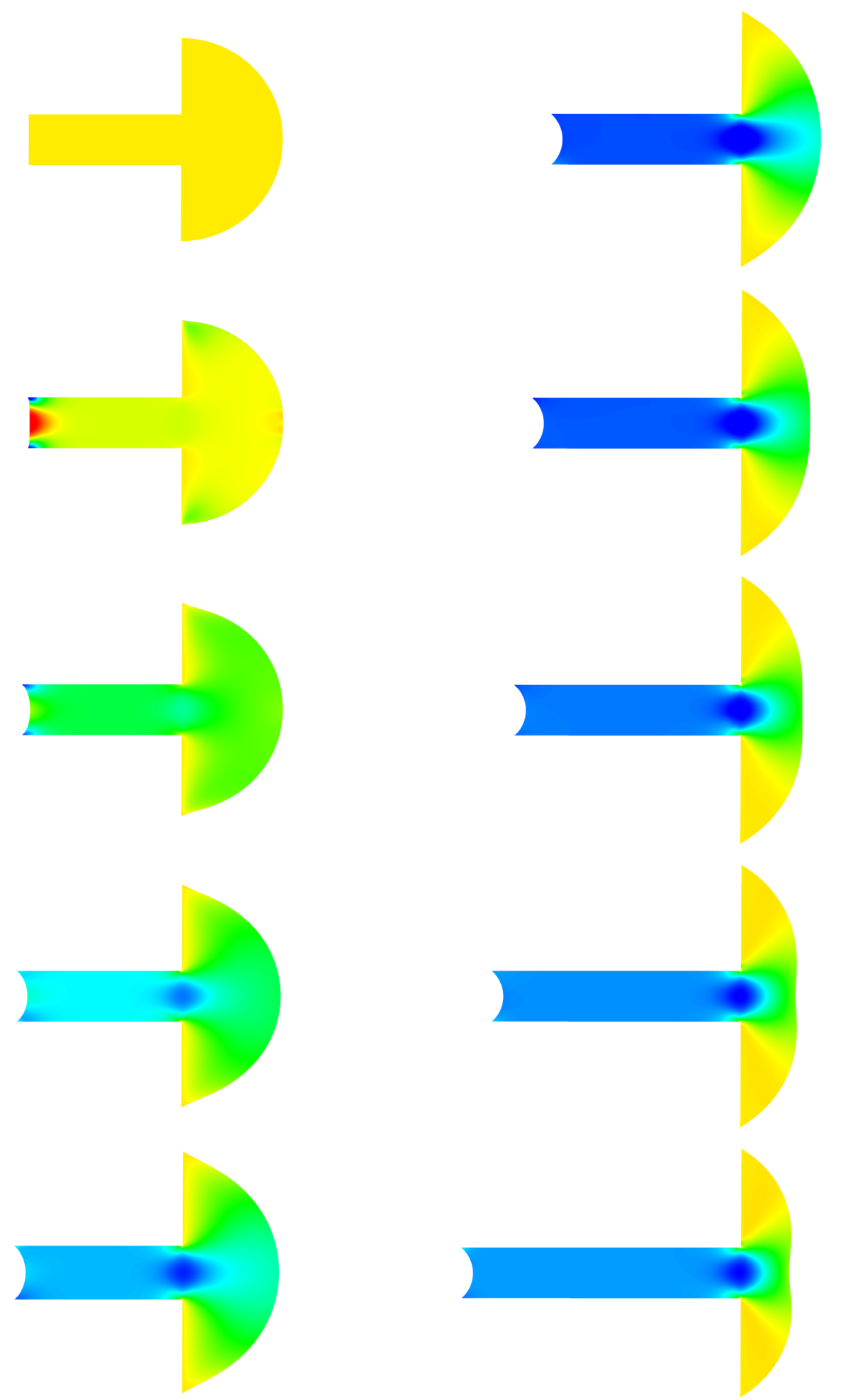

(a)-(e)

(f)-(j)

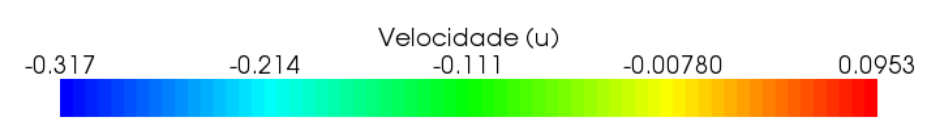

Figura 6.22: Escoamento em um tubo capilar com uma gota. 
Os resultados apresentados nos casos 1, 2 e 3, apresentam o comportamento semelhante ao que ocorre no tubo capilar, pois quando os ângulos de contato $\theta_{1}=45^{\circ}$ e $\theta_{4}=45^{\circ}$ são impostos nos pontos de contato $P C_{1}$ e $P C_{4}$ a tendência da superfície livre nesta região é tomar a forma que satisfaça esta condição "puxando" o fluido para fora do domínio, ocorrendo um maior espalhamento. O fluido da gota ligada ao canal capilar é drenado para o interior do canal. No caso 1, os ângulos de contato $\theta_{2}$ e $\theta_{3}$ já tem a inclinação desejada de $90^{\circ}$, com isso a gota diminui proporcionalmente, sem grande variação destes ângulos. Nos caso 2 e 3, além da dinâmica no canal capilar, há também a dinâmica da gota, pois os ângulos iniciais são diferentes do ângulo desejado $\left(\theta_{2}=135^{\circ}\right.$ e $\theta_{3}=135^{\circ}$ para o segundo caso e $\theta_{2}=60^{\circ}$ e $\theta_{3}=60^{\circ}$ para o terceiro caso). Estes resultados mostram a flexibilidade do código produzido para lidar com casos relativamente complexos. Esta simulação exige um intenso controle de malha na região de drenagem da gota, com muitas operações de inserção e remoção de pontos/elementos nesta região. A variação da massa para o caso 1 é de $0.0646 \%$, para o caso 2 é de $0.0421 \%$ e para o caso 3 é de $0.0420 \%$, sendo praticamente desprezível tal variação.

\subsubsection{Capilaridade}

A ascensão de um fluido dentro de um tubo capilar, sob a ação das forças capilares, é um problema encontrado na literatura de dinâmica dos fluidos. Devido à sua grande aplicabilidade para problemas de invasão em meios porosos, tem grande importância científica e tecnológica (Wolf et al., 2005).

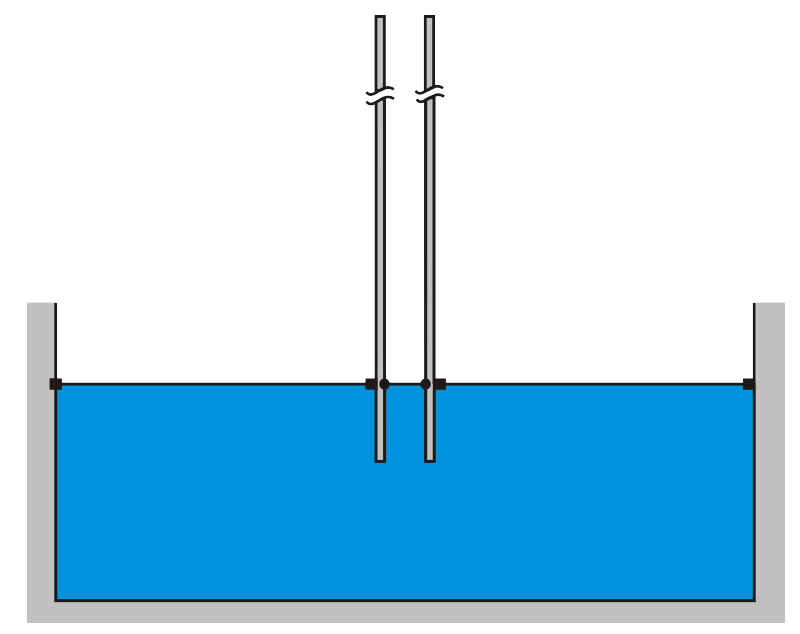

Figura 6.23: Ascensão de um fluido dentro de um tubo capilar. •são os pontos de contato com imposição do ângulo de contato $\theta_{S}$ e e são pontos de contato sem imposição do ângulo de contato (escorregamento livre). 
Neste teste os ângulos de contato iniciais para os pontos de contato internos ao canal capilar (identificados como •na Fig. 6.23) são iguais a $90^{\circ}$ e considera-se as grandezas adimensionais $G a=1.0$ e $E o=1.0$, com passo no tempo $\Delta t=10^{-4}$. A ascensão do fluido neste teste deve-se aos efeitos de tensão superficial, onde o ângulo imposto é $\theta_{S}=45^{\circ}$ para os pontos de contato $\bullet$, o que tende "puxar" os pontos de contato para cima. A situação de equilíbrio ocorre quando a força necessária para "subir" não é grande o suficiente para movimentar toda a coluna de fluido. Pode-se ver nas Figs. 6.24, 6.25 e 6.263 casos com diferentes larguras do canal capilar.

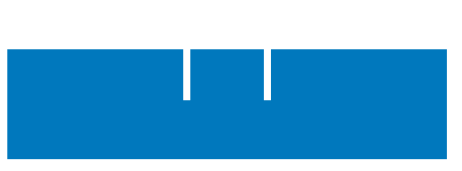

(a)

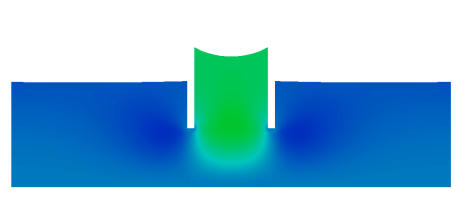

(b)

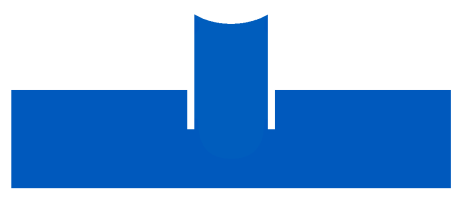

(c)

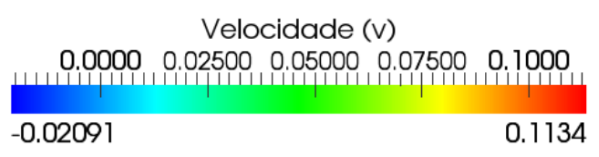

Figura 6.24: Caso 1 - Ascensão de um fluido dentro de um tubo capilar.

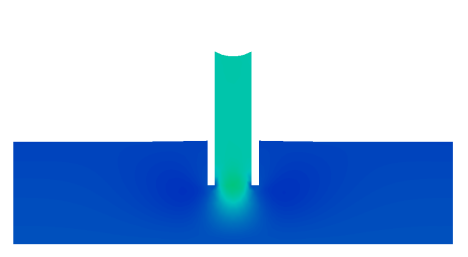

(b)

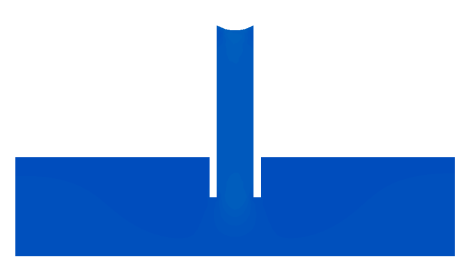

(c)

(a)

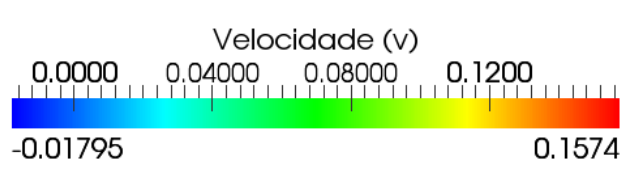

Figura 6.25: Caso 2 - Ascensão de um fluido dentro de um tubo capilar. 


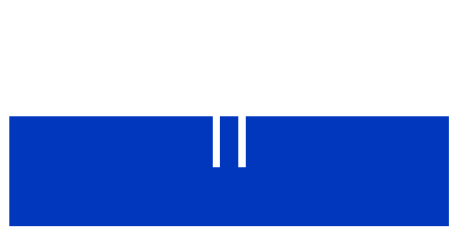

(a)

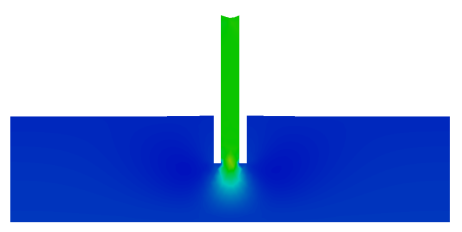

(b)

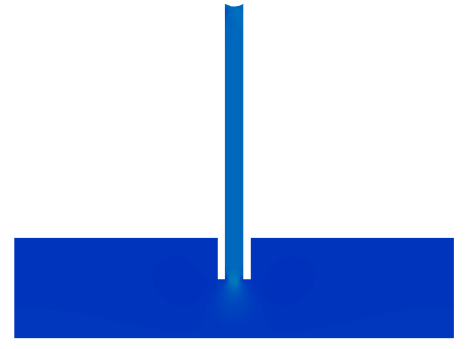

(c)

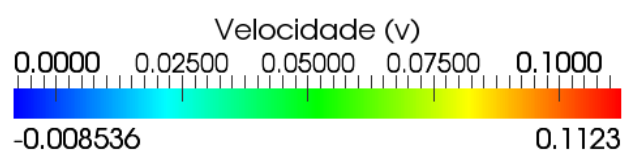

Figura 6.26: Caso 3 - Ascensão de um fluido dentro de um tubo capilar.

Os resultados obtidos nos casos 1, 2 e 3 são consistentes, pois quanto maior a largura do canal capilar menor será a altura de subida da coluna de fluido, tal fato pode ser observado nas Figs. 6.24(c), 6.25(c) e 6.26(c), que representam o estado estacionário da coluna de fluido.

Assim como no teste de um tubo capilar ligado a uma gota, este teste exige um controle de malha intenso na região de interseção entre o tanque e o canal capilar, com muitas operações de inserção e remoção de vértices/elementos na malha de elementos finitos. 


\section{Considerações finais}

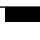

Um método lagrangeano-euleriano arbitrário para a resolução de escoamentos dominados por tensão superficial foi apresentado neste trabalho. Tais escoamentos são importantes em muitas aplicações, especialmente em canais capilares que frequentemente aparecem em escoamentos em microescala. O escoamento é resolvido somente para a fase líquida, com condições de contorno apropriadas para a superfície livre que delimita o líquido e o gás, que é representada por arestas e vértices da malha computacional. A malha computacional se move e se deforma, cuja qualidade é mantida sob controle para não degradar a solução numérica.

As equações de Navier-Stokes são discretizadas pelo método de elementos finitos em um referencial arbitrário. O domínio é discretizado por uma malha de elementos finitos triangulares, cuja fronteira é delimitada por arestas e vértices marcados como pertencendo à superfície livre ou ao substrato sólido. São denominados pontos de contato, os vértices que pertencem a interface tripla sólido/líquido/gás. Para a discretização por elementos finitos foram utilizados espaços de interpolação lineares para a pressão, e lineares enriquecidos por um termo cúbico ("bolha”) para a velocidade, formando um elemento estável conhecido como mini-elemento na literatura de elementos finitos.

Para a solução das equações de Navier-Stokes, utilizou-se um método que resolve de maneira acoplada as variáveis de pressão e velocidade. Como os termos não lineares são aproximados por uma estratégia semi-lagrangeana, o sistema resultante é linear, porém não simétrico, que é resolvido através do método direto LU. A marcha no tempo é realizada através de uma estratégia implícita, o que confere estabilidade e a possibilidade da utilização de passos de tempo maiores. 
Os efeitos da tensão superficial são incorporados no escoamento através de uma condição de contorno na superfície livre. Para calcular a curvatura, utilizou-se uma estratégia puramente geométrica, aproveitando a representação discreta da superfície livre como fronteira da triangulação. Cada dois elementos que possuam arestas na superfície livre definem três pontos nesta superfície, que podem ser utilizados para calcular um único circuncírculo, cujo o raio será tomado como o raio de curvatura local. Esta estratégia, apesar de simples, é eficiente e apresentou bons resultados.

A movimentação dos pontos interno da malha foi realizada utilizando uma estratégia ALE através da combinação entre a velocidade calculada do escoamento e uma velocidade dita elástica, que tende a posicionar os vértices de modo a suavizar a distribuição de espaçamentos na malha. Para a interface foi utilizado um esquema Lagrangeano, que utiliza a velocidade do fluido na direção normal.

Conforme a superfície livre evolui, a malha é deformada, resultando em elementos de má qualidade, que são prejudiciais para as interpolações através de elementos finitos. Para manter um controle de qualidade sobre a malha, uma estratégia baseada em triangulações de Delaunay é empregada. Como a malha está em constante movimento, manter a malha Delaunay todo o tempo é custoso, e evitado neste trabalho. Em 2D, o teste de arestas localmente Delaunay pode ser simplificado por um teste de comparação entre os comprimentos das diagonais dos quadriláteros formados por cada par de elementos. Isso, aliado a uma estratégia de enriquecimento e simplificação de malha, determina que os elementos terão qualidade controlada ao longo da simulação, sem comprometer a eficiência do método.

O método apresentado aqui foi validado através de vários casos teste, como bolhas estáticas, oscilantes e vibração de superfície livre, com comparações com soluções analíticas para grandezas específicas. Estes resultados validam o cálculo de tensão superficial, a correta aplicação das condições de contorno na superfície livre e a correta transferência entre enegia cinética e energia de superfície.

Validações também foram feitas para gotas apoiadas sob a ação da gravidade, que atestaram a correta imposição do ângulo de contato dinâmico. Finalmente problemas de convecção induzidos por tensão superficial foram simulados, atestando a robustez e aplicabilidade do método desenvolvido.

Em resumo, as principais características da metodologia são: (i) emprego de uma formulação lagrangiana-euleriana arbitrária (ALE), (ii) efeitos de tensão superficial incorporados como condições de contorno, (iii) estratégia de imposição do ângulo de contato estático, e (iv) implementação da condição de contorno GNBC em uma formulação ALE aplicada em ângulos de contato dinâmi- 
$\cos$.

Propõe-se como trabalhos futuros as seguintes atividades:

- Verificar a partir da variação da intensidade da interação fluido-sólido (forças de adesão) como o ângulo de contato é afetado;

- Maior entendimento do filme precursor, que exibe uma dinâmica própria, a nível microscópico;

- Simular a gota escorrendo em superfícies arbitrárias;

- Impor o ângulo de contato em função da velocidade do escoamento;

- Simular o escoamento em canais capilares com geometrias mais complexas.

- Estender a estratégia aplicada neste trabalho para um código tridimensional. 


\section{Referências Bibliográficas}

Arnold, D., Brezzi, F., \& Fortin, M., 1984. A stable finite element for the Stokes equations. Calcolo, vol. 21, pp. 337-344.

Ausas, R. F., Dari, E. A., \& Buscaglia, G. C., 2009. Opciones en la formulacion por elementos finitos para la fuerza de tension superficial. In Mecánica Computacional, volume XXVIII, pp. 1371-1389, Tandil, Argentina. Associación Argentina de Mecánica Computacional.

Brackbill, J., Kothe, D., \& Zemach, C., 1992. A continuum method for modeling surface tension. Journal of Computational Physics, vol. 100, pp. 335-354.

Bussmann, M., Mostaghimi, J., \& Chandra, S., 2000. Modelling the splash of a droplet impacting a solid surface. Phys. Fluids, vol. 12, pp. 3121.

Chew, L. P., 1989. Guaranteed-quality triangular meshes. Technical Report TR-89-983, Department of Computer Science, Cornell University.

Davies, A. J., 1980. The finite element method: a fisrt approach. Claredon Press, Oxford.

de Gennes, P. G., 1985. Wetting: statics and dynamics. Reviews of Modern Physics, vol. 57, n. 3, pp. $827-863$.

de Gennes, P.-G., Brochard-Wyart, F., \& Quéré, D., 2004. Capillarity and Wetting Phenomena: Drops, Bubbles, Pearls, Waves. Springer, New York.

Ding, H. \& Spelt, P. D. M., 2007. Inertial effects in droplet spreading: a comparison between diffuse-interface and level-set simulations. Journal Fluid Mechanics, vol. 576, pp. 287-296.

Edelsbrunner, H., 2001. Geometry and Topology for Mesh Generation. Cambridge University Press. 
Fortuna, A. O., 2000. Técnicas Computacionais para Dinâmica dos Fluidos: Conceitos Básicos e Aplicações. Edusp - Editora da Universidade de São Paulo, São Paulo.

Fukai, J., Shiiba, Y., Yamamoto, T., Miyatake, O., Poulikakos, D., Magaridis, C., \& Zhao, Z., 1995. Wetting effects on the spreading of a liquid droplet colliding with a flat surface: Experiment and modeling. Phys. Fluids, vol. 7, pp. 236.

Ganesan, S. \& Tobiska, L., 2009. Modelling and simulation of moving contact line problems with wetting effects. Comput Visual Sci, vol. 12, pp. 329-336.

Gerbeau, J.-F. \& Lelièvre, T., 2009. Generalized navier boundary condition and geometric conservation law for surface tension. Computer Methods in Applied Mechanics and Engineering, vol. 198, n. 5-8, pp. 644-656.

Hirt, C. W. \& Nichols, B. D., 1981. Volume of fluid (vof) method for the dynamics of free boundaries. Journal of Computational Physics, vol. 39, pp. 201-225.

Hughes, T. J. R., Liu, W. K., \& Zimmermann, T. K., 1981. Lagrangian-eulerian finite elemente formulation for incompressible viscous flows. Computer Methods in Applied Mechanics and Engineering, vol. 29, pp. 329-349.

Joanny, J. \& de Gennes, P., 1984. A model for contact angle hysteresis. The Journal of Chemical Physics, vol. 81, pp. 552-562.

Kreyszig, E., 1991. Differential Geometry. Dover Publications, New York.

Lamb, H., 1945. Hydrodynamics. Dover Publications, New York, 6 edition.

Levy, R. \& Shearer, M., 2004. Comparison of two dynamic contact line models for driven thin liquid films. European Journal of Applied Mathematics, vol. 15, pp. 625-642.

Liu, H., s. Krishnan, Marella, S., \& Udaykumar, H. S., 2005. Sharp interface cartesian grid method ii: A technique for simulation droplet interactions with surfaces of arbitrary shape. Journal of Computational Physics, vol. 210, pp. 32-54.

Liziér, M., 2006. Geração de malhas a partir de imagens com textura. Qualificação de doutorado, Instituto de Ciências Matemáticas e de Computação. Universidade de São Paulo. 
Mangiavacchi, N., Castelo, A., Tomé, M. F., Cuminato, J. A., de Oliveira, M. L. B., \& Mckee, S., 2005. An effective implementation of surface tension using the marker and cell method for axisymmetric and planar flows. SIAM Journal on scientific computing, vol. 26, pp. 1340-1368.

Manservisi, S. \& Scardovelli, R., 2009. A variational approach to the contact angle dynamics of spreading droplets. Computers \& Fluids, vol. 38, pp. 406-424.

Nachbin, A., 2001. Aspectos de Modelagem Matmática em Dinâmica dos Fluidos. IMPA, $23^{\circ}$ Colóquio Brasileiro de Matemática. Rio de Janeiro, RJ.

Niceno, B., 2001. A two-dimensional quality mesh generator. Technical report, Consortium for International Development of the University of Trieste.

O'Brien, S., 1991. On the shape of small sessile and pendant drops by singular perturbation techiniques. J. Fluid Mech., vol. 233, pp. 519-537.

Pedroso, L. J., JR., L. C. S., \& Neves, C. E. V., 2005. Estudo analítico e numérico para o efeito de superfície livre (sloshing) em tanques contendo líquidos. In XXVI CILAMCE - Iberian Latin American Congress on Computational Methods in Engineering.

Peterson, R. C., 1999. The Numerical Solution of Free-Surface Problems for Incompressible, Newtonian Fluids. PhD thesis, The University of Leeds - School of Computer Studies and Department of Applied Mathematics.

Prosperetti, A., 1981. Motion of two superposed viscous fluid. Phys. Fluids, vol. 24, n. 7, pp. $1217-1223$.

Qian, T., Wang, X.-P., \& Sheng, P., 2003. Molecular scale contact line hydrodynamics of immiscible flows. Phys. Rev. E, vol. 68.

Qian, T., Wang, X.-P., \& Sheng, P., 2006. Molecular hydrodynamics of the moving contact line in two-phase immiscible flows. Commun. Comput. Phys., vol. 1, pp. 1-52.

Rabier, S. \& Medale, M., 2003. Computation of free surface flows with a projection fem in a moving mesh framework. Computer Methods in Applied Mechanics and Engineering, vol. 192, pp. 4703-4721.

Rabockai, T., 1979. Físico-química de superfícies, volume VII of Série de química. Secretaria-Geral da Organização dos Estados Americanos, Programa Regional de Desenvolvimento Científico e Tecnológico, Washington, D.C. 
Saksono, P. H. \& Perić, D., 2006a. On finite element modelling of surface tension: Variational formulation and applications - part i: Quasistatic problems. Computational Mechanics, vol. 38, pp. 265-281.

Saksono, P. H. \& Perić, D., 2006b. On finite element modelling of surface tension: Variational formulation and applications - part ii: Dynamic problems. Computational Mechanics, vol. 38, pp. 251-263.

Schlangen, L. J. M., Koopal, L. K., Stuart, M. A. C., \& Lyklema, J., 1994. Wettability: thermodynamic relationships between vapour adsorption and wetting. Colloids and Surfaces A: Physicochemical and Engineering Aspects, pp. 157-167.

Shewchuk, J. R., 1997. Delaunay Refinement Mesh Generation. PhD thesis, School of Computer Science, Carnegie Mellon University, Pittsburgh, Pennsylvania.

Shewchuk, J. R., 1999. Lecture notes on delaunay mesh generation. Technical report, Department of Electrical Engineering and Computer Science, Universty of California at Berkeley.

Shewchuk, J. R., 2002. What is a good linear element? interpolation, conditioning, and quality measures. In Eleventh International Meshing Roundtable, pp. 115-126, Ithaca, New York.

Shikhmurzaev, Y., 1993. The moving contact line on a smooth solid surface. International Journal of Multiphase Flow, vol. 19, pp. 589-610.

Shikhmurzaev, Y., 1996. Dynamic contact angles in gas-liquid-solid systems and flow in vicinity of moving contact line. AIChe Journal, vol. 42, pp. 601-612.

Silva, A. A. N. \& Sousa, F. S., 2009. Simulação numérica de escoamentos bidimensionais com superfícies livres e ângulo de contato. In Congresso Ibero-Latino-Americano de Métodos Computacionais em Engenharia (CILAMCE), pp. 1-14, Armação dos Búzios.

Sousa, F. S., 2005. Simulação de escoamentos multifásicos em malhas não estruturadas. $\mathrm{PhD}$ thesis, Instituto de Ciências Matemáticas e de Computação. Universidade de São Paulo, São Carlos - SP.

Sousa, F. S., Castelo, A., L. G. Nonato, N. M., \& Cuminato, J. A., 2007. Local volume-conserving free surface smoothing. Communications in numerical methods in engineering, vol. 23, pp. 109120. 
Sousa, F. S. \& Mangiavacchi, N., 2005. A lagrangian level-set approach for the simulation of incompressible two-fluid flows. International Journal for Numerical Methods in Fluids, vol. 47, pp. 1393-1401.

Spelt, P. D. M., 2005. A level-set approach for simulations of flows with multiple moving contact lines with hysteresis. Journal of Computational Physics, vol. 207, pp. 389-404.

Sussman, M., Smereka, P., \& Osher, S., 1994. A level set approach for computing solutions to incompressible 2-phase flow. Journal of Computational Physics, vol. 114, pp. 171-189.

Tryggvason, G., Bunner, B., Esmaeeli, A., Juric, D., Al-Rawahi, N., Tauber, W., Han, J., Nas, S., \& Jan, Y.-J., 2001. A front-tracking method for the computations of multiphase flow. Journal of Computational Physics, vol. 169, pp. 708-759.

Wang, H., Mucha, P. J., \& Turk, G., 2005. Water drops on surfaces. ACM Transactions on Graphics (TOG), vol. 24, n. 3, pp. 921-929.

Wolf, F. G., dos Santos, L. O. E., \& Philippi, P. C., 2005. Fluid interfaces in phase transition problems: Lattice-boltzmann method. In 18th International Congress Of Mechanical Engineering, Ouro Preto, MG/Brazil. 